
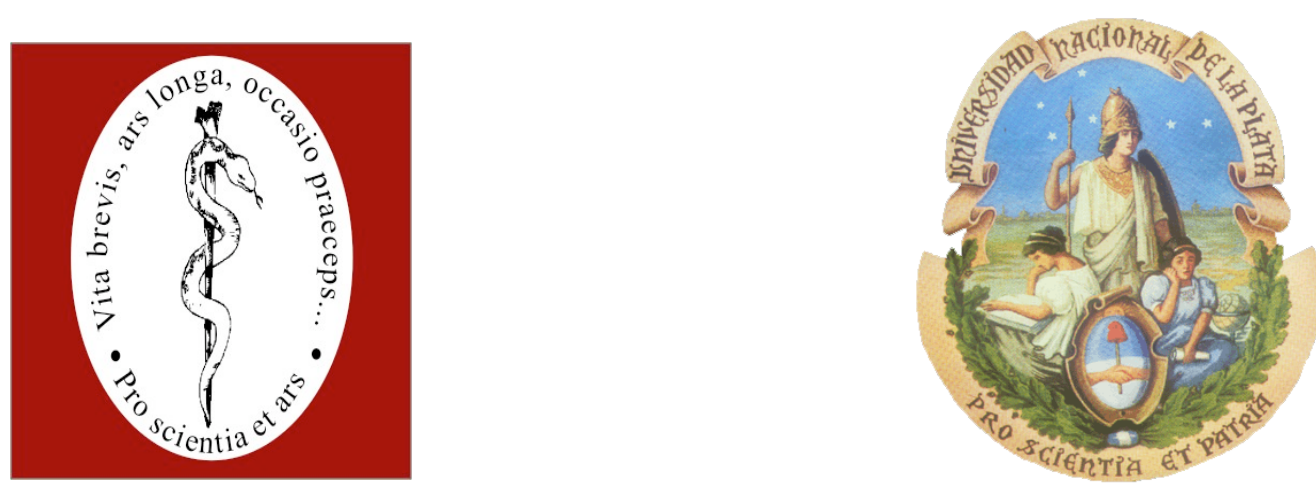

UNIVERSIDAD NACIONAL DE LA PLATA

Facultad de Ciencias Médicas

\title{
OPTIMIZACIÓN DEL USO DE ANTIMICROBIANOS: IMPACTO EN LA EVOLUCIÓN DE LA RESISTENCIA BACTERIANA Y LOS COSTOS HOSPITALARIOS
}

Tesis para acceder al título de Doctora en Ciencias de la Salud

Tesista: Farmacéutica Marisa lleana Gómez

Director: Prof. Dr. Juan Ángel Basualdo Farjat

Co-directora: Prof. Dra. María Cristina Lurá

Lugar de Trabajo: Cátedra de Microbiología y Parasitología

Facultad de Ciencias Médicas.

Universidad Nacional de La Plata 


\section{AGRADECIMIENTOS}

Mi agradecimiento al Dr. Juan A. Basualdo Farjat y a la Dra. María C. Lurá por sus sugerencias, orientaciones y guía en la preparación de esta tesis. Sin sus consejos nunca podría haber logrado concretar este objetivo.

Mi gratitud al Dr. Alfred de la Torre, la Dra. Marta R. Bina Estrada, la Dra. Heidi Schulz, a la Ing. Silvia Grenóvero, a la Bioq. Melina Herrera y a la Sra. Mirta Solis, secretaria del Centro de Investigaciones, por la revisión del manuscrito y sugerencias.

Mi especial agradecimiento a la Dra. Silvia Acosta de Gnass por su apoyo, guía y motivación en la realización de este trabajo.

A la Universidad Adventista del Plata por el apoyo financiero.

A mi familia, por su apoyo incondicional.

A Dios, el gran responsable de todas mis victorias.

Marisa I. Gómez 


\section{Fracultad de Giencias Médicas \\ Qlniversidad Slacional de Sa Olata}

\section{Autoridades}

Decano

Prof. Dr. Jorge Guillermo MARTINEZ

Vicedecano

Prof. Dr. Enrique PÉREZ ALBIZÚ

Secretarías

Secretaria de Asuntos Académicos

Prof. Dra. Ana Lía ERRACALDE

Secretaria de Asuntos Estudiantiles

Prof. Dra. María Marta DE LUCA

Secretaria de Extensión Universitaria

Prof. Dra. Graciela Susana ETCHEGOYEN

Secretario Docente Asistencial

Prof. Dr. Fernando CURCIO

Secretario Económico Financiero

Prof. Dr. Rubén GALLE

Director del Departamento de Postgrado

Prof. Dr. Eduardo RODRíGUEZ

Director de la Escuela Universitaria de Recursos Humanos del Equipo de Salud

Prof. Dr. Alberto Mario FONTANA
Secretario de Ciencias Técnicas

Prof. Dr. Gustavo Juan RINALDI

Secretario Médico Asistencial

Prof. Dr. Pedro Rodolfo ESTELRRICH

Secretario de Relaciones Institucionales

Prof. Dr. Julio César HIJANO

Director del Hospital Universitario

Prof. Dr. Guillermo Daniel PRAT

Asesor de Gestión

Dr. Felipe CAMPOAMOR

Secretaria de Supervisión Admnistrativa

Sra. Norma FORTUNATO de CARRADORI

Secretaria Administrativa

Sra. Elsa Lidia ANTONINI 


\section{ÍNDICE DE CONTENIDO}

RESUMEN

Pág.

1- INTRODUCCIÓN

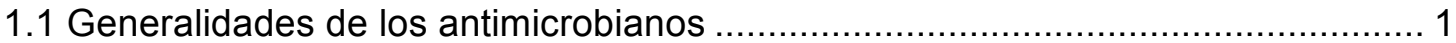

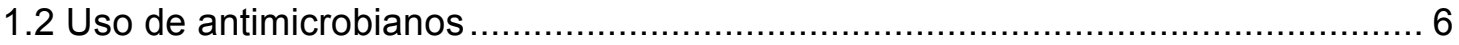

1.3 Uso de antimicrobianos y resistencia bacteriana .............................................. 7

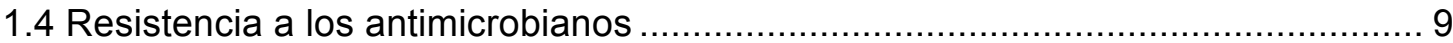

1.4.1 Mecanismos de resistencia bacteriana ................................................ 9

1.4.2 Desarrollo de resistencia en el hospital ................................................. 12

1.5 Vigilancia de la resistencia bacteriana y el uso de antimicrobianos..................... 13

1.6 Administración de antimicrobianos ..................................................................... 16

1.7 Estrategias para optimizar la utilización de antimicrobianos a nivel

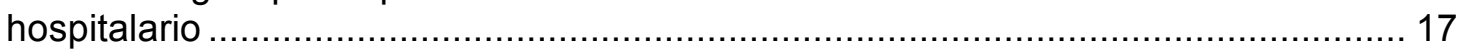

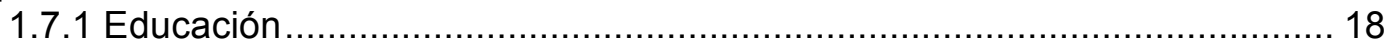

1.7.2 Uso restringido de algunos antimicrobianos ........................................... 18

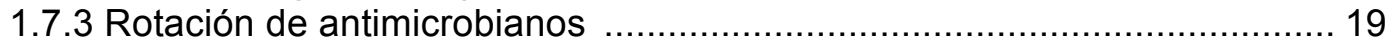

1.7.4 Formulario de pedido, orden de paro automático y aprobación por

parte del Servicio de Infectología ............................................................... 19

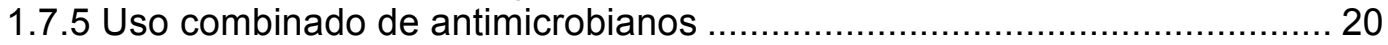

1.7.6 Base de datos computarizada ........................................................ 20

1.7.7 Revisión de las prescripciones y retroalimentación ................................ 21

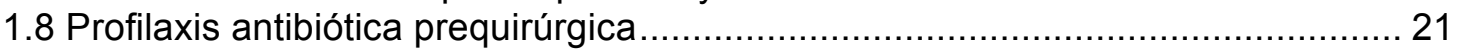

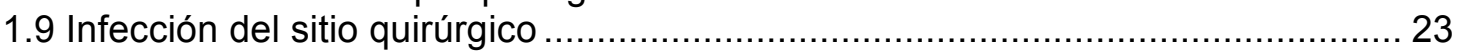

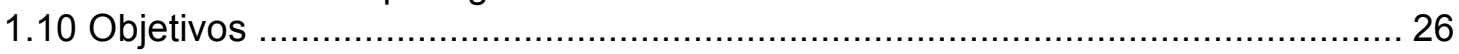

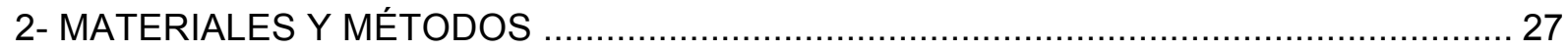

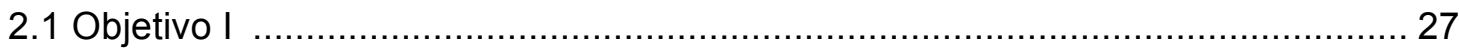

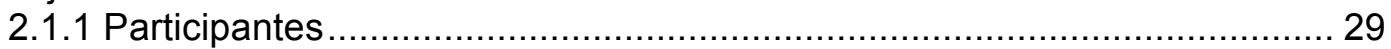

2.1.2 Recolección de datos ................................................................. 30

2.1.3 Evaluación de la profilaxis antimicrobiana prequirúrgica ........................ 30

2.1.4 Implementación del programa de control de profilaxis antimicrobiana ... 31

2.1.5 Evaluación de la intervención ............................................................... 32

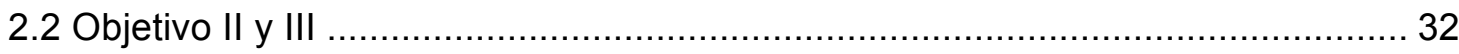

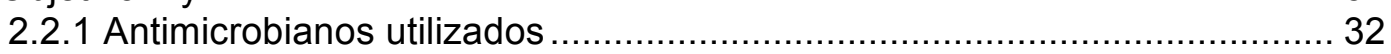

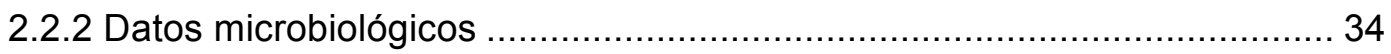

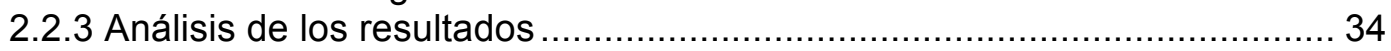

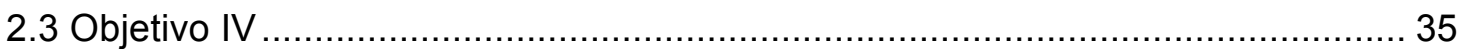

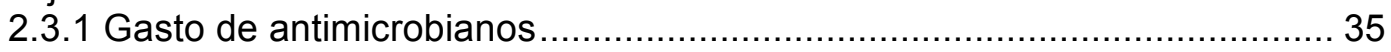

2.3.2 Comparación de costos directos generados por pacientes con

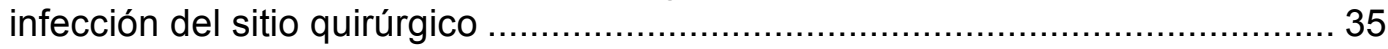

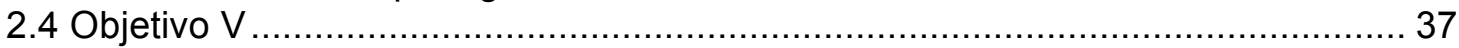




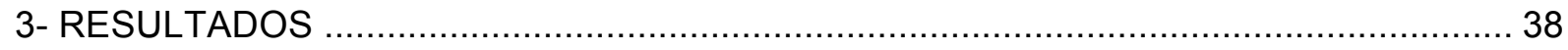

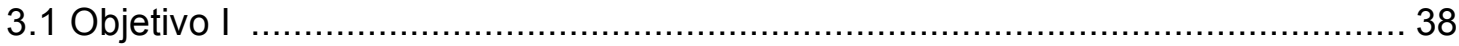

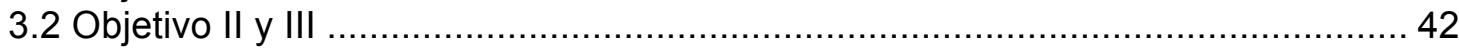

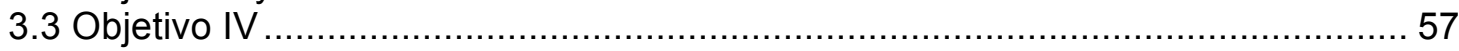

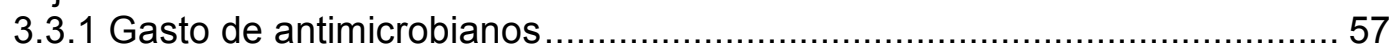

3.3.2 Comparación de costos directos generados por pacientes con

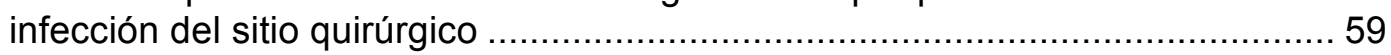

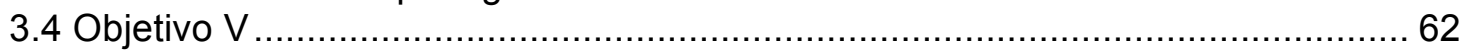

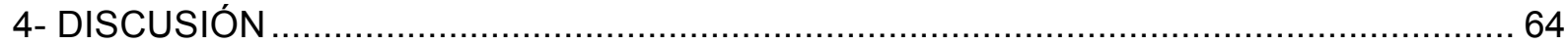

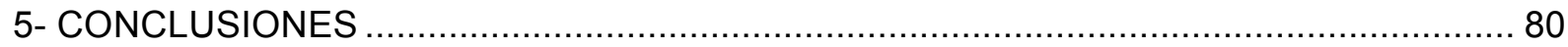

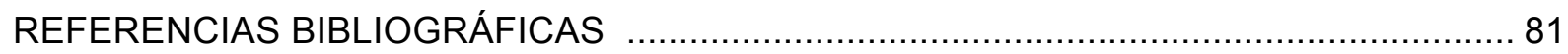

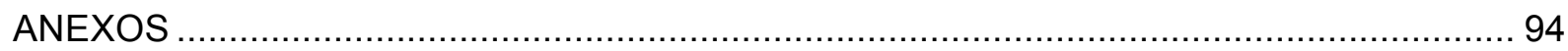

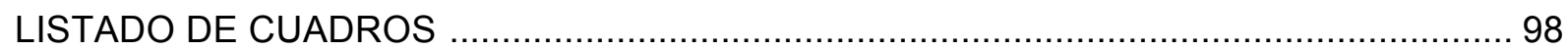

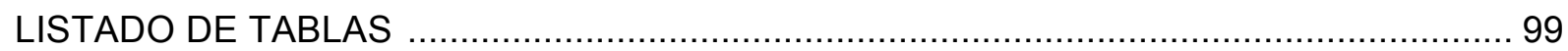

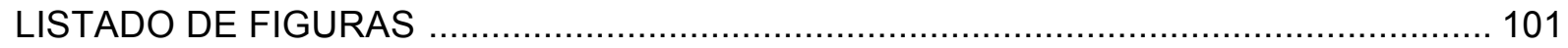

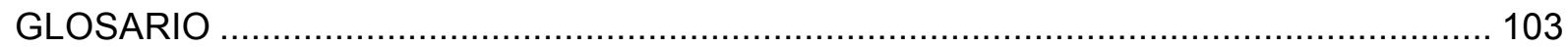

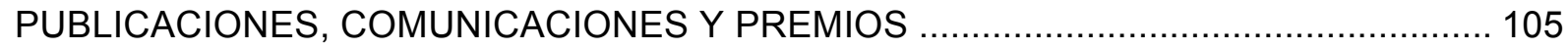




\section{RESUMEN}

Los antimicrobianos representan, en general, el tercer gasto de farmacia hospitalaria, después de los insumos biomédicos y las soluciones parenterales. El uso excesivo de dichos medicamentos es un problema de salud pública a nivel mundial y se ha visto que entre el $20 \%$ y $50 \%$ del total de los prescriptos, son administrados en forma innecesaria o inapropiada.

Se ha observado una relación importante entre los antimicrobianos usados y la prevalencia de bacterias resistentes. Por esta razón, resulta imperioso diseñar programas para evaluar y optimizar el uso de los antimicrobianos que están disponibles actualmente.

Los objetivos de esta tesis fueron evaluar la efectividad de un programa de profilaxis antimicrobiana prequirúrgica, controlado desde la farmacia hospitalaria y evaluar la efectividad de dicho programa sobre el patrón de resistencia de las cepas aisladas de los pacientes con infecciones asociadas al cuidado de la salud, adquiridas en el Sanatorio Adventista del Plata, Libertador San Martín, Argentina, durante los años 2001 a 2007.

El diseño fue cuasiexperimental, longitudinal con preprueba y posprueba con un solo grupo, en el cual se efectuó un programa de intervención para controlar el uso de antimicrobianos en la profilaxis quirúrgica. Para ello se aplicó un formulario elaborado de acuerdo con recomendaciones nacionales e internacionales. Se realizaron reuniones con los diferentes equipos quirúrgicos y talleres educativos para el personal de quirófanos, enfermería y farmacia. Los formularios eran completados para cada cirugía en quirófano y controlados diariamente en la farmacia desde donde se suministraban los antimicrobianos o se enviaba la orden de paro-automático cuando la indicación no estaba de acuerdo a los protocolos establecidos. Se vigiló la utilización de antimicrobianos, la resistencia bacteriana de todos los cultivos no duplicados, aislados de las muestras clínicas de infecciones adquiridas en el hospital y se analizó la variación económica surgida como consecuencia de dicha intervención.

En la etapa inicial del estudio, el 55\% de los pacientes recibieron el antimicrobiano dentro de las 2 horas previas a la incisión quirúrgica, mientras que en la etapa final, se aplicó al $60 \% \quad(p=0,01)$. La utilización del esquema antimicrobiano adecuado en la etapa inicial del estudio fue del $74 \%$ mientras que en la etapa final fue del $87 \%(p<0,01)$. En la etapa inicial, la duración de la profilaxis fue adecuada en el $44 \%$ de las cirugías y en la etapa final fue en el $55 \%(p<0,01)$. Teniendo en cuenta los días paciente que hubieron en los 8 meses durante los cuales se realizó el seguimiento de las cirugías, se logró con el esquema 
propuesto un ahorro de $\$ 2478,50(28,53 \%)$ solamente en antimicrobianos en la profilaxis quirúrgica.

Además, se obtuvo una disminución del $55 \%$ en el desarrollo de infección del sitio quirúrgico. Lo cual conlleva a un ahorro adicional para el sistema de salud de $\$ 3336,73$ $(83,84 \%)$ por cada cirugía de hígado, páncreas y conductos biliares y $\$ 1889,29(75,63 \%)$ por cada cirugía vascular, cuando se contabilizan los gastos extra ocasionados por el desarrollo de la infección del sitio quirúrgico.

El ahorro por uso de antimicrobianos en la unidad de cuidados intensivos fue de $\$ 1755,84$ cada 1000 días paciente $(9,42 \%)$, mientras que en internación general fue de $\$ 248,64$ cada 1000 días paciente $(5,49 \%)$. Se observó una disminución significativa en la resistencia de Staphylococcus aureus resistente a la meticilina durante los 7 años de estudio tanto en la unidad de cuidados intensivos como en internación general. Al analizar genéticamente a 6 aislamientos, se diferenciaron 4 clones.

En este estudio se demostró que en el ámbito hospitalario un programa para controlar la administración de los antimicrobianos utilizados en la profilaxis quirúrgica permitió obtener una reducción significativa en el uso de dichos fármacos mediante la disminución del número de dosis administradas y del empleo del antimicrobiano adecuado para cada tipo de procedimiento. Además, este programa mejoró la evolución postquirúrgica de los pacientes, contribuyó a disminuir la incidencia de ciertos patógenos nosocomiales y produjo una disminución en el gasto para el sistema de salud. Los esfuerzos y las erogaciones necesarios para implementar y mantener este tipo de programas son más que justificados habida cuenta de sus beneficios tanto para el hospital y como para el paciente. 


\section{INTRODUCCIÓN}

\subsection{Generalidades de los antimicrobianos}

Los medicamentos han constituido desde siempre un componente importante de la vida del hombre y de las organizaciones sociales. Se considera medicamento a toda droga, o preparación efectuada con drogas, que por su forma farmacéutica y dosis puede destinarse a la curación, al alivio, a la prevención o al diagnóstico de las enfermedades de los seres vivientes (1).

Dentro del amplio espectro que comprenden los medicamentos, se encuentran los antimicrobianos (ATM), compuestos que en pequeñas concentraciones del orden de $\mu \mathrm{g} / \mathrm{mL}$, son capaces de inhibir el crecimiento o producir la muerte de los microorganismos (2). Los microorganismos son organismos microscópicos que existen como células aisladas o asociadas; incluyendo también los virus, que son microscópicos pero no celulares (3). Este grupo heterogéneo de seres vivos pueden realizar todos los procesos vitales como células individuales, es decir unicelulares, o formando agrupaciones en las cuales todas las células son equivalentes, es decir, sin diferenciación celular, presentando una gran diversidad, de capacidades metabólicas como de hábitats. Dentro de este grupo se incluyen células procariotas como por ejemplo bacterias y células eucariotas como protozoos, hongos levaduriformes, mohos y virus. $(4,5)$.

Los ATM constituyen 2 grupos de fármacos: antibióticos y quimioterápicos. Los antibióticos son sustancias sintetizadas por un microorganismo vivo, como por ejemplo la penicilina. Los compuestos quimioterápicos son productos obtenidos por síntesis orgánica, como las sulfonamidas (2). Se caracterizan por poseer "toxicidad selectiva"; es decir, que no afectan o son relativamente inocuos para las células del hospedador. La actividad específica de los ATM se debe a su selectividad sobre blancos determinados, que son únicos en los microorganismos o más importantes en ellos que en los humanos (6). En relación con el tipo de microorganismo sobre los que actúan, los ATM se clasifican en antibacterianos, antivíricos, antifúngicos y antiparasitarios. De aquí en más cuando hagamos referencia a ATM se considerarán a aquellos que ejercen actividad antibacteriana.

El primer agente con actividad antimicrobiana fue descubierto por el médico y bacteriólogo alemán Paul Ehrlich (figura 1), quien tras probar varios productos encontró un derivado arsenical, el producto 606 comercializado en 1910 como Salvarsan®, que poseía una acción específica para poder ser utilizado en el tratamiento de la sífilis, dando lugar así al nacimiento de la quimioterapia antimicrobiana. Recién en 1932, el también alemán 
Gerhard Domagk (figura 2), trabajando con productos de síntesis orgánica descubrió una sustancia a la que llamó Prontosil, que protegía a los ratones y conejos contra dosis letales de estreptococos y estafilococos hemolíticos. Con el descubrimiento del Prontosil, un derivado de la sulfanilamida, se consolidó la quimioterapia antibacteriana $(2,7)$.

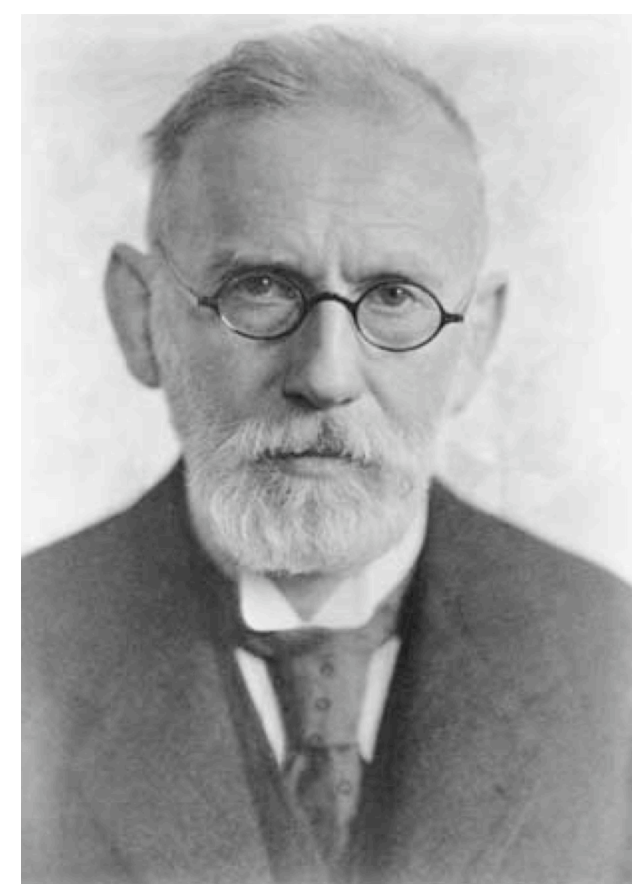

Figura 1. Paul Ehrlick (8)

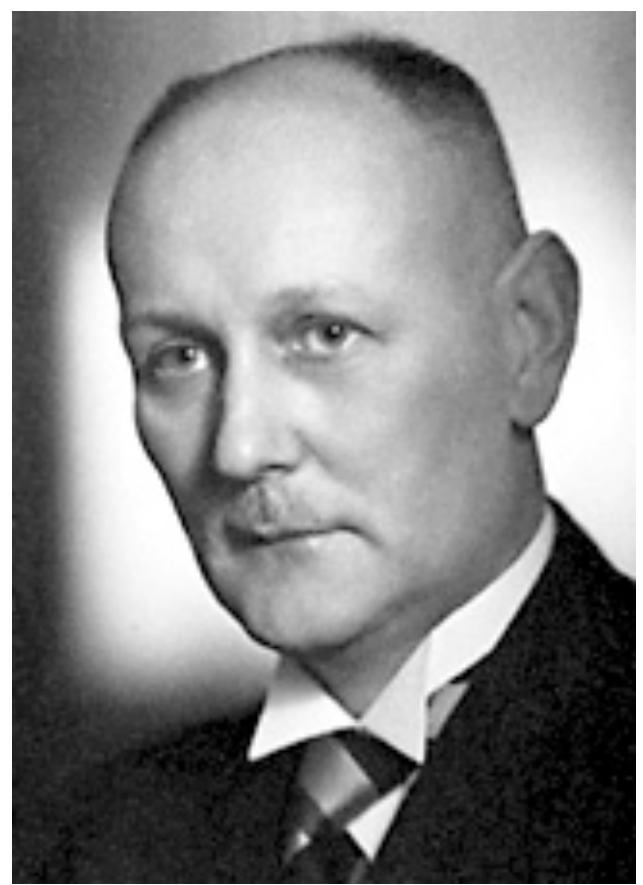

Figura 2. Gerhard Domagk (7)

El médico microbiólogo escocés Alexander Fleming (figura 3), trabajando en el Hospital St. Mary de Londres, en 1928 sobre el virus de la influenza, observó que un hongo contaminante de una placa, en la que estaban creciendo estafilococos, inhibía el crecimiento de las bacterias a su alrededor. Realizó más experimentos y encontró que el hongo prevenía el crecimiento de estafilococos. Teniendo en cuenta que el hongo productor pertenecía al género Penicillium notatum (luego $P$. chrysogenum), denominó a la sustancia inhibidora como penicilina (figura 4), dando lugar así al nacimiento de la antibioterapia. Sin embargo, recién en 1939, gracias al trabajo del médico Howard Florey y el bioquímico Ernst Chain se logró aislar y purificar la penicilina $(2,9,10)$. 


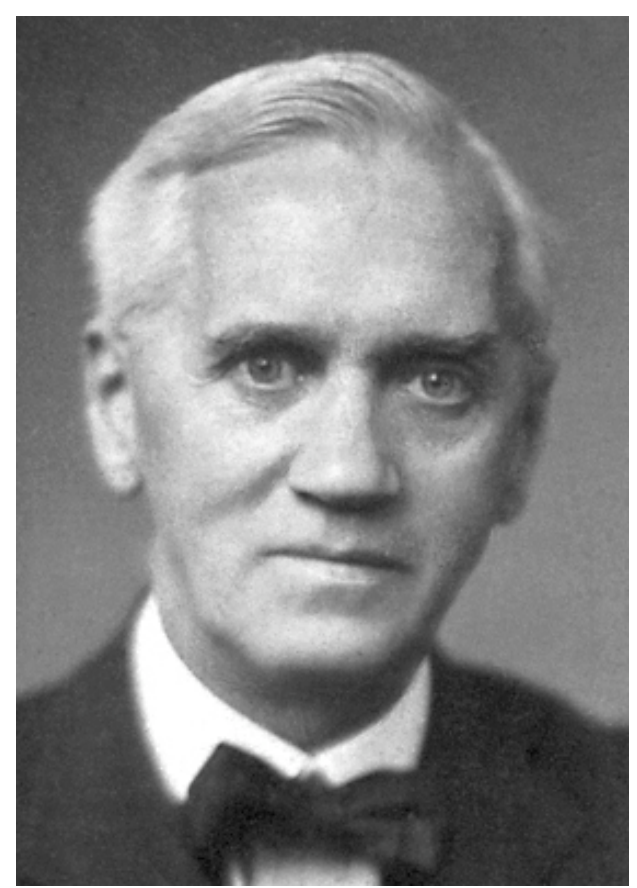

Figura 3. Sir Alexander Fleming (10)

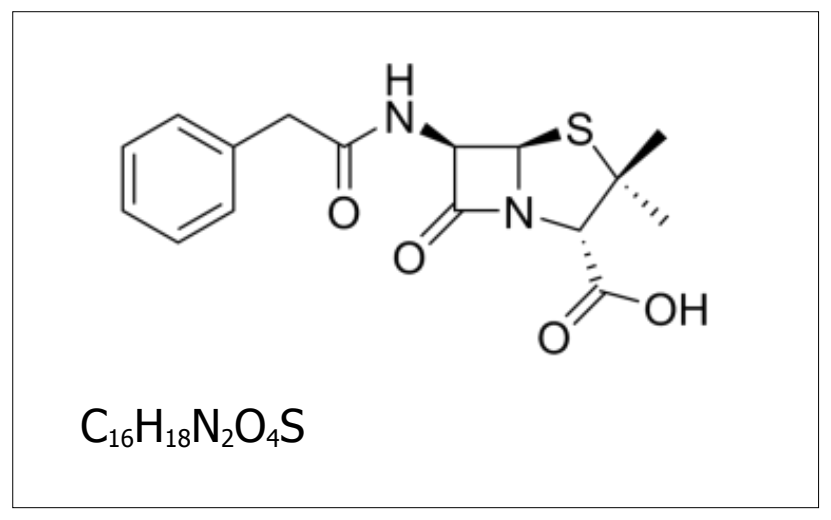

Figura 4. Fórmula química de la penicilina (11)

Los ATM ejercen su acción en algunas de las siguientes estructuras o funciones bacterianas (figura 5): inhiben la síntesis de la pared celular, alteran la integridad de la membrana citoplasmática, inhiben metabolitos, bloquean la síntesis o las funciones de los ácidos nucleicos (actúan sobre la DNA girasa y RNA polimerasa) e impiden la síntesis proteica (inhibidores de $30 \mathrm{~S}, 50 \mathrm{~S}$ y tRNA) (12).

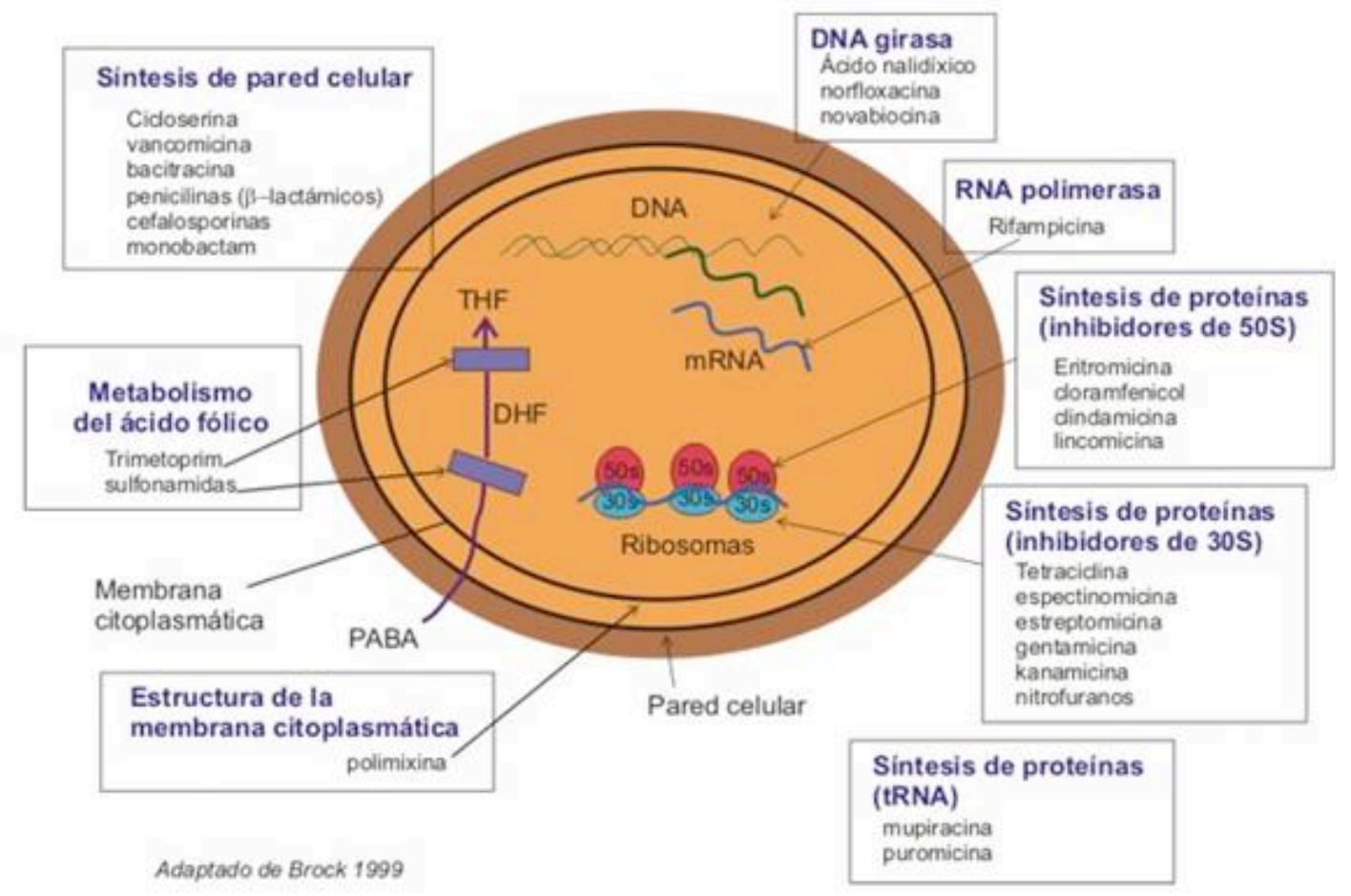

Figura 5. Mecanismos de acción de los antimicrobianos (Sánchez de Rivas) (13). 
La eficacia del tratamiento de una enfermedad infecciosa depende de la concentración que alcanza el ATM en el sitio de infección, entre otros factores. Esta concentración debe ser suficiente como para inhibir la multiplicación o matar al agente etiológico. Si el sistema inmunológico del hospedador se encuentra intacto y activo, basta con un efecto inhibidor mínimo, como el que proporcionan los bacteriostáticos (sustancias que interfieren con el crecimiento o la multiplicación del microorganismo sin ocasionar la pérdida de su viabilidad). Por otro lado, cuando existe inmunodeficiencia se necesita un agente bactericida para erradicar la infección (9).

Es importante destacar que la concentración del fármaco en el sitio de infección no sólo debe inhibir al microorganismo sino también permanecer por debajo de la concentración que es tóxica para las células humanas. Si esto se logra, se considera que el microorganismo es sensible. Cuando la concentración inhibidora o bactericida es mayor de la que se puede utilizar con cierto margen de seguridad in vivo, se considera que el microorganismo es resistente (9).

Los ATM pueden ser administrados con finalidad profiláctica o terapéutica. Teniendo en cuenta esta consideración, pueden especificarse cuatro categorías (9):

a. Pueden ser administrados con finalidad profiláctica. La indicación es considerada profiláctica cuando se indica con sentido preventivo en ausencia de infección, como es el caso de la profilaxis antibiótica prequirúrgica (PAP), para prevenir la infección del sitio quirúrgico.

b. Pueden ser usados en un tratamiento empírico. Esto implica la aplicación frente a un síndrome en particular sin el conocimiento preciso del microorganismo causante de la infección, como sucede con la neumonía asociada a respirador o la infección del tracto urinario de la comunidad.

c. El uso del ATM puede estar dirigido a un patógeno en particular. En otras palabras, es conocido el microorganismo causante de la infección, pero su sensibilidad es desconocida.

d. La terapia antimicrobiana está guiada por la sensibilidad in vitro. En este caso, son conocidos tanto la identidad del microorganismo causante de la infección, como su perfil de sensibilidad.

La indicación terapéutica es empírica cuando se utiliza sin conocer el agente etiológico responsable de la misma, y dirigida cuando se ajusta al hallazgo microbiológico. Las indicaciones profilácticas y empíricas se consideran adecuadas cuando se ajustan a las guías institucionales o a evidencias científicas. Los tratamientos dirigidos se consideran adecuados cuando se ajustan a los hallazgos de la sensibilidad. Además, el fármaco 
escogido debe ser el más efectivo, el más seguro, el más económico y el menos toxico para el paciente (9).

Los ATM han probado ser extraordinariamente efectivos para el control de las infecciones bacterianas. Sin embargo, luego de que su uso se generalizara en medicina, rápidamente se aislaron patógenos humanos que expresaron resistencia a estos agentes y algunos otros se volvieron rápidamente resistentes a muchas drogas que originalmente eran efectivas, tal como se observa en el cuadro 1. Por ejemplo, Staphylococcus aureus desarrolló resistencia a la penicilina a través de la producción de beta-lactamasas a partir de 1954. Esto llevó a una disminución rápida de la utilidad de la penicilina en infecciones por estafilococos, especialmente entre pacientes hospitalizados, donde las cepas resistentes frecuentemente se encuentran antes que se diseminen a la comunidad (14).

Cuadro 1. Año de descubrimiento de los agentes antimicrobianos más importantes y año de comunicación de la existencia de cepas resistentes a los mismos (15).

\begin{tabular}{|l|c|c|c|}
\hline Droga & Descubrimiento & Uso clínico & Resistencia clínica \\
\hline Penicilina & 1928 & 1943 & 1954 \\
\hline Estreptomicina & 1944 & 1947 & 1956 \\
\hline Eritromicina & 1952 & 1955 & 1956 \\
\hline Vancomicina & 1956 & 1972 & 1994 \\
\hline Gentamicina & 1963 & 1967 & 1968 \\
\hline Fluoroquinolonas & 1978 & 1982 & 1985 \\
\hline
\end{tabular}

Lo que ha sido sorprendente es la habilidad de los microorganismos para desarrollar resistencia a los ATM modificados para evadir el mecanismo original de resistencia, como fue el caso del surgimiento de la meticilina, la primera penicilina semisintética resistente a la $\beta$-lactamasa, pero rápidamente se reportaron cepas resistentes a esta droga (16). Este es un testimonio importante sobre la presión de selección que los agentes antimicrobianos ejercen sobre los microorganismos, y del inmenso número de estos que pueden estar en el ambiente sirviendo de reservorios de genes resistentes a los ATM (17).

Los Centros para la Prevención y Control de Enfermedades de Estados Unidos (Centers for Disease Control and Prevention, CDC) han incluido las infecciones por microorganismos resistentes dentro del grupo de enfermedades emergentes, es decir aquellas cuya incidencia en humanos se ha incrementado dramáticamente en los últimos años y que plantean un desafío terapéutico para el futuro (18). 
Como consecuencia de la infección por un agente etiológico resistente a múltiples ATM, el paciente prolonga su estadía en el hospital, requiere a menudo técnicas complejas de diagnóstico $\mathrm{y}$, al haber mayores posibilidades de falla terapéutica, requiere ATM más onerosos y aumenta su riesgo de muerte $(19,20)$. Es por ello que la resistencia bacteriana a los ATM no debe ser considerada solo en términos médicos sino también económicos.

Por lo tanto, el desarrollo de la resistencia presenta no sólo el desafío de proveer una terapéutica efectiva, sino que también lleva al incremento de los costos del tratamiento, la duración del tiempo de hospitalización del paciente, la morbilidad y la mortalidad que implica ese agente infeccioso (19-21).

La resistencia antimicrobiana ha sido y es un real problema de salud pública y como un enorme desafío clínico. Aun cuando el uso de ATM sea apropiado, con un objetivo profiláctico o terapéutico, estará asociado con la aparición de microorganismos resistentes como consecuencia de la presión de selección, lo que destaca la importancia en la prudencia en su uso $(21,22)$.

\subsection{Uso de antimicrobianos}

El gasto de medicamentos en los países desarrollados es del 8 al $20 \%$ del presupuesto total de salud, mientras que en los países en vía de desarrollo es del 40 al $60 \%$ (23). Los ATM representan en general el tercer gasto de farmacia (15-30\% del presupuesto hospitalario) después de los insumos biomédicos y las soluciones parenterales (24), y si bien no son los medicamentos más caros, su peso económico en la farmacia es muy importante por su volumen de uso. Equivalen al 15\% del consumo de medicamentos de la práctica médica ambulatoria y del 23 al $37 \%$ de la prescripción en un hospital $(25,26)$.

En las estrategias para prevenir las infecciones asociadas al cuidado de la salud, publicadas en 2008 por el comité mixto conformado por la Sociedad de Epidemiología Hospitalaria de América (Society for Healthcare Epidemiology of America, SHEA) y la Sociedad de Enfermedades Infecciosas de América (Infectious Diseases Society of America, IDSA) se enfatizó el manejo apropiado de ATM como un componente principal de los programas diseñados para prevenir la resistencia antimicrobiana en hospitales (27). Dado que el desarrollo de nuevos productos es un proceso lento, es necesario optimizar y extender la efectividad de los agentes disponibles, lo cual implica la importancia de la administración en forma adecuada (22).

El uso excesivo de ATM es un problema a nivel mundial. Se ha estimado que de todos los pacientes hospitalizados en los Estados Unidos, aproximadamente entre el $25 \%$ y el $40 \%$ reciben este tipo de medicamentos (22), y en Israel, se observó esta situación en el $62 \%$ de todos los pacientes hospitalizados que se estudiaron (28). Al mismo tiempo, numerosos estudios han sugerido que entre el $20 \%$ y $50 \%$ del total de ATM prescriptos, son 
usados en forma innecesaria o inapropiada $(22,25,29,30)$. Además, entre el $27 \%$ y el $44 \%$ de los días de terapia son debidos a tratamientos innecesarios (30).

El uso de ATM puede ser inapropiado cuando $(22,31)$ :

a. no hay evidencia de enfermedad infecciosa por bacterias,

b. se administran a pacientes que solo están colonizados con el microorganismo,

c. se los indica como tratamiento de enfermedades infecciosas causadas por microorganismos resistentes a dicho fármaco,

d. se suministra un ATM de amplio espectro cuando la administración de uno de espectro reducido hubiera sido efectivo y viable,

e. se prescriben múltiples ATM cuyos espectros de acción se superponen,

f. se administran ATM que no alcanzan la concentración adecuada en el sitio de infección,

g. se suministran en dosis, intervalos o duración del tratamiento inapropiado.

El uso apropiado de ATM es una meta que tiene gran urgencia debido a la inminente crisis concerniente a la emergencia de la resistencia bacteriana. Su administración inapropiada es un problema en todo el mundo, no sólo por el desarrollo e incremento de la resistencia, sino también por las reacciones adversas que se producen y por el aumento de los costos para el sistema de salud (32-34).

\subsection{Uso de antimicrobianos y resistencia bacteriana}

Para utilizar ATM en forma óptima y de este modo contribuir con la disminución de la resistencia, es necesario tener una comprensión precisa de la relación entre el uso de ATM y la resistencia. El espectro de conocimiento se extiende desde las interacciones entre las moléculas de antimicrobianos y los blancos microbianos in vitro, hasta el efecto ecológico del uso de estos medicamentos, que se estudia a partir de los datos obtenidos a nivel hospitalario o a nivel nacional. La naturaleza de la relación droga-organismo es altamente variable dependiendo de cada caso en particular (17).

La habilidad de diferentes especies bacterianas para resistir la acción inhibitoria de los ATM difiere enormemente de un microorganismo a otro. Bacterias que por décadas habían sido sensibles, han desarrollado resistencia no sólo a las terapias clásicas sino también a agentes más nuevos. Algunas bacterias han desarrollado resistencia a drogas de reciente aparición casi tan pronto como aparecieron en el mercado (35). Podemos mencionar como ejemplo lo que ocurrió con la ciprofloxacina. Cuando se introdujo en el mercado para administración por vía oral en 1988, tenía un nivel alto de actividad antibacteriana, incluyendo Pseudomonas aeruginosa y $S$. aureus sensible y resistente a la meticilina. Sin embargo, con el transcurso del tiempo, tal como lo comprobó un estudio 
realizado por Ali y col., se observó que la resistencia a la ciprofloxacina era del 21,95\% para los aislamientos de $S$ aureus y del $44,44 \%$ para los de $P$. aeruginosa (36).

En distintos trabajos se ha descripto una relación temporal fuerte entre los ATM usados y la prevalencia de bacterias resistentes a lo largo del tiempo $(37,38)$. Hay evidencias directas que provienen de estudios que examinan el efecto de bajas dosis de antibióticos usados como promotores de crecimiento en animales y la presencia de bacterias resistentes. También, a nivel hospitalario, en un estudio realizado en Taiwan, una reducción en el uso de los macrólidos (principalmente la eritromicina) se relacionó con una disminución en la tasa de resistencia a la eritromicina en Streptococcus pyogenes (39) y en Canadá, se demostró una correlación significativa entre el aumento del número de prescripciones de fluoroquinolonas, particularmente ciprofloxacina, y un incremento en la frecuencia de Streptococcus pneumoniae con sensibilidad disminuida a ese ATM (22). Asimismo se describió que la aparición de bacteriemia durante la internación, la historia de hospitalización y la presencia de úlceras de decúbito estaban asociados con un aumento en la probabilidad de infecciones por $S$. aureus resistente a la meticilina (SARM) versus $S$. aureus sensible a la meticilina. Sin embargo, el uso previo de ATM fue el factor predictivo más significativo con un odds ratio de 9,2 (40).

La generación de resistencia a los betalactámicos también ha sido objeto de estudio (41). Se considera altamente probable que la utilización de cefoxitina y cefalosporinas de tercera generación seleccionen cepas resistentes. Estos mutantes suelen ser resistentes tanto a las cefalosporinas de tercera generación como a las penicilinas. Debido a esto, el tratamiento con cefalosporinas puede fracasar debido a la selección de mutantes altamente resistentes durante la terapia, incluso cuando los patógenos son inicialmente sensibles a dicha droga (42).

Luego del rápido incremento de aislamientos de enterococos resistentes a vancomicina, ocurrido en Estados Unidos durante los años noventa, se recomendó enérgicamente la restricción del uso intravenoso de dicho ATM (43). Estas recomendaciones estaban basadas en estudios previos donde se lo señalaba como un factor de riesgo para el desarrollo de infecciones por enterococos resistentes a dicho antibiótico (44, 45). Fue así que con el objetivo principal de restringir y controlar el uso de vancomicina, se desarrollaron diferentes intervenciones (46). Sin embargo, estudios posteriores demostraron que no solo vancomicina, sino también las cefalosporinas de amplio espectro y la clindamicina inducen o facilitan la colonización o infección por enterococos resistentes a vancomicina (47). La cantidad total de ATM, la duración del tratamiento o de la profilaxis, también parecen ser factores de riesgo importantes para la adquisición de estas bacterias (47). 
De manera similar, algunos trabajos han asociado el uso de fluoroquinolonas con el aislamiento de SARM (48).

Las leyes de selección natural establecen que las bacterias serán resistentes a prácticamente cualquier ATM. La presión de selección ejercida por el uso de ATM de amplio espectro está forzando su aparición (35).

Los patrones de resistencia varían en todo el mundo, aún en distintas zonas de un mismo país y también según las instituciones, y esto se debe a los variados usos de ATM. Por eso, la resistencia es un problema local, que seguramente está relacionado con las cantidades de ATM que se usan en el hospital y a la atención que se presta al control de infecciones $(49,50)$.

\subsection{Resistencia a los ATM}

La resistencia a los ATM es particularmente marcada en las infecciones nosocomiales, y el uso inapropiado de estos medicamentos contribuye al aumento de la resistencia bacteriana por seleccionar las cepas más resistentes de una población, y por otro lado, por la eliminación de la microbiota endógena del paciente, que podría competir con el patógeno (42).

\subsubsection{Mecanismos de resistencia bacteriana}

Un microorganismo susceptible evade la actividad antimicrobiana por variados mecanismos. Pueden sufrir mutaciones en su genoma o en material genético extracromosomal preexistente, generando nuevos "genes de resistencia", expresar un gen de resistencia latente, y/o adquirir genes de resistencia a partir de una fuente exógena, siendo esta última vía la más frecuentemente reconocida (51).

Dentro de los mecanismos de transferencia horizontal se encuentran la conjugación, la transducción y la transformación (figura 6) (52). Por lo general, la resistencia farmacológica se adquiere por transferencia horizontal de una célula donadora por uno de los mecanismos mencionados. Este tipo de resistencia se extiende con rapidez, por propagación clonal de la cepa resistente o por transferencias subsecuentes hacia otras cepas sensibles (9). De los mecanismos de intercambio genético, el más relevante para la diseminación de genes de resistencia entre poblaciones bacterianas en los pacientes hospitalizados es la conjugación (51).

La conjugación es la transferencia de genes por contacto entre dos células a través de un puente sexual (pilus). Este mecanismo es muy importante puesto que es posible transferir varios genes de resistencia en un solo evento a través de un plásmido conjugativo (9). 


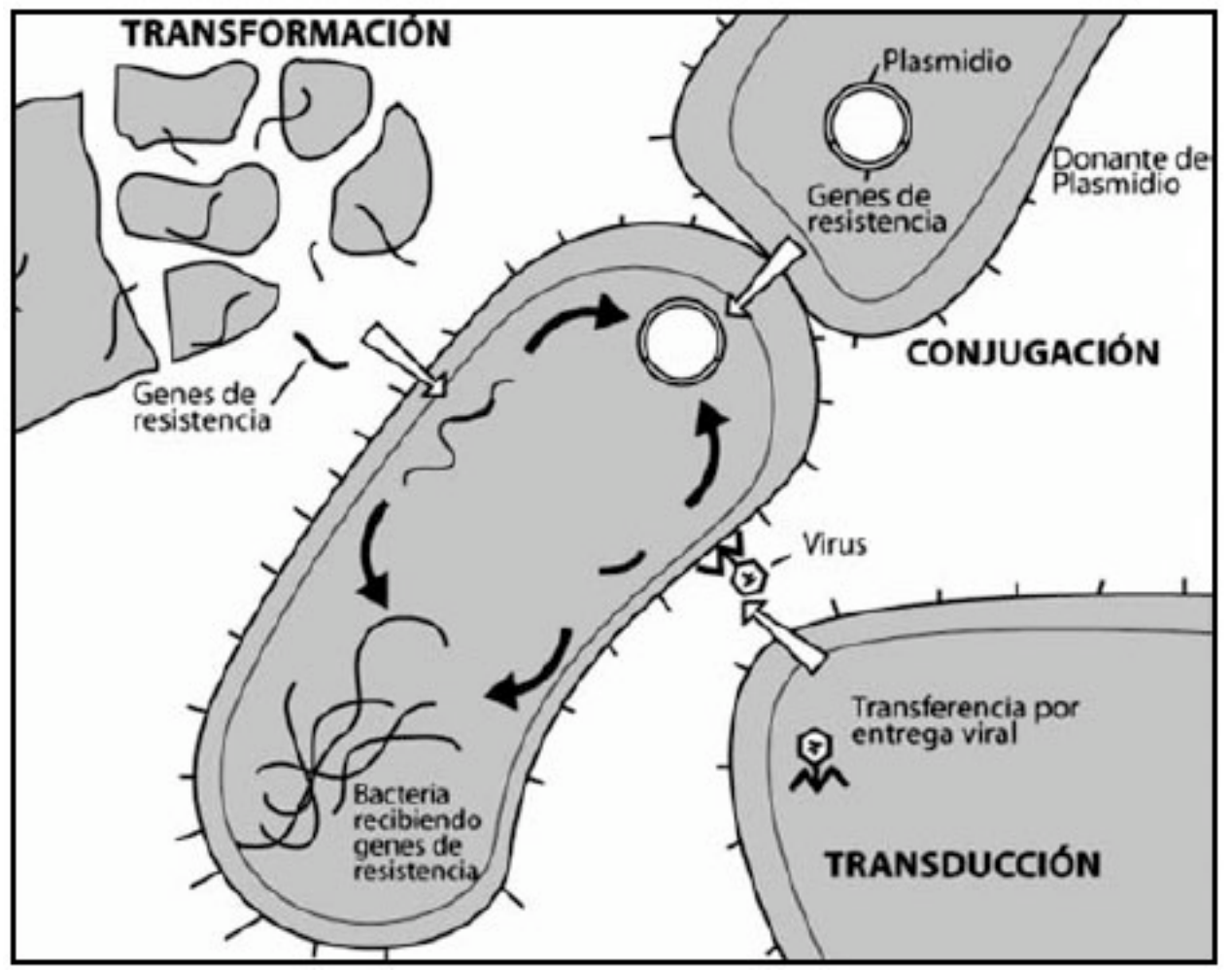

Figura 6. Mecanismos de transferencia horizontal de genes de resistencia (53)

En la transducción, el ADN de la célula dadora penetra en la célula receptora por infección viral. Cuando el $A D N$ posee un gen de resistencia farmacológica, la célula bacteriana recién infectada adquiere la resistencia (52).

El proceso de transformación involucra la captación e incorporación en el genoma de la bacteria receptora de ADN desnudo liberado en el ambiente por otras células bacterianas (52).

La información codificada en el material genético da lugar a diversos tipos de alteraciones que le confieren resistencia a las drogas (figura 7) (9):

a. Reducción de la concentración intracelular del medicamento: interferencia en el transporte de la droga a través de la membrana (impermeabilidad) o por bombas de extracción que pueden transportar los fármacos hacia el exterior de la célula (eflujo).

b. Inactivación enzimática del antimicrobiano.

c. Modificación de la ruta metabólica ("by-pass").

d. Modificación del sitio receptor de la droga (cambios en la conformación de porinas, ribosomas, proteínas ligadores de penicilina). 


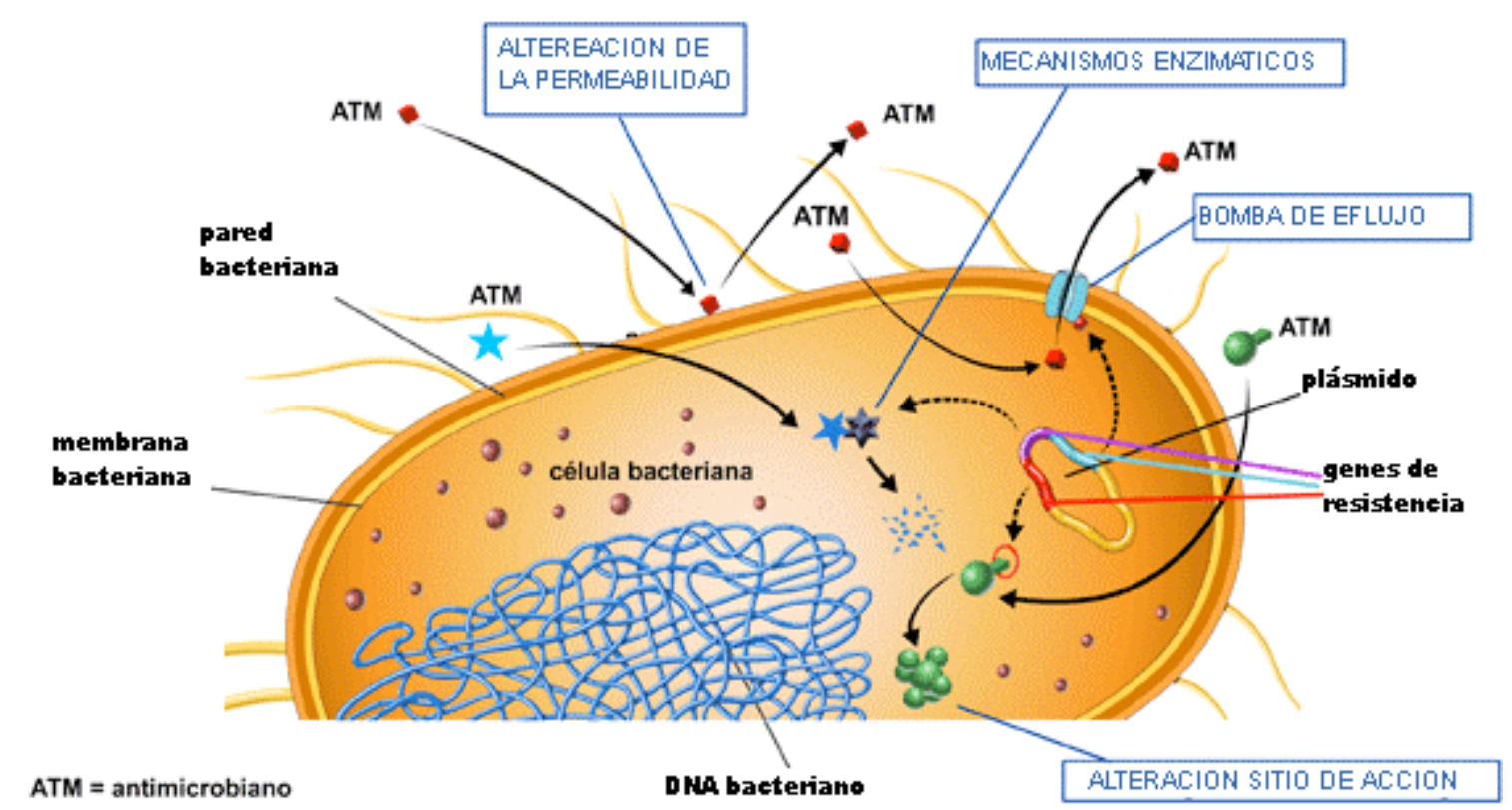

Figura 7. Mecanismos de resistencia bacteriana a los antimicrobianos (54).

La membrana externa de las bacterias gramnegativas es una barrera permeable que impide la penetración de moléculas polares grandes. Las moléculas polares pequeñas, como muchos antibióticos, penetran en la célula a través de canales proteínicos llamados porinas. La ausencia, mutación o pérdida de una porina disminuye la velocidad con la que el fármaco penetra en la célula o impide su entrada, lo que reduce la concentración del medicamento en su sitio de acción. Cuando el objetivo es intracelular y el fármaco requiere transporte activo a través de la membrana celular, cualquier mutación o cambio fenotípico que interrumpa este mecanismo de transporte confiere resistencia. Por ejemplo, la gentamicina, que se fija a la subunidad $30 \mathrm{~S}$ del ribosoma bacteriano e inhibe la síntesis proteica, se transporta activamente a través de la membrana celular utilizando la energía proporcionada por el gradiente electroquímico de la membrana. Cualquier mutación en una enzima de esta ruta reducen la velocidad con la que penetra la gentamicina en la célula, lo que provoca resistencia. Además, las bacterias poseen bombas de eflujo, que pueden ser altamente específicas para un solo agente o pueden involucrar a distintas clases de ATM. Estas bombas de eflujo transportan al medicamento hacia el exterior, como en la resistencia a tetraciclinas, cloranfenicol, fluoroquinolonas, macrólidos y antibióticos beta-lactámicos (9).

Otro de los mecanismos generales de resistencia a los medicamentos es la inactivación farmacológica. La resistencia bacteriana a los aminoglucósidos y antibióticos beta-lactámicos casi siempre se debe a la producción de enzimas que modifican al aminoglucósido o betalactamasas, respectivamente (9).

Por último, la resistencia farmacológica producida por la alteración del blanco molecular, lleva a una disminución en la afinidad con el ATM (resistencia de estafilococo a la 
meticilina gracias a la producción de una proteína enlazadora de penicilina de baja afinidad) (9).

\subsubsection{Aparición de resistencia en el hospital}

En el hospital, la aparición de cepas resistentes puede deberse a diferentes razones. Cuando un paciente infectado con un patógeno resistente es derivado al hospital desde otro centro de salud, a través de algún mecanismo de transferencia genética entre microorganismos, a través de la transferencia debido a una higiene inadecuada de las manos o a la contaminación ambiental y por selección de las mutantes resistentes seleccionadas por el uso de $\operatorname{ATM}(55,56)$.

La transferencia de patógenos resistentes de pacientes provenientes de otro centro de salud a pacientes internados en otro hospital ha sido bien documentada. Luego de un ataque terrorista en Bali, las víctimas, inicialmente tratadas en un hospital local, desarrollaron infección por Acinetobacter spp. multi-resistente. Trasladados a un hospital en Australia, resultaron los reservorios a partir de los cuales se originó un brote (57). Quale et al.(58) describieron una relación clonal en el surgimiento de $A$. baumannii resistente a carbapenems en 15 hospitales del área metropolitana de Nueva York, un hallazgo que claramente indica el efecto de la transferencia de microorganismos resistentes entre hospitales.

La transferencia de patógenos multi-resistentes entre pacientes internados en una misma institución también está bien documentada. Por ejemplo, en un brote descripto por Deplano et al.(59) 16 de 18 pacientes afectados tuvieron aislamientos de $P$. aeruginosa con idéntico serotipo y patrones de electroforesis en gel de campo pulsante (PFGE). En el estudio se detectó contaminación del medio ambiente en la unidad de cuidados intensivos y en las manos de una enfermera. En otro brote, se ha documentado a los jabones como fuente de A. baumannii, en brotes de hospitalarios, habiéndose demostrado que luego de la desinfección de la unidad, no hubo más casos de infección (60).

Como ya se comentara previamente, varias líneas de evidencia sugieren una asociación causal entre el uso de ATM en el hospital y la resistencia bacteriana $(55,61,62)$ :

a. Cambios en el uso de ATM van en paralelo con cambios en la prevalencia de resistencia.

b. La resistencia es más frecuente entre las bacterias aisladas en el hospital que en aquellas de infecciones adquiridas en la comunidad.

c. Durante brotes de infecciones asociadas al cuidado de la salud (IACS), es frecuente que los pacientes infectados con cepas resistentes hayan recibido tratamiento ATM previo. 
d. Dentro del hospital, las áreas que tienen los valores más altos de resistencia, también tienen los valores más elevados de uso de ATM.

e. Los pacientes que tienen mayor tiempo de exposición a los ATM tienen un incremento en la probabilidad de estar colonizados con microorganismos resistentes.

\subsection{Vigilancia de la resistencia bacteriana y el uso de antimicrobianos}

No hay evidencias que permitan vislumbrar la disminución de la emergencia de cepas resistentes, por lo que es de esperar, como se comentara previamente, que, en los próximos años, no exista tratamiento adecuado para algunos patógenos.

La resistencia comienza en una institución particular y es influenciada por una variedad de factores locales que, en última instancia, determinan su potencial de expandirse o disminuir. Por consiguiente, el conocimiento de los niveles locales de resistencia es fundamental. Un porcentaje elevado de las infecciones contraídas en los hospitales son causadas por bacterias resistentes, como Staphylococcus aureus resistente a la meticilina o los enterococos resistentes a la vancomicina (50). Además, la aparición de cepas resistentes en cualquier parte del mundo representa no sólo una amenaza en el lugar en que surgió, sino también un potencial problema en cualquier otra parte (figura 8) (63). La globalización incrementa la vulnerabilidad de los países para importar enfermedades, debido a que las enfermedades infecciosas viajan más rápido y más lejos que antes (21). Los datos de sensibilidad derivados de programas de vigilancia pueden ser predictores de problemas de resistencia (64).

La vigilancia de la sensibilidad a los ATM de las bacterias aisladas en el hospital, puede servir como una guía para la elección de la terapia empírica en el tratamiento de las infecciones así como un medio inicial para tipificar las cepas de un posible brote (65). También es importante conocer los patrones de prescripción antibiótica para identificar dónde se deben hacer mejoras en la práctica clínica (25). 


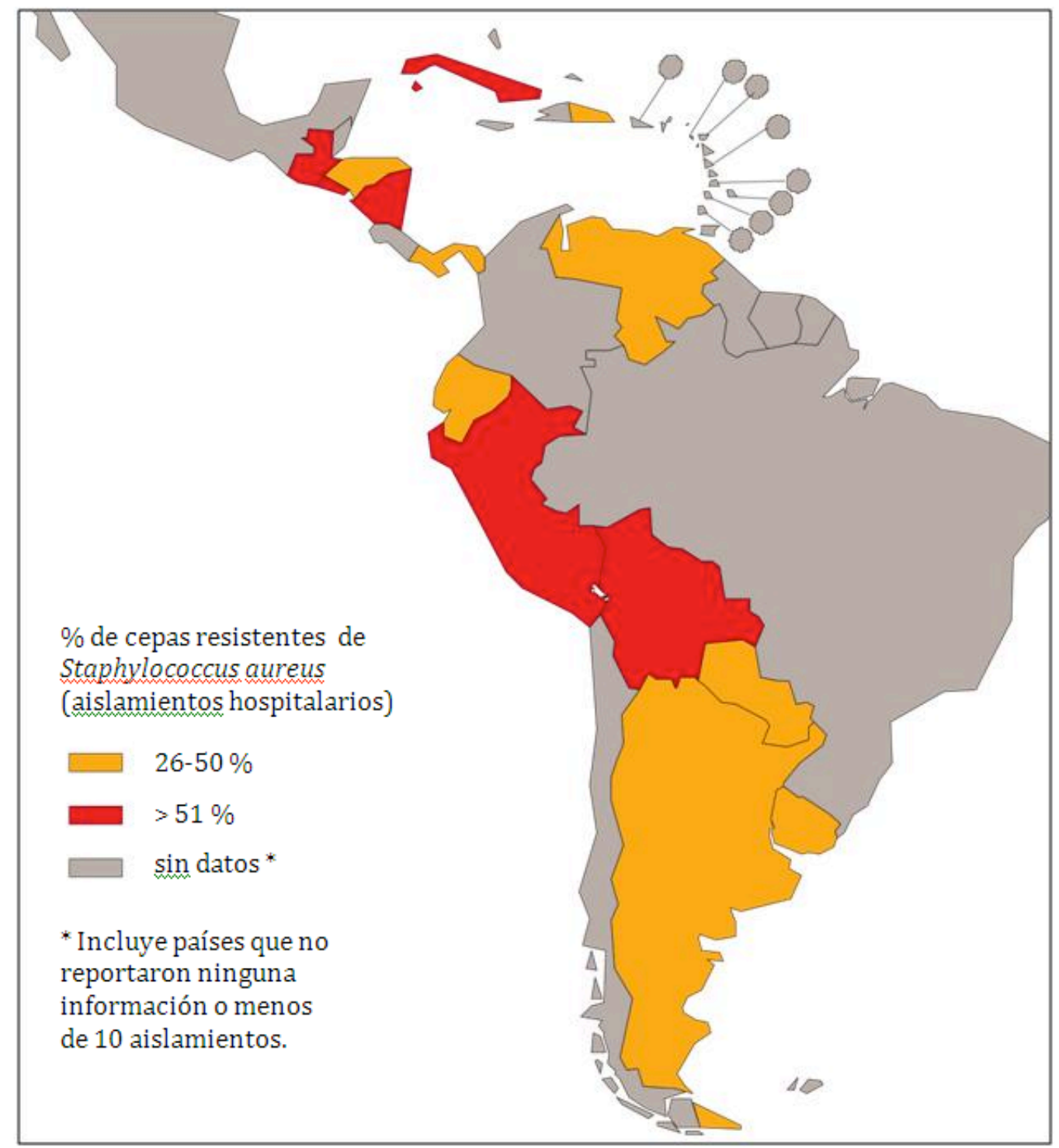

Figura 8. Porcentaje de cepas de Staphylococcus aureus resistentes a la meticilina aislados de hospitales, 2007, America Latina y el Caribe (50).

Para minimizar el impacto del incremento de la resistencia se requieren propuestas internacionales $(36,66,67)$. La Organización Mundial de la Salud (OMS) y la Comisión Europea (European Commission) han reconocido la importancia de estudiar la emergencia y los determinantes de la resistencia y la necesidad de estrategias para su control.

La OMS ha desarrollado un programa de vigilancia de la resistencia a los ATM, denominado "WHONET" $(68,69)$. Uno de sus principales objetivos es facilitar los estudios de prevalencia sobre ese aspecto en cada unidad hospitalaria. La creación de redes de laboratorios permite monitorizar la diseminación de los distintos perfiles de resistencia. Utilizando un programa informático único para el tratamiento de los datos, es posible 
establecer tendencias regionales, detectar la emergencia de resistencias inusuales y aportar bases racionales para el uso de los ATM (70).

En los países europeos, este tipo de monitoreo se lleva a cabo desde 1998 por el Sistema Europeo de Vigilancia de Resistencias Antimicrobianas (European Antimicrobial Resistance Surveillance System, EARSS). Fundado por la Comisión Europea, EARSS es una red internacional de vigilancia que pretende recolectar datos comparables y fiables de resistencia. Su propósito es documentar variaciones en la resistencia bacteriana a lo largo de tiempo y lugar y proveer las bases para evaluar la efectividad de los programas de prevención (71).

Algunos países, como España, cuentan con su propio proyecto, denominado Vigilancia de la Resistencia a los Antimicrobianos (VIRA), iniciado en el año 2001, y que consiste en realizar periódicamente estudios de seguimiento epidemiológico de la resistencia a los antibióticos.(72)

El Consejo Mundial de Resistencia a Antibióticos (Global Advisory on Antibiotic Resistance Data, GAARD), iniciativa de la Alianza para el Uso Prudente de Antibióticos (Alliance for the Prudent Use of Antibiotics, APUA) fue el primer proyecto formulado para recopilar datos de muchos de los programas de control de antimicrobianos efectuando un reporte completo del estado de sensibilidad de los antimicrobianos a nivel mundial. Incluye un profundo análisis de la resistencia a la droga por parte de un microorganismo en particular en una escala global, e informa las características comunes de la resistencia entre todos los microorganismos (63).

EI CDC y la Fundación Nacional de Enfermedades Infecciosas (National Foundation for Infectious Diseases) también recomendaron que los hospitales efectúen el control del uso de antimicrobianos en un intento de reducir la emergencia y diseminación de bacterias resistentes. La División de Promoción de la Calidad de Sanitaria (Division of Healthcare Quality Promotion) del CDC en cooperación con la Escuela Rollins de Salud Pública de la Universidad de Emory (Rollins School of Public Health at Emory University), crearon una herramienta de control: el Proyecto Intensive Care Antimicrobial Resistance Epidemiology (ICARE). El proyecto ICARE provee datos de la resistencia antimicrobiana y del uso de antimicrobianos $(73,74)$.

La Organización Panamericana de la Salud (OPS) igualmente promueve el uso apropiado de antibióticos en las Américas, por lo que ha recomendado el desarrollo de una red panamericana para la vigilancia de la resistencia a los mismos (75).

Argentina, al igual que otros países, comparte la preocupación por la resistencia de las bacterias a los ATM. El Instituto Nacional de Enfermedades Infecciosas (INEI) "Dr. C.G. Malbrán", dependiente de la Administración Nacional de Enfermedades Infecciosas (ANLIS) 
participa del programa WHONET y ha convocado a 70 laboratorios (76) representativos de casi todas las áreas geográficas del país para obtener datos a escala nacional y constituir un sistema de vigilancia de la resistencia a los ATM (77). También, en el año 2004 se puso en marcha el Sistema Informático para la Vigilancia de las Infecciones Hospitalarias de la Argentina (VIHDA), creado por el Instituto Nacional de Epidemiología Dr. Juan H. Jara (también dependiente de ANLIS), para el Ministerio de Salud de la Nación (78).

En suma, las redes de vigilancia proponen mejorar la capacidad para detectar, monitorear y manejar la resistencia a los ATM. La información de estos estudios proporciona información acerca de cómo fluctúa la resistencia en diferentes lugares geográficos. Además, la supervisión constante de las tasas de resistencia en todo el mundo permite dirigir los recursos de manera más eficiente. Esta orientación racional de los recursos, a su vez, reduce el costo de la asistencia sanitaria, preservando la efectividad de los ATM actuales. Investigar por qué algunos lugares tienen bajas tasas de resistencia, mientras que otros tienen tasas altas, también permite formular ideas sobre las causas subyacentes de la resistencia a los medicamentos (79).

En coincidencia con otros autores, para asegurar las opciones para el tratamiento de infecciones que ya existen, es imperioso hacer el mejor uso de los ATM que están disponibles actualmente. Los programas de uso adecuado de ATM se enfocan en: asegurar su aplicación apropiada para alcanzar los mejores resultados en los pacientes, disminuir el riesgo de efectos adversos, económicamente razonables, promover del tratamiento y reducir o estabilizar los niveles de resistencia (17).

\subsection{Administración de antimicrobianos}

Existen diferentes términos para referirse al uso adecuado de ATM: políticas de uso, programas de manejo, programas de control, programas de uso racional, y otros términos pueden ser utilizados como sinónimos. Todos ellos están destinados a cambiar y direccionar el uso de ATM en una institución de salud, que puede emplear distintos tipos de estrategias.

Por lo tanto, se define como programa para el uso adecuado de ATM al esfuerzo continuo para optimizar su aplicación entre los pacientes hospitalizados, asegurar una terapia costo efectiva y reducir sus efectos adversos (incluyendo la resistencia antimicrobiana) en las instituciones de salud (17).

La administración correcta de ATM incluye la elección apropiada de la droga, dosis y duración del tratamiento para lograr una eficacia óptima en el manejo de las infecciones (80). El ideal que se busca alcanzar, entonces, es que todos los pacientes estén tratados con el medicamento más efectivo, menos tóxico, y menos costoso durante el tiempo preciso para curar o prevenir una infección. 
Estos programas pueden clasificarse en forma general de acuerdo con la estrategia aplicada. Sin embargo, debido a que en muchos casos se utilizan estrategias combinadas (81), no siempre es posible una clasificación estricta de estos programas.

\subsection{Estrategias para optimizar la utilización de antimicrobianos a nivel hospitalario}

Las autoridades del área de salud sugieren que en todo hospital se forme un Comité de Farmacia y Terapéutica que tenga a su cargo el desarrollo del vademécum, de guías o algoritmos y del control de ATM a través de una variedad de mecanismos $(82,83)$. El vademécum consta de una lista de medicamentos disponibles en la institución, y las guías son documentos que ofrecen recomendaciones acerca de qué droga debería prescribirse para una condición clínica específica (84). Además, debe evaluar la situación de la resistencia a los ATM en todo el hospital y dentro de cada una de las áreas que lo integran de tal forma que las decisiones terapéuticas institucionales se encuentren respaldadas por información clínica, microbiológica y farmacológica (75).

Un aspecto importante a tener en cuenta es definir lo que la institución considera uso adecuado de ATM. Debido al tiempo limitado para enseñar farmacología antimicrobiana y enfermedades infecciosas en la carrera de medicina, los profesionales muchas veces adquieren los hábitos de prescripción de la práctica de sus colegas, de los manuales de ATM y de la información provista por los representantes de la industria farmacéutica (85).

Los hospitales deben contar con guías para el uso de ATM, educación médica grupal o individual con respecto a la terapia antimicrobiana y la retroalimentación de los resultados observados. La retroalimentación consiste en proveer a los médicos datos sobre sus hábitos de prescripción, en comparación con las normas establecidas o con las indicaciones de otros médicos de la misma área. Con esta estrategia se trata de influir la prescripción durante la evaluación del paciente y la selección de la terapia ATM. Sin embargo, las guías necesitan ser revisadas y actualizadas continuamente (22).

Una vez que se han implementado guías, uno de los factores más importantes que va a garantizar su éxito es el nivel de adhesión a ellas. Debido a la resistencia para adherir la prescripción a este tipo de guía, deben establecerse normas con las estrategias del hospital (84), a fin de realizar un control externo sobre la indicación de estos medicamentos (22).

Para hacer cumplir las normas establecidas en el hospital han sido empleados múltiples mecanismos. Éstos incluyen:
a. Educación.
b. Uso restringido de algunos ATM.
c. Rotación de ATM. 
d. Formulario de pedido de ATM.

e. Orden de paro de ATM de uso terapéutico y profiláctico.

f. Aprobación por parte del Servicio de Infectología de la aplicación de los ATM prescriptos.

g. Uso combinado de ATM.

h. Base de datos computarizada para correlacionar los resultados del laboratorio de bacteriología y del servicio de farmacia.

i. Revisión de las prescripciones y retroalimentación.

\subsubsection{Educación}

Cuando se desarrolla una guía, se ha demostrado que los profesionales adhieren mejor a ellas cuando están acompañadas con educación, que cuando simplemente se realiza una restricción (86). También se ha indicado que las guías desarrolladas a nivel local tienen más probabilidades de ser aceptadas y seguidas que las que se implementan a nivel nacional (25).

Una parte importante de un programa para el uso adecuado de ATM y el manejo de la resistencia bacteriana es la educación médica. Las intervenciones basadas en educación son más efectivas si los médicos lo perciben como una ayuda más que como una restricción. La mejor forma es proveer un informe sobre los patrones de prescripción y las sugerencias educativas para permitir que posteriormente el profesional tome la decisión final basado en la información. La participación de los médicos en la implementación de las guías para utilización de ATM genera una mayor adhesión a las mismas (42). Según la institución que los implemente, los programas de educación varían entre conferencias, circulares con material instructivo, consulta con área de farmacología, boletín informativo de farmacia hospitalaria, distribución de guías clínicas, y otros. La revisión de las guías por parte de los pares para el manejo de infecciones específicas puede ser útil en el proceso de toma de decisiones por parte de los médicos y puede asistir en la implementación del uso adecuado o en el buen manejo de ATM (22). Se recomienda, además, que los médicos consideren el informe microbiológico como una orientación para tomar sus decisiones terapéuticas.

\subsubsection{Uso restringido de algunos antimicrobianos}

El uso restringido de algunos ATM generalmente consiste en el establecimiento de un formulario ad hoc, de tal forma que sólo un grupo selecto de ATM es dispensado en forma libre desde la farmacia. Otros antibióticos estarán solo disponibles si cumplen ciertos criterios para su dispensación, como ser si se obtiene la aprobación para su uso por parte de un médico infectólogo (80). 
El formulario de ATM de uso restringido es el método más directo para influir en el uso de los mismos y contener los costos de las drogas (22). Generalmente son considerados los patrones de resistencia o la sensibilidad de los patógenos locales, la toxicidad y los costos para elegir el grupo de drogas que se va a incluir en la lista. Estos formularios limitan el uso de las drogas de precio elevado y de amplio espectro, pero tienen la desventaja potencial que es el uso excesivo de un grupo permitido de ATM de amplio espectro $(42,75,87)$. Se ha demostrado que cuando un agente específico es excluido de la lista de uso restringido, aumenta su utilización (22). Finalmente, la lista restringida debe ser dinámica y permitir modificaciones apropiadas respondiendo a los cambios de los patógenos locales y de los patrones de sensibilidad, disponibilidad de nuevas drogas y otra información pertinente, como ser los costos y las características farmacocinéticas de la droga (22).

\subsubsection{Rotación de antimicrobianos}

La rotación de ATM consiste en el reemplazo de una droga por otra de similar espectro de acción. Un estudio donde se realizó la sustitución en el formulario farmacoterapéutico, de amikacina por gentamicina y tobramicina, sugirió que la estrategia de cambiar el ATM podría ser efectiva en la disminución del surgimiento de resistencia a dichos agentes (88). Estas investigaciones llevaron al desarrollo de estrategias que seguían esquemas de rotación de ATM con el fin de minimizar la aparición de resistencia. Teóricamente, durante el período en que el ATM fue rotado y su uso mínimo, la resistencia a ese agente debería haber disminuido. La idea consiste en reducir la presión de selección a una clase de ATM a través de un uso más heterogéneo de ellos.

Sin embargo, los modelos matemáticos sobre evolución de la resistencia sugieren que esta estrategia no es suficiente para prevenir el surgimiento de resistencia (89).

\subsubsection{Formulario de pedido, orden de paro automático y aprobación del Servicio Infectología}

Los programas de uso adecuado de ATM que requieren autorización previa a su administración, como los formularios de pedido, las órdenes de paro automático, o la aprobación por parte de un especialista, actúan predominantemente en la disponibilidad del ATM para la elección en la prescripción (22). Este tipo de programa generalmente tiene un impacto positivo en los resultados clínicos, especialmente en la aparición de resistencia (22). Sin embargo, estas estrategias, pueden aumentar el trabajo administrativo, llevar a conflictos dentro del equipo médico, y pueden o no mejorar la terapéutica $(22,42,87)$.

Frecuentemente, en respuesta a los resultados microbiológicos se debe realizar una modificación en la terapia empírica inicial. Esta práctica, que no se lleva a cabo con frecuencia, puede ser útil para reducir tanto el uso de los ATM de amplio espectro como la 
aparición de resistencia. La terapia empírica generalmente tiende a cubrir un amplio espectro de microorganismos, pero puede y debe ser modificada a un régimen reducido si los resultados microbiológicos indican que ese cambio está garantizado. Igualmente, si los resultados no proveen evidencia de infección bacteriana, debería evaluarse la suspensión de la terapia antimicrobiana (22).

La participación de un comité para el manejo de ATM junto con la aplicación de una combinación de estrategias para optimizar su uso puede asociarse a una modificación significativa de la práctica de prescripción, reducción en el uso de ATM, resistencia bacteriana y costos (31).

No todas las estrategias han demostrado ser exitosas para controlar la administración de dichos medicamentos. Gould y Jappy (90) describieron la implementación de un programa de uso restringido de ATM para mejorar la calidad de las prescripciones y controlar los costos. Luego de implementar las normas y un formulario de ATM, se vio que, desafortunadamente, el gasto aumentó de 11,9\% a 18,7\%. Sin embargo, otros estudios han informado éxito en reducir el uso de ATM con la implementación de diferentes estrategias de control. También se observó que se puede obtener una disminución en el uso de droga, pero sin obtener una reducción correspondiente en el grado de resistencia (6). En un estudio realizado en Pensilvania, USA, se implementó una norma de uso restringido de vancomicina mediante el permiso del Servicio de Aprobación de Enfermedades Infecciosas para continuar la terapia por más de 72 horas, y se evaluó si ésta era apropiada, si había cambios en la administración de este ATM y la incidencia de especies del género Enterococcus spp. resistentes a la vancomicina (ERV). Se compararon los datos antes y después de la implementación de las normas. La cantidad total en gramos de vancomicina usada, disminuyó un 9\%, mientras que la incidencia de ERV se mantuvo sin cambios hasta 2 años después de la implementación de las normas (91).

\subsubsection{Uso combinado de antimicrobianos}

El uso de una combinación de ATM para reducir la resistencia es teóricamente atractivo, y es la base del tratamiento de la tuberculosis, con múltiples antimicrobianos. Todavía no ha sido adecuadamente probado a nivel clínico si la resistencia institucional general puede reducirse por el uso de una terapia combinada en cada paciente en particular (80).

\subsubsection{Base de datos computarizada}

El incremento de la computarización en el ambiente hospitalario, ofrece nuevas oportunidades para los programas de optimización de uso de ATM. Consisten en sistemas computarizados para prescripción y pueden facilitar el uso racional de ATM como se 
mencionó anteriormente. Las estrategias educativas pueden ser tan simples como acceder a través de un enlace a las guías terapéuticas institucionales, o tan sofisticadas como contar con un sistema computarizado que integre los datos específicos de un paciente, de laboratorio y microbiológicos, y sugiera un régimen terapéutico. Si se indica un medicamento restringido, el sistema puede sugerir una lista de alternativas. Cuando se requiere una autorización, la orden puede ser enviada en tiempo real o quedar en espera para una revisión posterior por parte del personal del programa (92).

\subsubsection{Revisión de las prescripciones y retroalimentación}

Un aspecto importante para destacar es que las estrategias de restricción generalmente no contienen especificaciones acerca del uso apropiado de los ATM no restringidos, que habitualmente corresponden a la mayoría de los que se utilizan en el hospital. Para optimizar el uso de los mismos, o para emplear ciertos ATM en instituciones que no cuentan con estrategias de restricción, pueden aplicarse programas que se basan en una revisión retrospectiva de los fármacos administrados. Si una indicación parece ser inapropiada, un miembro del equipo de uso de ATM se pone en contacto con el médico prescriptor con el objetivo de optimizar la terapia (17). La retroalimentación realizada por un equipo multidisciplinario ha demostrado ser un método efectivo para mejorar el uso de dichos fármacos en el hospital (93).

También es necesario evaluar periódicamente y por área hospitalaria, el impacto de las medidas terapéuticas recomendadas, prestando especial atención a su costo y al grado de resistencia a los ATM empleados, por lo que se debe llevar a cabo la vigilancia de la sensibilidad de los microorganismos e implementar prácticas de control de infecciones (94, 95).

Por último, se recomienda evaluar, mediante estudios de consumo, el impacto de las intervenciones adoptadas a lo largo del tiempo, a fin de determinar si es necesario modificar dichas intervenciones según sus resultados y los patrones de resistencia observados en el nivel local (75).

De ahí que sea importante el esfuerzo multidisciplinario de todo el equipo de salud: profesionales, tanto médicos como en control de infecciones, microbiólogos, farmacéuticos, personal de enfermería, y asimismo, personal de servicio y administrativos.

Un problema a considerar es que numerosas intervenciones sólo se han puesto en práctica en países desarrollados y que, por consiguiente, los resultados no se pueden extrapolar automáticamente a los países en desarrollo, en dónde las condiciones económicas son distintas. 


\subsection{Profilaxis antibiótica prequirúrgica}

Como ya se comentara, el objetivo general de cualquier programa de uso adecuado de ATM debe ser: mejorar su utilización, reducir la resistencia bacteriana, mejorar el estado del paciente y disminuir el gasto para el sistema de salud (42).

Dentro de los costos generados por el uso inapropiado de ATM, se encuentra el causado por la prescripción excesiva y la aplicación innecesaria de fármacos de utilidad no demostrada (96).

De los ATM administrados en el hospital, aproximadamente un tercio se destina a la PAP, entendiéndose por tal a los aplicados en pacientes que van a ser sometidos a cirugía con el fin de disminuir el riesgo de la infección del sitio quirúrgico (ISQ) (97). En los últimos años, una de las aplicaciones más frecuentes de los ATM en el hospital es en la profilaxis prequirúrgica.

El objetivo de la PAP consiste en alcanzar niveles séricos y tisulares altos y sostenidos del ATM utilizado, durante todo el procedimiento quirúrgico $(65,98)$. Su mayor efectividad puede lograrse con la administración intravenosa del ATM adecuado al tipo de cirugía antes de que ocurra la contaminación del sitio quirúrgico, con el mantenimiento de niveles suficientes del mismo en los tejidos mientras dure el procedimiento, y la interrupción adecuada de la profilaxis posquirúrgica $(65,99,100)$.

La elección del ATM, el tiempo y la vía de administración han sido estandarizados sobre la base de estudios clínicos. La PAP se recomienda en cirugías con riesgo de infección mayor o igual al 5\%, o en aquéllas en que el riesgo es menor pero su presencia podría implicar elevada morbimortalidad, siendo menos claros sus beneficios en otros procedimientos (99). La administración de una única dosis preoperatoria es suficiente para la mayoría de las cirugías limpias (L), y limpio-contaminadas (LC) $(42,99)$. Existen determinados ATM que deben ser utilizados según el tipo de cirugía, ya que se los selecciona de acuerdo con la identificación del patógeno más probable asociado al procedimiento. La droga debe ser provista en una dosis adecuada sobre la base del peso del paciente. Se aconseja que la infusión de la primera dosis sea efectuada por el médico anestesiólogo dentro de las dos horas previas a la incisión, siendo preferible hacerlo 30 minutos antes del comienzo de la misma. Generalmente se recomiendan dosis adicionales cuando la cirugía se prolonga por más de dos vidas medias después de la primera dosis del ATM administrado, para asegurar niveles adecuados de droga antes que se cierre la herida. Finalmente, como regla general, la PAP debe ser discontinuada dentro de las $24 \mathrm{~h}$ posteriores a la finalización de la cirugía $(65,98-101)$.

Sin embargo, a pesar de la publicación de las guías para la PAP y de su comprobada eficacia, con frecuencia se suministra inadecuadamente (32, 96, 102-104). La logística para el desarrollo y la implementación de estas guías en el ámbito local es 
compleja. Varios estudios previos han demostrado que el tiempo de administración, la selección del agente ATM y la duración de la profilaxis suele ser inapropiada (33, 96, $102-$ 104). En el año 2002, el Centers for Medicare \& Medicaid Services, en colaboración con el CDC, implementaron el proyecto nacional Prevención de Infecciones Quirúrgicas (Surgical Infection Prevention, SIP) (98). Su objetivo era disminuir la morbilidad y la mortalidad asociada a la ISQ, promoviendo la selección y el tiempo de administración de los ATM profilácticos en forma apropiada. Un grupo de expertos en prevención de la ISQ, control de infecciones y epidemiología desarrollaron tres medidas de rendimiento para la vigilancia nacional y el mejoramiento de la calidad. Estas medidas eran:

a. la proporción de pacientes a quienes se les administraba el ATM profiláctico parenteral dentro de la hora previa a la incisión quirúrgica,

b. la proporción de pacientes a quienes se les administraba el ATM que era consecuente con las guías publicadas, y

c. la proporción de pacientes a quienes se les discontinuaba la aplicación del ATM dentro de las 24 horas posteriores a la finalización de la cirugía (98).

Finalmente, es importante tener presente que a pesar de que la eficacia de la PAP ya ha sido bien establecida, ésta no evita las IACS no relacionadas con el sitio quirúrgico, ni es un sustituto de las medidas de control de infecciones de comprobada eficacia como son la preparación apropiada del paciente, la adecuada evaluación preoperatoria jerarquizando la ausencia de infección concurrente, el quirófano seguro y los cuidados posoperatorios (65, 96). Por lo tanto, el uso empírico, pero racional de la PAP complementa la técnica quirúrgica meticulosa y las medidas de control de infecciones para reducir la incidencia de ISQ $(65,96$, 100).

\subsection{Infección del sitio quirúrgico}

Como ya se comentó, en la actualidad, para la mayoría de los procedimientos quirúrgicos, los pacientes reciben ATM para reducir la probabilidad de complicaciones por infecciones (99). El uso apropiado de la PAP disminuye en forma significativa el porcentaje de infección del sitio quirúrgico porque previene la proliferación bacteriana favorecida durante la incisión quirúrgica, siendo esta reducción en algunos procedimientos, mayor del 50\% (105).

La ISQ es aquella que ocurre dentro de los 30 días luego de la cirugía (61). Los factores de riesgo más importantes para el desarrollo de infección están relacionados con la técnica quirúrgica, el grado de contaminación del lecho quirúrgico y las características endógenas del paciente $(106,107)$.

La ISQ es uno de los mayores contribuyentes de la morbilidad y mortalidad de los pacientes, y de los costos del sistema de salud (103). En Estados Unidos, la tasa de mortalidad es dos a tres veces mayor en los pacientes que desarrollan ISQ en comparación con los 
pacientes que no se infectan $(108,109)$. Además, incrementa el tiempo de hospitalización en un promedio de 7 días, y por lo tanto, también deben implementarse tratamientos más costosos y prolongados. En Estados Unidos se demostró que los costos se pueden incrementar en aproximadamente US\$ 3000 (108), que en el caso de pacientes sometidos a cirugías cardíacas u ortopédicas pueden alcanzar más de US\$ $30000(107,110)$. Además, no es menos importante, considerar los cuidados que el paciente requiere luego del alta, el lucro cesante y la pérdida de productividad de los pacientes afectados y muchas veces también la de su familia (111-114).

En años recientes ha adquirido mayor relevancia estimar el incremento de los costos en asistencia médica que son directamente atribuibles a la ISQ, debido a que los hospitales se han enfrentado a la presión de reducir costos bajo la perspectiva del sistema de pago.

El mantenimiento, la prevención y el restablecimiento de la salud conllevan costos que van mucho más allá de los correspondientes al del medicamento. Es imprescindible, por tanto, el análisis de estos gastos asociados dado que incrementan notablemente el costo de la salud (115).

La evaluación de dichos costos es compleja y difícil de establecer. Se han propuesto distintos diseños para evaluarlos, pero con el que se obtienen los resultados más precisos, y que se considera como el estándar de oro, es el estudio comparativo, pareado por edad, género, y algún indicador de gravedad y de la enfermedad de los casos, comparando dos grupos de pacientes: uno sin IACS y otro con ella. En estos estudios, la obtención de los datos es de dificultad diversa pues el proceso de "parear" es laborioso. Otra limitación de estos estudios es que muchas veces es difícil encontrar el "par" de un caso complejo. Por esto, en general, este tipo de estudios se ha limitado a las IACS más frecuentes (116).

Los costos directos, indirectos e intangibles son numerosos y difíciles de medir. Los directos son aquellos que se producen durante la hospitalización. Son relativamente fáciles de valorar. Los más frecuentes son los días de hospitalización, consumo de antimicrobianos, reintervenciones quirúrgicas, curaciones, visitas profesionales, necesidad de aislamiento y otros. Los costos indirectos son los sociales secundarios al hecho de haber tenido una IACS: están relacionados con cambios en la capacidad productiva del individuo, tales como ausentismo laboral, pérdida de la función, traslado de familiares. Los costos intangibles son los relacionados con el dolor o el sufrimiento de los pacientes y la muerte. Los costos indirectos e intangibles son muy difíciles de valorar y la mayoría de los estudios se limita a evaluar los costos directos (116). El cálculo se torna aún más complejo, si se considera que algunas ISQ se presentan en pacientes ambulatorios, muchos de los cuales no requieren de internación $(110,113)$. A pesar de esto, y de que se acepta que al igual que otras IACS la ISQ prolonga los días de internación, aumenta el consumo de ATM y produce un incremento 
de los gastos de hospitalización, es importante estimar el costo que genera para el sistema de salud la ISQ en pacientes internados en la Argentina.

La responsabilidad es clara: se debe trabajar para preservar la potencia de los ATM y volver estos agentes a su posición legítima como tratamientos efectivos de las enfermedades infecciosas. 


\subsection{Objetivos}

\section{Objetivos generales}

1. Evaluar la efectividad de un programa de profilaxis antimicrobiana prequirúrgica, controlado desde la farmacia hospitalaria, realizado en el Sanatorio Adventista del Plata de la localidad de Libertador San Martín, Argentina, durante los años 2001 a 2007.

2. Evaluar la efectividad de dicho programa sobre el patrón de resistencia de las cepas aisladas de los pacientes con infecciones asociadas al cuidado de la salud adquiridas en el Sanatorio Adventista del Plata, Libertador San Martín, Argentina, durante los años 2001 a 2007.

\section{Objetivos específicos}

I. Evaluar la efectividad de un programa de control de uso de antimicrobianos en la profilaxis prequirúrgica, implementado desde enero de 2002 hasta octubre de 2003.

II. Evaluar el uso de antimicrobianos en los pacientes internados en la unidad de cuidados intensivos y en internación general previo a la aplicación del programa de profilaxis antimicrobiana prequirúrgica y después de ella.

III. Conocer el porcentaje de resistencia a determinados antimicrobianos de 12 cepas centinelas aisladas de infecciones adquiridas en el hospital, antes de la instauración de dicho programa y después de ella.

IV. Analizar la variación económica surgida como consecuencia de la aplicación de un programa de control de uso de antimicrobianos en las profilaxis quirúrgicas evaluando el gasto de antimicrobianos y el costo del desarrollo de infección del sitio quirúrgico.

V. Conocer la relación clonal entre las cepas de Staphylococcus aureus resistente a la meticilina aisladas de pacientes con infecciones adquiridas en el Sanatorio Adventista del Plata. 


\section{MATERIALES Y MÉTODOS}

\subsection{Materiales y métodos correspondientes al objetivo I}

Objetivo I: Evaluar la efectividad de un programa de control de uso de ATM en la profilaxis prequirúrgica, implementado desde enero de 2002 hasta octubre de 2003.

El diseño del trabajo fue cuasiexperimental, longitudinal con preprueba y posprueba con un solo grupo, en el cual se efectuó una intervención para controlar la PAP. El ámbito del estudio fue el Sanatorio Adventista del Plata (SAP) (figura 9), un Hospital Universitario polivalente de 78 camas, en el período comprendido entre el 1 de enero de 2002 al 30 de octubre de 2003.

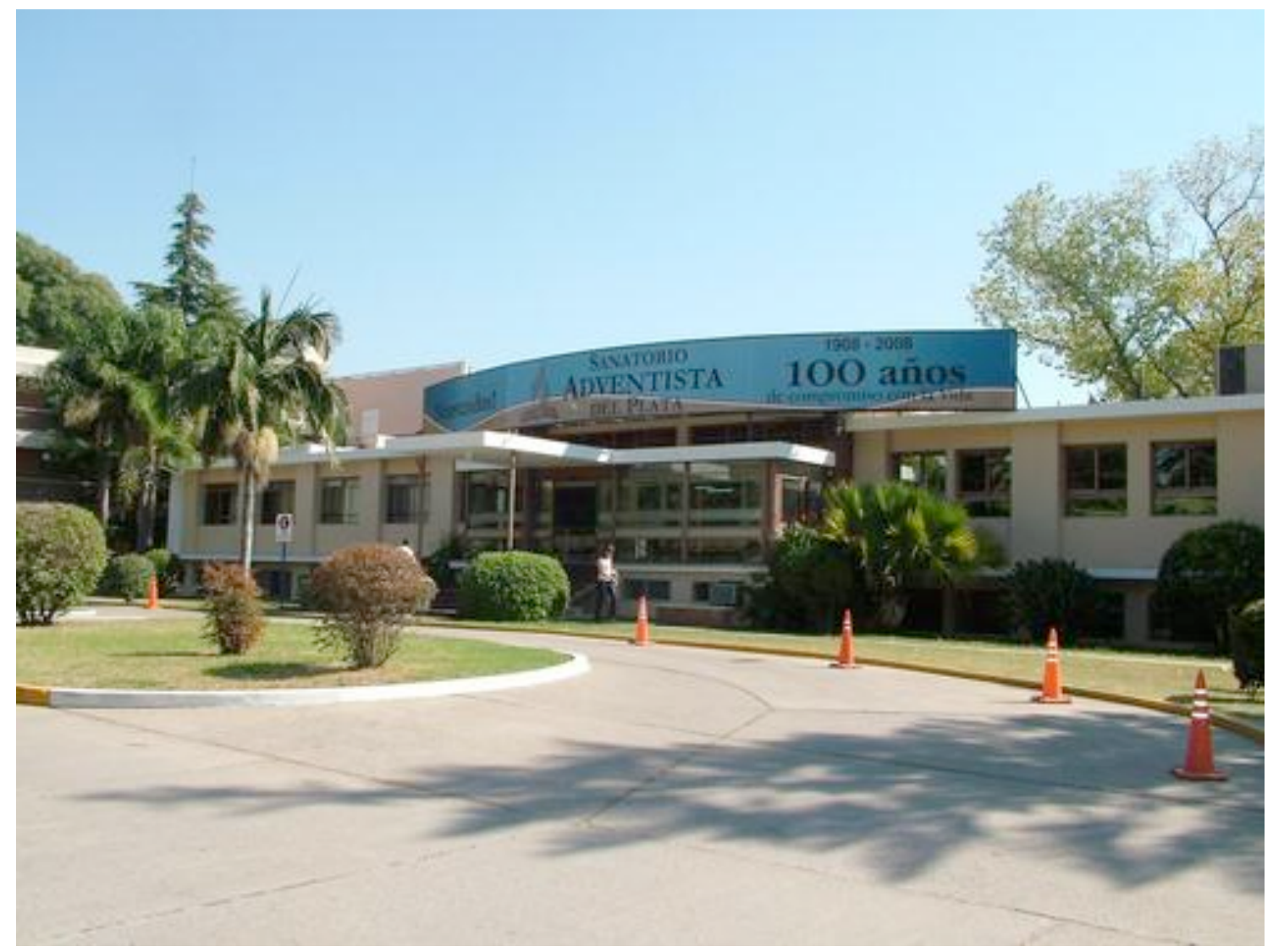

Figura 9. Vista de la entrada del Sanatorio Adventista del Plata, Libertador San Martín, Entre Ríos, Argentina (117).

EI SAP se encuentra en la localidad de Libertador San Martín, una ciudad de la Provincia de Entre Ríos, Argentina, ubicada al suroeste de la provincia, entre las ciudades 
de Crespo y Diamante y a $60 \mathrm{~km}$ de la capital provincial; en el Departamento Diamante (Coordenadas: $\left.33^{\circ} 05^{\prime} \mathrm{S} 58^{\circ} 15^{\prime} \mathrm{O}\right)$ (figura 10 ).
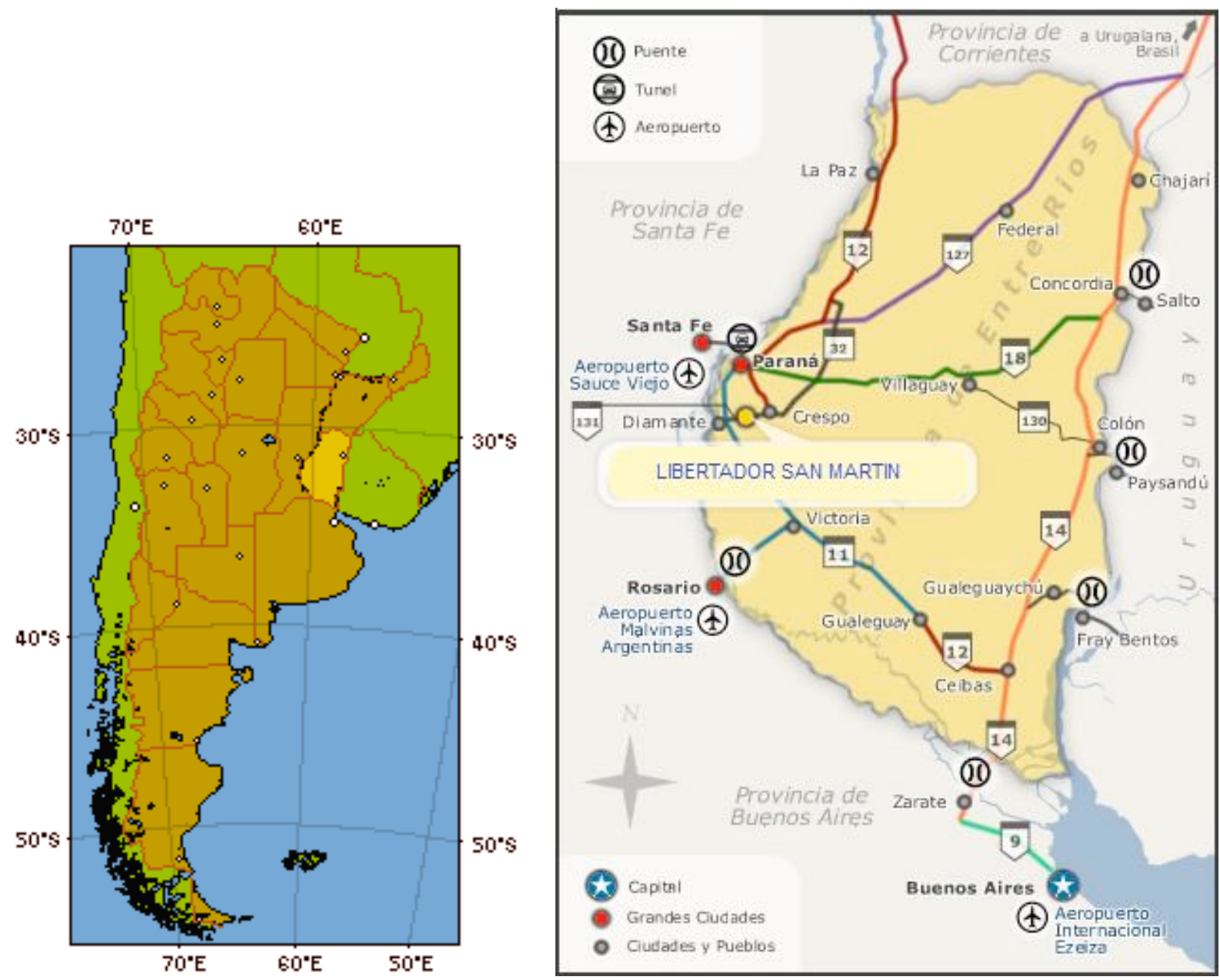

Figura 10. Ubicación geográfica de Libertador San Martín. Entre Ríos, Argentina $(118,119)$.

El estudio constó de tres etapas: una evaluación inicial de la PAP durante 8 meses (enero-agosto de 2002), una intervención durante 6 meses (septiembre de 2002 - febrero de 2003), donde se aplicaron un formulario para el uso de ATM en cirugía y una orden de paro automático del ATM, y finalmente, la etapa de evaluación final de la PAP que se llevó a cabo entre marzo y octubre de 2003 (8 meses) (figura 11). 


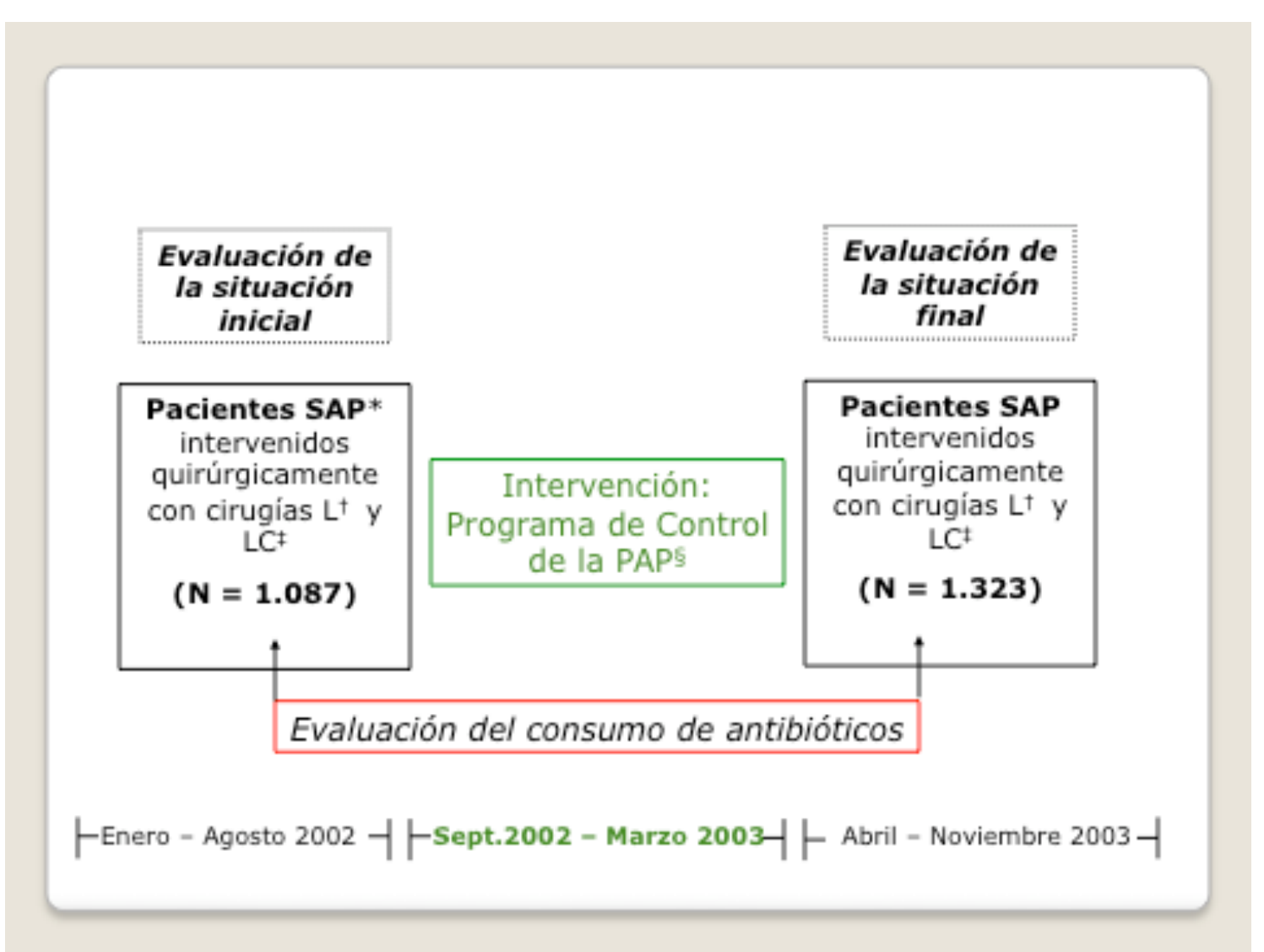

Figura 11. Esquema de la aplicación del programa para controlar el uso de antimicrobianos en la profilaxis quirúrgica.

*SAP: Sanatorio Adventista del Plata; $\uparrow$ L: Limpia; $\$$ LC: limpio-contaminado; § PAP: Profilaxis antibiótica prequirúrgica.

\subsubsection{Participantes}

En total, se evaluaron 2410 PAP indicadas a pacientes internados durante los dos períodos mencionados. El total de pacientes estudiados en el primer período fue de 1087, de los cuales el 52\% ( $\mathrm{N}=564)$ correspondió a pacientes de género femenino y el $48 \%$ ( $N=523)$ al género masculino. La edad promedio fue de 51 años (rango, 1 a 99 años), y la moda, 65 años. Durante la etapa de evaluación final se estudiaron 1323 PAP; el 55\% $(\mathrm{N}=728)$ fueron del género femenino y el $45 \% \quad(\mathrm{~N}=595)$, género masculino. La edad promedio fue de 51 años (rango, 1 a 96 años) y la moda, de 62 años.

\subsubsection{Criterios de inclusión}

Todos los pacientes internados, sometidos a cirugías con heridas L y LC.

Las heridas $L$ fueron definidas como aquellas no infectadas en las que no se encontró inflamación y en las que no se abrió el tracto respiratorio, digestivo, genital o urinario. También se incluyeron las heridas $L$ que se cerraron primariamente y fueron drenadas con sistemas de drenaje cerrados cuando fue necesario. Las heridas incisionales 
que ocurrieron en el trauma penetrante fueron incluidas si cumplieron con estos criterios (120).

Las heridas LC fueron definidas como aquellas en las cuales se penetró en el tracto respiratorio, digestivo, genital o urinario bajo condiciones controladas y sin contaminación inusual. Específicamente, operaciones que comprometían el tracto biliar, el apéndice, la vagina y la orofaringe; se incluyeron en esta categoría, teniendo en cuenta que no hubiera evidencia de infección o transgresión de la técnica quirúrgica (120).

\subsubsection{Criterios de exclusión}

Pacientes que estaban recibiendo tratamiento ATM previo a la cirugía.

\subsubsection{Recolección de datos}

La información recolectada incluyó los datos demográficos del paciente, el tipo de cirugía, el score de severidad según la Sociedad Americana de Anestesiólogos (American Society of Anesthesiologists, ASA) (121), la clase de herida y el tiempo de duración de la cirugía, evidencias de infección del sitio quirúrgico (ISQ), y los antimicrobianos prescriptos.

Los datos se obtuvieron de las historias clínicas, los relatos operatorios del cirujano, las hojas de anestesia y de la farmacia hospitalaria.

Para la clasificación del tipo de cirugía, la clase de herida y la ISQ se utilizaron las definiciones del CDC, Atlanta (122). El número de ASA, la clase de herida y el tiempo de duración de la cirugía se utilizaron para calcular el índice de riesgo de la ISQ (120).

\subsubsection{Evaluación de la profilaxis antimicrobiana prequirúrgica}

Los ATM prescriptos se evaluaron de acuerdo con el protocolo de PAP (esquema ATM), el tiempo de administración del ATM y la duración de la profilaxis. Se expresaron en dosis diaria definida (DDD) utilizadas cada 1000 días paciente. Se definió DDD como la dosis diaria promedio, en gramos, de un agente ATM específico dado a un paciente adulto promedio (123).

El tiempo de administración del ATM profiláctico se consideró adecuado cuando era administrado en la inducción anestésica, durante las 2 horas previas a la incisión quirúrgica (100). Cuando el tiempo de administración del ATM no estaba registrado en la hoja de anestesia, o estaba fuera del esquema aconsejado, se consideró tiempo inadecuado.

Para la mayoría de las intervenciones quirúrgicas, la duración de la profilaxis se consideró adecuada cuando la administración del ATM se suspendía a las 24 horas posteriores a la cirugía, excepto para las cirugías cardiovasculares y las cirugías de colon donde el tiempo de suspensión fue a las 48 h (100). De igual manera, el esquema ATM se 
calificó como "adecuado" o "inadecuado" según se ajustara o no a las recomendaciones preestablecidas.

La presencia de ISQ se evaluó siguiendo al paciente mientras estaba internado, a través de los consultorios externos, en las readmisiones o por vigilancia telefónica. Se respetaron las definiciones del CDC realizando el corte a los 30 días de efectuado el acto quirúrgico (61).

\subsubsection{Implementación del programa de control de profilaxis antimicrobiana}

Previo al comienzo de este estudio, el departamento Control de Infecciones había confeccionado los protocolos para la administración de la PAP, indicando el esquema de ATM más conveniente para cada tipo de cirugía, teniendo en cuenta recomendaciones nacionales e internacionales $(99,100,124)$. El mismo había sido repartido individualmente a todos los médicos cirujanos y anestesiólogos.

Para controlar la PAP se aplicó un formulario de solicitud de ATM elaborado de acuerdo con los protocolos ya establecidos, las recomendaciones nacionales e internacionales. También, se realizaron reuniones con los diferentes equipos quirúrgicos para consensuar los esquemas de ATM que se utilizarían. Por otra parte, se organizaron talleres educativos para el personal de quirófanos, enfermería y farmacia con el fin de capacitarlos en el uso del nuevo formulario.

El formulario incluía el nombre y la historia clínica del paciente, la fecha, el tipo de cirugía, si padecía alergias medicamentosas, el nivel probable de contaminación bacteriana de la cirugía y el médico cirujano interviniente. También presentaba una lista de las cirugías más frecuentemente realizadas y su respectiva profilaxis ATM, por lo que el médico solamente debía indicar en la lista cuál era la cirugía que había efectuado. Se dejó un espacio para la solicitud de profilaxis ATM para cirugías que no se encontraban en la lista y para la prescripción de dosis adicionales de ATM (ANEXO I).

Para cada cirugía se completaba el formulario de PAP en quirófano, y luego se lo enviaba a farmacia donde se proveían los ATM correspondientes. Allí se efectuaba, cada mañana, el control de los ATM suministrados y se identificaban aquellas prescripciones que no estaban de acuerdo con el protocolo.

Se desarrolló una orden de paro-automático que consistía en un aviso gráfico que se enviaba desde farmacia a enfermería a fin de comunicarle al médico tratante que era la última dosis de antimicrobiano profiláctico. Si el médico consideraba que debía continuar con la administración del medicamento, debía comunicarse con farmacia para solicitarlo (ANEXO II). 


\subsubsection{Evaluación de la intervención}

El Programa de Control fue evaluado comparando el uso de los ATM utilizados en la profilaxis prequirúrgica previo a la implementación del programa y después de ella.

Los datos fueron analizados con Epi Info (versión 6.04, C, Atlanta, GA). La comparación de los grupos fue realizada con el test de Chi cuadrado, con un nivel de significancia de $p \leq 0,05$ (125).

\section{2 Materiales y métodos correspondientes a los objetivos II y III}

Objetivo II: Evaluar el uso de ATM en los pacientes internados en la unidad de cuidados intensivos y en internación general previo a la aplicación del programa de profilaxis antimicrobiana prequirúrgica y después de ella.

Objetivo III: Conocer el porcentaje de resistencia a determinados antimicrobianos de 12 cepas centinelas aisladas de infecciones adquiridas en el hospital, antes de la instauración de dicho programa y después de ella.

El diseño del trabajo fue cuasiexperimental, longitudinal con preprueba-posprueba con un solo grupo, durante los años 2001 a 2007. Se vigiló el uso de antimicrobianos que recibieron todos los pacientes internados y la resistencia bacteriana de todos los cultivos no duplicados, aislados de las muestras clínicas de infecciones adquiridas en el hospital, teniendo en cuenta el área de internación de los pacientes: unidad de cuidados intensivos (UCI) e internación general.

Se utilizó un protocolo que estuvo basado en la herramienta del proyecto ICARE creado por la Escuela Rollins de Salud Pública de la Universidad de Emory y la División de Promoción de la Calidad de Salud (Rollins School of Public Health of Emory University y la Division of Healthcare Quality Promotion) del CDC (126). Aunque este protocolo fue presentado en los año 1996-1997 se lo aplicó en esta investigación porque en el año 2001, cuando se comenzó este trabajo, era de reciente aparición.

Durante los siete años (2001 a 2007 inclusive) en que se realizó el seguimiento del uso de ATM y de la resistencia bacteriana los días paciente en UCl fueron: 1344; 1230; 1061; 993; 954; 1150 y 1217 respectivamente para cada año, y en internación general los días paciente fueron: $14.755,13.774,16.725,16.569,17.346,20.127$ y 19.479 respectivamente para cada año.

\subsubsection{Antimicrobianos utilizados}

Se tuvo en cuenta la cantidad de gramos de un grupo seleccionado de ATM, administrados por vía oral y parenteral. Los datos se obtuvieron de los registros de la Farmacia del hospital. Los ATM se agruparon según que los pacientes estuvieran internados en la $\mathrm{UCl}$ o en internación general y por grupo farmacológico. Para el análisis, los gramos de 
ATM fueron convertidos en DDD cada 1000 días paciente. En el cuadro 2 se presentan los grupos farmacológicos y los gramos de cada ATM utilizados correspondientes a una DDD.

Cuadro 2. Grupos farmacológicos y gramos de cada antimicrobiano utilizado correspondientes a una dosis diaria definida.

\begin{tabular}{|c|c|c|c|}
\hline Grupo farmacológico & Antimicrobianos & $\mathrm{DDD}^{*}$ & \\
\hline \multirow[t]{2}{*}{ Aminoglucósidos } & Amikacina & 1 & $g$ \\
\hline & Gentamicina & 0,24 & g \\
\hline \multirow[t]{6}{*}{ Aminopenicilinas } & Ampicilina (parenteral) & 4 & g \\
\hline & Ampicilina (oral) & 2 & g \\
\hline & Ampicilina-sulbactam (parenteral) & 6 & g \\
\hline & Amoxicilina (parenteral) & 1 & g \\
\hline & Amoxicilina (oral) & 1,5 & g \\
\hline & Amoxicilina-clavulánico (oral) & 1,5 & g \\
\hline \multirow[t]{2}{*}{ Carbapenems } & Imipenem cilastatina & 2 & $g$ \\
\hline & Ertapenem & 1 & g \\
\hline \multirow[t]{3}{*}{ Cefalosporinas $1^{a}$ generación } & Cefazolina & 3 & g \\
\hline & Cefalotina & 4 & g \\
\hline & Cefalexina & 2 & $\mathrm{~g}$ \\
\hline Cefalosporinas $2^{\mathrm{a}}$ generación & Cefuroxima & 3 & g \\
\hline \multirow[t]{3}{*}{ Cefalosporinas $3^{a}$ generación } & Cefotaxima & 3 & g \\
\hline & Ceftazidima & 3 & $g$ \\
\hline & Ceftriaxona & 1 & g \\
\hline \multirow[t]{2}{*}{ Clindamicina } & Clindamicina (parenteral) & 1,8 & g \\
\hline & Clindamicina (oral) & 1,2 & g \\
\hline \multirow[t]{4}{*}{ Fluoroquinolonas } & Ciprofloxacina (parenteral) & 0,8 & g \\
\hline & Ciprofloxacina (oral) & 1,5 & g \\
\hline & Norfloxacina & 0,8 & g \\
\hline & Levofloxacina (oral) & 0,5 & g \\
\hline \multirow[t]{2}{*}{ Nitroimidazoles } & Metronidazol (parenteral) & 1,5 & g \\
\hline & Metronidazol (oral) & 1,5 & g \\
\hline \multirow[t]{2}{*}{ Penicilinas } & Penicilina G sódica & $12 \times 10^{6}$ & $\mathrm{U}$ \\
\hline & Pencilina benzatínica & $1,2 \times 10^{6}$ & $\mathrm{U}$ \\
\hline \multirow[t]{2}{*}{ Penicilinas antipseudomonas } & Piperacilina & 18 & g \\
\hline & Piperacilina-tazobactam & 13,5 & g \\
\hline \multirow[t]{2}{*}{ Trimetoprima-sulfametoxazol (TMS) } & TMS (parenteral) & 0,84 & g \\
\hline & TMS comp $^{\dagger}$ & 0,32 & g \\
\hline Glucopéptidos & Vancomicina (parenteral) & 2 & g \\
\hline
\end{tabular}

*DDD: dosis diaria definida. Los valores de DDD utilizados para cada antimicrobiano fueron los recomendados por la OMS (123) y por el proyecto ICARE.(126), † comp: comprimidos 


\subsubsection{Datos microbiológicos}

Los datos de la resistencia de las bacterias centinelas, no duplicadas, aisladas de las muestras clínicas de pacientes con infecciones adquiridas en el hospital se recogieron de los archivos del laboratorio de Microbiología y de los registros del Departamento de Control de Infecciones y expresados como el porcentaje de cepas resistentes con respecto al total de aislamientos estudiados para un patógeno en particular. Los datos fueron obtenidos diariamente de los aislamientos clínicos, no duplicados. Un aislamiento duplicado se definió como "un aislamiento de la misma especie de bacteria con el mismo patrón de susceptibilidad, en el mismo paciente, sin importar el sitio anatómico de aislamiento". Para calcular el porcentaje de resistencia se consideró necesario que hubiera, al menos, 10 aislamientos no duplicados en cada una de las áreas de internación.

Para el cálculo de la proporción de cepas resistentes, los aislamientos con resistencia intermedia se consideraron resistentes (126). Los datos fueron agrupados según los pacientes se encontraran internados en el área de internación general o en la UCI.

Las bacterias resistentes a determinados antimicrobianos consideradas "centinelas" fueron: SARM y Staphylococcus spp. (coagulasa negativo) resistente a la meticilina, ERV, S. pneumoniae resistente a penicilina, Klebsiella pneumoniae resistente a cefalosporinas de $3^{a}$ generación (como cefotaxima y ceftriaxona), Escherichia coli resistente a cefalosporinas de $3^{a}$ generación y a ciprofloxacina, Enterobacter spp. resistente a cefalosporinas de $3^{\text {a }}$ generación y Pseudomonas aeruginosa resistente a piperacilina, cefalosporinas de $3^{a}$ generación (ceftazidima), imipenem y ciprofloxacina.

\subsubsection{Análisis de los resultados}

Para obtener la tasa de resistencia bacteriana se estudiaron, al menos, 10 aislamientos no duplicados en cada área. Los resultados obtenidos se separaron en dos grupos, teniendo en cuenta la intervención con el uso de ATM en la profilaxis quirúrgica realizada en el año 2003.

Para el análisis de los datos y los cálculos estadísticos se utilizó Microsoft Excel 2000, y SPSS 11.5. Se realizó, según correspondiera, Prueba t de Student para muestras independientes, el Test de Fisher, ANOVA y comparación de dos proporciones, con una significancia de $p \leq 0,05$ (125).

En aquellos casos en que se detectaron diferencias significativas entre los promedios de uso de ATM analizados se continuó con una de las pruebas de diferencia mínima significativa, como el test de Tukey (125). 


\subsection{Materiales y métodos correspondientes al objetivo IV}

Objetivo IV: Analizar la variación económica surgida como consecuencia de la aplicación de un programa de control de uso de antimicrobianos en las profilaxis quirúrgicas evaluando el gasto de antimicrobianos y el costo del desarrollo de infección del sitio quirúrgico.

\subsubsection{Gasto de antimicrobianos}

El impacto económico se evaluó comparando el costo de los ATM utilizados en la profilaxis prequirúrgica previo a la implementación del formulario y después de ello.

También se calculó el costo de todos los ATM utilizados en el hospital. Para ello, sobre la base de los datos de las DDD de ATM, se estimó el gasto producido por el uso de dicha droga (por ejemplo, cefazolina, cefalexina) y después se los clasificó por grupo farmacológico (por ejemplo, en el caso de las drogas citadas, cefalosporinas de $1^{\text {a }}$ generación). La valoración se realizó durante dos períodos, teniendo en cuenta la aplicación del formulario realizada en el año 2003.

Para el cálculo de los costos, se tomó en cuenta el valor del precio de compra de una DDD a abril de 2008.

\subsubsection{Comparación de costos directos generados por pacientes con infección del sitio quirúrgico}

El diseño fue observacional, retrospectivo, transversal y correlacional. Se llevó a cabo en el Sanatorio Adventista del Plata, Argentina, entre enero de 1998 y diciembre de 2004, para determinar los costos directos surgidos de la ISQ. Fue necesario extender el período de estudio a 6 años para poder tener al menos 10 casos de cada tipo de cirugía.

Para conocer el exceso de costo atribuible a la ISQ se aplicó la metodología propuesta por la OPS en el Protocolo para determinar el Costo de la Infección Hospitalaria (116). Los criterios de inclusión de ISQ se determinaron a partir de la definición de infección nosocomial del sitio quirúrgico propuesta por el Sistema Nacional de Vigilancia de Infecciones Nosocomiales de los Estados Unidos de América (National Nosocomial Infections Surveillance System, NNIS) (127).

Los casos incluyeron todos los pacientes diagnosticados con ISQ luego de haber sido sometidos a cirugías de hígado, páncreas y conductos biliares (BILI) y cirugías vasculares (VS) durante el período estudiado. Los controles estuvieron representados por pacientes $\sin I S Q$ hospitalizados durante el mismo período y que reunían características comunes para el apareamiento. La selección de los casos y los controles se hicieron a través de la revisión de los registros de vigilancia epidemiológica del Departamento de 
Control de Infecciones y de las historias clínicas de los pacientes que fueron sometidos a alguna de las cirugías estudiadas.

La edad promedio de los pacientes sometidos a cirugías BILI que presentaron ISQ fue de 55 años y la de los pacientes control fue de 61 años. En los casos, hubo 4 pacientes de género femenino y 6 de género masculino y en los controles 5 de género femenino y 5 de género masculino. La edad promedio de los pacientes con ISQ sometidos a cirugía VS fue de 63 años y la de los pacientes control fue de 62 años. En el grupo de pacientes con ISQ hubo 4 sujetos de género femenino y 6 de género masculino y en el grupo control 3 de género femenino y 7 de género masculino.

Se seleccionaron 10 pacientes con ISQ (casos) para cada tipo de cirugía y 10 pacientes (control) que fueron sometidos al mismo tipo de cirugía y no presentaron ISQ. Se parearon los pacientes del grupo control según su edad (+/- 10 años), género, diagnóstico principal (el que motivó el ingreso) y número de diagnósticos adicionales (+/- 1), que figuraban en su historia clínica, incluido el diagnóstico principal que motivó la internación. Cuando se encontró más de un control para un caso determinado, se seleccionó uno al azar.

Como indicadores para comparar los costos directos surgidos de las ISQ se utilizaron los días de estancia en el hospital, la administración de ATM y el número de cultivos bacteriológicos efectuados durante la internación del paciente.

\subsubsection{Días de estancia desde el ingreso}

Para el cálculo de los días de internación, se consideró por separado los días de permanencia en la $\mathrm{UCl}$ y en internación general. Los datos se obtuvieron de los registros de la historia clínica de cada paciente. El precio de internación por día se obtuvo del Departamento de Facturación del hospital. Se estimó en \$86,12 el día/cama en el área de internación general y de $\$ 459,81$ el día/cama en $\mathrm{UCl}$ a valores correspondientes a abril de 2008.

\subsubsection{Administración de fármacos ATM}

Para el gasto de ATM se utilizó como registro la prescripción médica asentada en la historia clínica y la cantidad de dosis dispensadas desde la Farmacia, que se expresó en DDD. El Servicio de Farmacia suministró los precios de costo de las DDD para cada medicamento a valores correspondientes a abril de 2008.

\subsubsection{Cultivos microbiológicos}

Se registró el número total de cultivos realizados durante la hospitalización de los pacientes incluidos en el estudio, que se obtuvo de los archivos del Servicio de Control de 
Infecciones. El Departamento de Facturación proveyó el precio estimado de $\$ 21,80$ para cada cultivo. Todos los precios utilizados fueron referidos a abril de 2008.

\subsubsection{Plan de análisis y evaluación estadística}

Para el cálculo del costo atribuible a la ISQ se calculó el promedio de las erogaciones efectuadas para 10 pacientes con ISQ y sin ella, y se calculó la diferencia entre ambos grupos.

Para el análisis de los datos y de los cálculos estadísticos se utilizaron Epilnfo, versión 6.04 (software creado por el CDC, Atlanta, Georgia) y Microsoft Excel@ 2000. Para comparar los grupos estudiados, se empleó la prueba de Mann-Whitney (125).

\subsection{Materiales y métodos correspondientes al objetivo $\mathrm{V}$}

Objetivo V: Conocer la relación clonal entre las cepas de Staphylococcus aureus resistente a la meticilina aisladas de pacientes con infecciones adquiridas en el Sanatorio Adventista del Plata.

Se trabajó con los aislamientos de SARM recuperados de pacientes con infecciones adquiridas en el Sanatorio Adventista del Plata, Argentina, durante los años 2004-2007.

Las cepas se recolectaron en el laboratorio de Microbiología, donde se realizó la fenotipificación de los mismos. La técnica empleada para determinar el grado de sensibilidad a los antimicrobianos fue el método de difusión por discos (Kirby-Bauer), y se respetaron los lineamientos de Instituto de Estándares de Laboratorios Clínicos (Clinical and Laboratory Standards Institute, CLSI) (128). Las cepas fueron conservadas en agar tripteina-soya (Laboratorio Britania, Argentina) entre $4-8^{\circ} \mathrm{C}$ hasta su estudio molecular (129).

La genotipificación por reacción en cadena de la polimerasa (PCR) con oligonucleótidos degenerados (OD-PCR), se llevó a cabo en el Instituto de Biología Molecular y Celular de Rosario, Facultad de Ciencias Bioquímicas y Farmacéuticas, Universidad Nacional de Rosario (Anexo III).

Se definió si las infecciones fueron adquiridas en el hospital o en la comunidad u otros nosocomios a través de los datos obtenidos de las historias clínicas de los pacientes de los cuales se aislaron los microorganismos. 


\section{RESULTADOS}

\subsection{Resultados correspondientes al objetivo I}

Objetivo I: Evaluar la efectividad de un programa de control de uso de ATM en la profilaxis prequirúrgica, implementado desde enero de 2002 hasta octubre de 2003.

La distribución de pacientes sometidos a intervenciones quirúrgicas de acuerdo al servicio que realizó el procedimiento en los dos períodos estudiados se muestra en la tabla 1.

Tabla 1. Número de pacientes sometidos a intervenciones quirúrgicas por cada Servicio durante la etapa inicial y final del estudio. Sanatorio Adventista del Plata, Argentina, enero de 2002 a octubre de 2003.

\begin{tabular}{lcc}
\hline \multicolumn{1}{c}{ Servicio } & Etapa Inicial & Etapa final \\
& $\mathrm{N}$ & $\mathrm{N}$ \\
\hline Cirugía General & 340 & 442 \\
Cirugía Cardiovascular & 37 & 30 \\
Ginecología & 221 & 257 \\
Neurocirugía & 37 & 25 \\
ORL $^{*}$ & 81 & 95 \\
Traumatología $^{*}$ & 206 & 310 \\
Urología & 165 & 164 \\
\multicolumn{1}{c}{ Total } & 1087 & 1323 \\
\hline
\end{tabular}

*ORL: Otorrinolaringología.

En la etapa inicial del estudio, el 55\% ( $\mathrm{N}=595)$ de los pacientes recibieron el ATM dentro de las 2 horas previas a la incisión quirúrgica, mientras que en la etapa final, se aplicó al 60\% (N=794) $(p=0,01)$ (Tabla 2). 
Tabla 2. Número de pacientes a quienes se les administró el antimicrobiano en el tiempo considerado adecuado o inadecuado, por Servicio, antes y después de la aplicación del formulario para el uso de antimicrobianos en cirugía. Sanatorio Adventista del Plata, Argentina, enero de 2002 a octubre de 2003.

\begin{tabular}{|c|c|c|c|c|c|}
\hline \multirow{4}{*}{ Servicio } & \multicolumn{2}{|c|}{ Etapa inicial } & \multicolumn{2}{|c|}{ Etapa final } & \multirow{4}{*}{$p$} \\
\hline & \multicolumn{2}{|c|}{ Tiempo de administración } & \multicolumn{2}{|c|}{ Tiempo de administración } & \\
\hline & Adecuado & Inadecuado & Adecuado & Inadecuado & \\
\hline & $\mathrm{N}(\%)$ & $\mathrm{N}(\%)$ & $\mathrm{N}(\%)$ & $\mathrm{N} \quad(\%)$ & \\
\hline Cirugía General & 195 (57) & 145 (43) & 271 (61) & 171 (39) & 0,26 \\
\hline $\begin{array}{l}\text { Cirugía } \\
\text { cardiovascular }\end{array}$ & 32 (86) & 5 (14) & 28 (93) & $2 \quad(7)$ & 0,36 \\
\hline Ginecología & $145(66)$ & 76 (34) & 168 & 89 (35) & 0,96 \\
\hline Neurocirugía & 26 (70) & 11 (30) & 21 (84) & $4 \quad(16)$ & 0,22 \\
\hline ORL* & 39 (48) & 42 (52) & 45 (47) & 50 (53) & 0,92 \\
\hline Traumatología & $124(60)$ & 82 (40) & 212 (68) & $98 \quad(32)$ & 0,06 \\
\hline Urología & 34 (21) & 131 (79) & 49 (30) & 115 (70) & 0,05 \\
\hline Total & 595 (55) & 492 (45) & 794 (60) & 529 (40) & 0,01 \\
\hline
\end{tabular}

*ORL: Otorrinolaringología.

La adecuación al protocolo de la PAP por parte de cada servicio antes de la aplicación del formulario y después de ella, se encuentra expresada en la tabla 3 . La utilización del esquema ATM adecuado en la etapa inicial del estudio fue del $74 \%(\mathrm{~N}=805)$ mientras que en la etapa final fue del $87 \%(N=1150)(p<0,01)$. 
Tabla 3. Número de pacientes sometidos a intervenciones quirúrgicas por cada Servicio, con el esquema antimicrobiano adecuado o inadecuado, antes y después de la aplicación del formulario para el uso de antimicrobianos en cirugía. Sanatorio Adventista del Plata, Argentina, enero de 2002 a octubre de 2003.

\begin{tabular}{|c|c|c|c|c|c|c|}
\hline \multirow{4}{*}{ Servicio } & \multicolumn{2}{|c|}{ Etapa inicial } & \multicolumn{3}{|c|}{ Etapa final } & \multirow{4}{*}{$p$} \\
\hline & \multicolumn{2}{|c|}{ Esquema antimicrobiano } & \multicolumn{3}{|c|}{ Esquema antimicrobiano } & \\
\hline & \multirow{2}{*}{$\begin{array}{c}\text { Adecuado } \\
\text { N (\%) }\end{array}$} & Inadecuado & \multicolumn{2}{|c|}{ Adecuado } & Inadecuado & \\
\hline & & $\mathrm{N} \quad(\%)$ & $\mathrm{N}$ & $(\%)$ & $\mathrm{N} \quad(\%)$ & \\
\hline Cirugía General & 241 (71) & 99 (29) & 387 & (88) & 55 (12) & $<0,01$ \\
\hline $\begin{array}{l}\text { Cirugía } \\
\text { cardiovascular }\end{array}$ & 34 (92) & 3 (8) & 30 & $(100)$ & $0 \quad(0)$ & 0,11 \\
\hline Ginecología & 218 (99) & (1) & 252 & (98) & (2) & 0,62 \\
\hline Neurocirugía & 34 (92) & (8) & 23 & (92) & (8) & 0,99 \\
\hline ORL* & 58 (72) & $23(28)$ & 83 & (87) & 12 (13) & 0,01 \\
\hline Traumatología & 168 & 38 (18) & 304 & (98) & (2) & $<0,01$ \\
\hline Urología & 52 (32) & 113 (68) & 71 & (43) & $93 \quad(57)$ & 0,02 \\
\hline Total & 805 (74) & 282 (26) & 1150 & (87) & 173 (13) & $<0,01$ \\
\hline
\end{tabular}

*ORL: Otorrinolaringología.

Los resultados referidos a la duración de la profilaxis por parte de cada Servicio se encuentran en la tabla 4. En la etapa inicial, la duración de la profilaxis fue adecuada en el $44 \%(N=478)$ de las cirugías y en la etapa final fue en el $55 \%(N=724)(p<0,01)$. 
Tabla 4. Número de pacientes sometidos a intervenciones quirúrgicas por cada Servicio, con duración de la profilaxis antimicrobiana adecuada o inadecuada, antes y después de la aplicación del formulario para el uso de antimicrobianos en cirugía. Sanatorio Adventista del Plata, Argentina, enero de 2002 a octubre de 2003.

\begin{tabular}{|c|c|c|c|c|c|c|c|}
\hline \multirow{4}{*}{ Servicio } & \multicolumn{3}{|c|}{ Etapa inicial } & \multicolumn{3}{|c|}{ Etapa final } & \multirow{4}{*}{$p$} \\
\hline & \multicolumn{3}{|c|}{ Duración de la profilaxis } & \multicolumn{3}{|c|}{ Duración de la profilaxis } & \\
\hline & \multicolumn{2}{|c|}{ Adecuada } & \multirow{2}{*}{$\begin{array}{c}\text { Inadecuada } \\
\mathrm{N} \text { (\%) }\end{array}$} & Adecuada & \multicolumn{2}{|c|}{ Inadecuada } & \\
\hline & $\mathrm{N}$ & $(\%)$ & & $\mathrm{N} \quad(\%)$ & $\mathrm{N}$ & (\%) & \\
\hline Cirugía General & 161 & $(47)$ & 179 (53) & 305 (69) & 137 & (31) & $<0,01$ \\
\hline $\begin{array}{l}\text { Cirugía } \\
\text { cardiovascular }\end{array}$ & & (3) & 36 (97) & $0 \quad(0)$ & 30 & $(100)$ & 0,36 \\
\hline Ginecología & 150 & (68) & 71 (32) & 196 (76) & 61 & (24) & 0,04 \\
\hline Neurocirugía & 4 & (11) & 33 (89) & 6 (24) & 19 & (76) & 0,17 \\
\hline $\mathrm{ORL}^{*}$ & 53 & (65) & 28 (35) & $45 \quad(47)$ & 50 & (53) & 0,02 \\
\hline Traumatología & 92 & $(45)$ & 114 & 158 & 152 & (49) & 0,16 \\
\hline Urología & 17 & (10) & 148 (90) & $14 \quad(9)$ & 150 & (91) & 0,58 \\
\hline Total & 478 & (44) & 609 (56) & 724 (55) & 599 & (45) & $<0,01$ \\
\hline
\end{tabular}

${ }^{*}$ ORL: Otorrinolaringología.

Los ATM que se utilizaron en la PAP fueron cefalosporinas de $1^{\text {a }}$ generación, gentamicina, metronidazol y aminopenicilinas. Dentro de las cefalosporinas de $1^{\text {a }}$ generación se usaron la cefazolina, cefalotina y cefalexina, y de las aminopenicilinas la ampicilina y la amoxicilina. Las DDD cada 1000 días paciente utilizadas antes de la aplicación del formulario y después de ello, se encuentran expresadas en la tabla 5.

Tabla 5. Antimicrobianos utilizados en la profilaxis antibiótica prequirúrgica, expresado en dosis diarias definidas/1000 días paciente antes y después de la aplicación del formulario para el uso de antimicrobianos en cirugía. Sanatorio Adventista del Plata, Argentina, enero de 2002 a octubre de 2003.

\begin{tabular}{|c|c|c|c|c|}
\hline \multirow[b]{2}{*}{ ATM $^{*}$} & \multirow{2}{*}{$\begin{array}{c}\text { Etapa inicial } \\
\text { DDD }{ }^{\dagger} / 1000 \text { días } \\
\text { paciente }\end{array}$} & \multirow{2}{*}{$\begin{array}{c}\text { Etapa final } \\
\text { DDD }{ }^{\dagger} / 1000 \text { días } \\
\text { paciente }\end{array}$} & \multicolumn{2}{|c|}{ Variación } \\
\hline & & & $\begin{array}{c}\mathrm{DDD}^{\dagger} / 1000 \\
\text { días paciente }\end{array}$ & (\%) \\
\hline $\begin{array}{l}\text { Cefalosporinas } 1^{a} \\
\text { generación }\end{array}$ & 559,7 & 427,7 & 132,0 & $(23,68)$ \\
\hline Gentamicina & 138,3 & 95,8 & 42,5 & $(30,73)$ \\
\hline Metronidazol & 79,5 & 43,1 & 36,4 & $(45,79)$ \\
\hline Aminopenicilinas & 31,3 & 34,0 & $-2,7$ & $(-8,63)$ \\
\hline Total & 808,8 & 600,6 & 208,2 & $(25,74)$ \\
\hline
\end{tabular}

*ATM: antimicrobiano, †DDD: Dosis diaria definida. 
De los 1087 pacientes intervenidos quirúrgicamente durante la etapa inicial, 29 $(2,7 \%)$ se complicaron con ISQ y en la etapa final, de las 1323 cirugías realizadas, sólo 13 $(0,98 \%)$ presentaron la misma complicación $(p<0,01)$. Se observó una disminución del $55 \%$ en el desarrollo de ISQ (Figura 12).

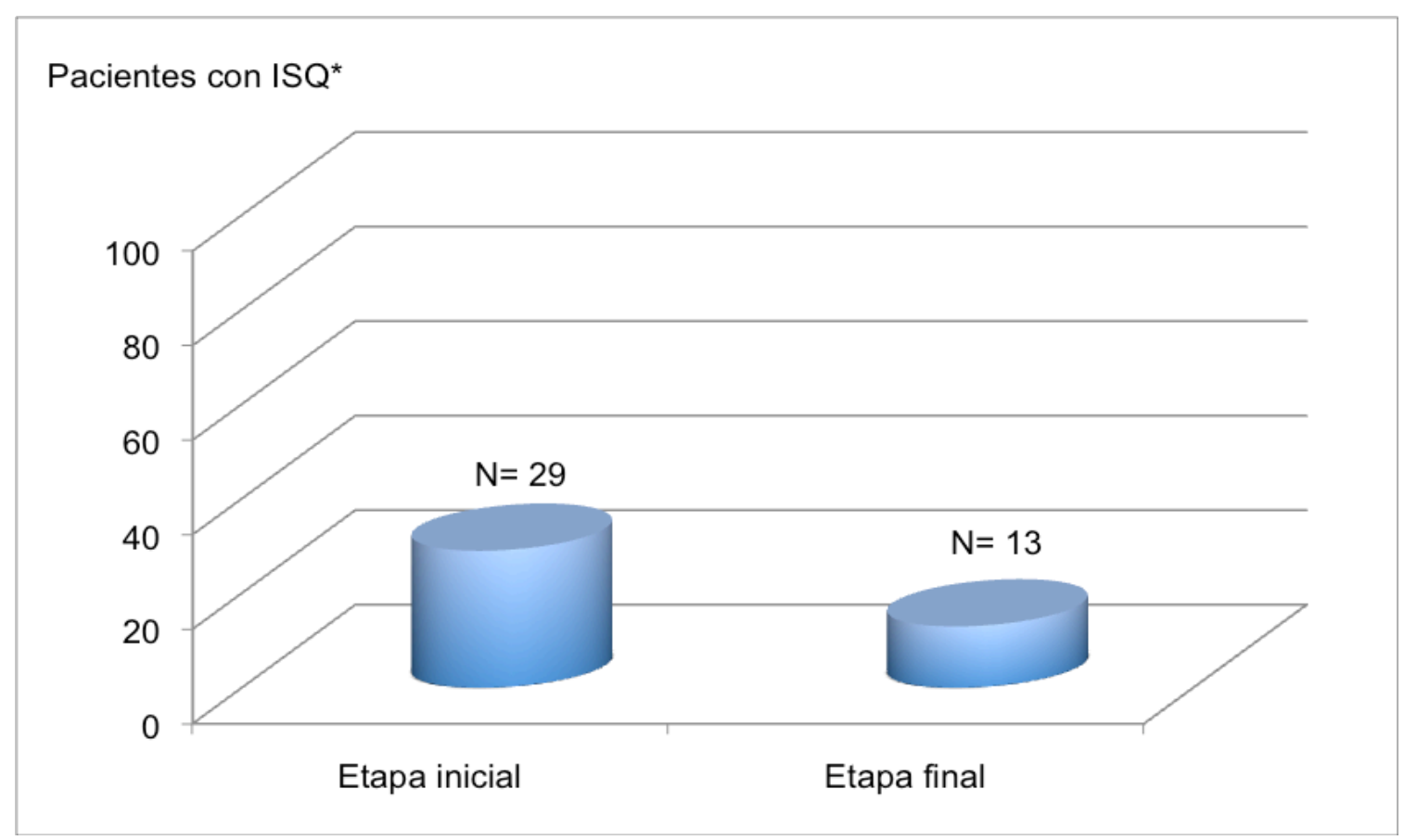

Figura 12. Número de pacientes con infección del sitio quirúrgico antes y después de la aplicación del formulario para el uso de antimicrobianos en cirugía. *ISQ: infección del sitio quirúrgico.

\subsection{Resultados correspondientes a los objetivos II y III}

Objetivos II: Evaluar el uso de ATM en los pacientes internados en la unidad de cuidados intensivos y en internación general previo a la aplicación del programa de profilaxis antimicrobiana prequirúrgica y después de ella.

Objetivo III: Conocer el porcentaje de resistencia a determinados antimicrobianos de 12 cepas centinelas aisladas de infecciones adquiridas en el hospital, antes de la instauración de dicho programa y después de ella.

Para la mayoría de los ATM, su administración fue significativamente mayor $(p \leq 0,01)$ en el sector de $\mathrm{UCl}$ que en el de internación general. En contraste, se reportaron valores mayores de DDD/ 1000 días paciente de gentamicina y trimetoprima-sulfametoxazol $(p \leq 0,01)$ en internación general (tabla 6$)$. Las penicilinas antipseudomonas no presentaron diferencia en su uso entre $\mathrm{UCl}$ e internación general. 
Tabla 6. Comparación del uso de antimicrobianos en los pacientes internados en la unidad de cuidados intensivos y en internación general del Sanatorio Adventista del Plata, Argentina, durante los años 2001-2007.

\begin{tabular}{|c|c|c|c|}
\hline \multirow{2}{*}{ Antimicrobianos } & \multicolumn{2}{|c|}{ DDD $* 1000$ días paciente } & \multirow{2}{*}{$p$} \\
\hline & $\mathrm{UCl}^{\dagger}$ & Internación general & \\
\hline Amikacina & 38,78 & 6,00 & $<0,01$ \\
\hline Aminopenicilinas & 85,65 & 60,32 & 0,01 \\
\hline Carbapenems & 36,72 & 3,16 & $<0,01$ \\
\hline Cefalosporinas $1^{\mathrm{a}}$ generación & 251,15 & 184,47 & $<0,01$ \\
\hline Cefalosporinas $2^{\mathrm{a}}$ generación & 0,62 & 0,02 & 0,34 \\
\hline Cefalosporinas $3^{\mathrm{a}}$ generación & 227,61 & 38,26 & $<0,01$ \\
\hline Clindamicina & 45,32 & 17,85 & $<0,01$ \\
\hline Fluoroquinolonas & 71,34 & 33,84 & $<0,01$ \\
\hline Gentamicina & 52,41 & 70,70 & $<0,01$ \\
\hline Metronidazol & 81,14 & 44,13 & $<0,01$ \\
\hline Penicilinas & 20,42 & 6,27 & $<0,01$ \\
\hline Penicilina antipseudomonas & 0,17 & 0,21 & 0,79 \\
\hline $\mathrm{TMS}^{\ddagger}$ & 0,92 & 3,02 & 0,01 \\
\hline Vancomicina & 38,32 & 4,99 & $<0,01$ \\
\hline
\end{tabular}

*DDD: dosis diarias definidas; † UCl: unidad de cuidados intensivos; $\ddagger$ TMS: trimetoprima-sulfametoxazol

Las cefalosporinas de $1^{a}$ generación y de $3^{a}$ generación fueron los ATM más utilizados en la UCI antes de la aplicación del formulario y después de ello. El $64 \%$ de los ATM disminuyeron sus DDD en el período evaluado; existió una disminución significativa en el uso de penicilinas y vancomicina $(p=0,05)$ y un aumento significativo en el uso de aminopenicilinas $(p<0,01)$, clindamicina $(p=0,05)$ y metronidazol $(p=0,02)$. La cefalosporinas de $2^{\mathrm{a}}$ generación y las penicilinas antipseudomonas se dejaron de utilizar en el segundo período de evaluación. En la Tabla 7 se presentan las DDD de ATM usados en la UCI por cada 1000 días paciente en los dos períodos estudiados. 
Tabla 7. Comparación del uso de antimicrobianos en la unidad de cuidados intensivos expresado en dosis diarias definidas/1000 días paciente, durante los años 2001-2002 (preintervención) y 2003-2007 (posintervención). Sanatorio Adventista del Plata, Argentina.

\begin{tabular}{|c|c|c|c|c|c|}
\hline \multirow{2}{*}{ Antimicrobianos } & \multicolumn{2}{|c|}{ DDD ${ }^{*} / 1000$ días paciente } & \multicolumn{2}{|c|}{ Variación } & \multirow{2}{*}{$p$} \\
\hline & $2001-2002$ & 2003-2007 & DDD* & (\%) & \\
\hline Amikacina & 52,45 & 33,31 & 19,14 & $(36,49)$ & 0,14 \\
\hline Aminopenicilinas & 32,49 & 106,92 & 74,47 & $(229,21)$ & $<0,01$ \\
\hline Carbapenems & 40,15 & 35,35 & 4,80 & $(11,96)$ & 0,69 \\
\hline $\begin{array}{l}\text { Cefalosporinas } 1^{\mathrm{a}} \\
\text { generación }\end{array}$ & 280,92 & 239,24 & 41,68 & $(14,84)$ & 0,13 \\
\hline $\begin{array}{l}\text { Cefalosporinas } 2^{a} \\
\text { generación }\end{array}$ & 2,16 & 0,00 & 2,16 & $(100,00)$ & 0,33 \\
\hline $\begin{array}{l}\text { Cefalosporinas } 3^{a} \\
\text { generación }\end{array}$ & 188,29 & 223,26 & 34,97 & $(18,57)$ & 0,28 \\
\hline Clindamicina & 28,91 & 51,88 & 22,97 & $(79,45)$ & 0,05 \\
\hline Fluoroquinolonas & 78,48 & 68,48 & 10,00 & $(12,74)$ & 0,43 \\
\hline Gentamicina & 58,61 & 49,94 & 8,67 & $(14,79)$ & 0,40 \\
\hline Metronidazol & 59,10 & 89,96 & 30,86 & $(52,22)$ & 0,02 \\
\hline Penicilinas & 40,84 & 12,25 & 28,59 & $(70,00)$ & 0,05 \\
\hline $\begin{array}{l}\text { Penicilinas } \\
\text { antipseudomonas }\end{array}$ & 0,59 & 0,00 & 0,59 & $(100,00)$ & 0,10 \\
\hline $\mathrm{TMS}^{\dagger}$ & 0,92 & 0,92 & 0,00 & $(0,00)$ & 1,00 \\
\hline Vancomicina & 62,89 & 28,49 & 34,40 & $(54,70)$ & 0,05 \\
\hline
\end{tabular}

${ }^{*}$ DDD: dosis diaria definida, †TMS: trimetoprima-sulfametoxazol. 
Tabla 8. Comparación del uso de ATM en la unidad de cuidados intensivos expresado en dosis diarias definidas/1000 días paciente, durante los años 2001 a 2007. Sanatorio Adventista del Plata, Argentina.

\begin{tabular}{|c|c|c|c|c|c|c|c|}
\hline \multirow{2}{*}{ Antimicrobianos } & \multicolumn{7}{|c|}{ DDD ${ }^{*} / 1000$ días paciente } \\
\hline & 2001 & 2002 & 2003 & 2004 & 2005 & 2006 & 2007 \\
\hline Amikacina & 57,24 & 47,66 & 35,86 & 28,89 & 47,64 & 17,23 & 43,09 \\
\hline Aminopenicilinas & 29,15 & 35,82 & 73,37 & 71,38 & 114,26 & 165,13 & 110,44 \\
\hline Carbapenems & 31,76 & 48,53 & 21,74 & 26,95 & 51,11 & 29,43 & 47,49 \\
\hline $\begin{array}{l}\text { Cefalosporinas } 1^{a} \\
\text { generación }\end{array}$ & 257,35 & 304,50 & 268,49 & 295,24 & 216,79 & 214,52 & 201,16 \\
\hline $\begin{array}{l}\text { Cefalosporinas } 2^{\mathrm{a}} \\
\text { generación }\end{array}$ & 4,31 & 0,00 & 0,00 & 0,00 & 0,00 & 0,00 & 0,00 \\
\hline $\begin{array}{l}\text { Cefalosporinas } 3^{a} \\
\text { generación }\end{array}$ & 176,01 & 200,56 & 161,91 & 376,93 & 195,25 & 266,28 & 216,35 \\
\hline Clindamicina & 32,95 & 24,87 & 19,87 & 20,48 & 50,14 & 92,30 & 76,59 \\
\hline Fluoroquinolonas & 69,74 & 87,22 & 67,66 & 66,16 & 40,89 & 77,10 & 90,59 \\
\hline Gentamicina & 83,11 & 34,10 & 53,84 & 56,65 & 46,87 & 53,03 & 39,30 \\
\hline Metronidazol & 56,72 & 61,48 & 105,42 & 97,93 & 67,69 & 102,75 & 76,01 \\
\hline Penicilinas & 56,34 & 25,33 & 9,75 & 22,76 & 20,03 & 0,00 & 8,73 \\
\hline $\mathrm{TMS}^{\dagger}$ & 1,83 & 0,00 & 3,85 & 0,00 & 0,00 & 0,00 & 0,76 \\
\hline Vancomicina & 76,77 & 49,01 & 15,07 & 27,00 & 16,35 & 64,78 & 19,25 \\
\hline
\end{tabular}

*DDD: dosis diaria definida, †TMS: trimetoprima-sulfametoxazol.

En la Tabla 8 se presenta el uso año a año de ATM expresado en DDD/1000 días paciente en $\mathrm{UCl}$. Al realizar el análisis se observó una diferencia significativa en el empleo de aminopenicilinas, cefalosporinas $3^{a}$ generación, gentamicina, penicilina. En los gráficos siguientes se presentan los resultados obtenidos. 


\section{Aminopenicilinas en $\mathrm{UCl}^{*}$}

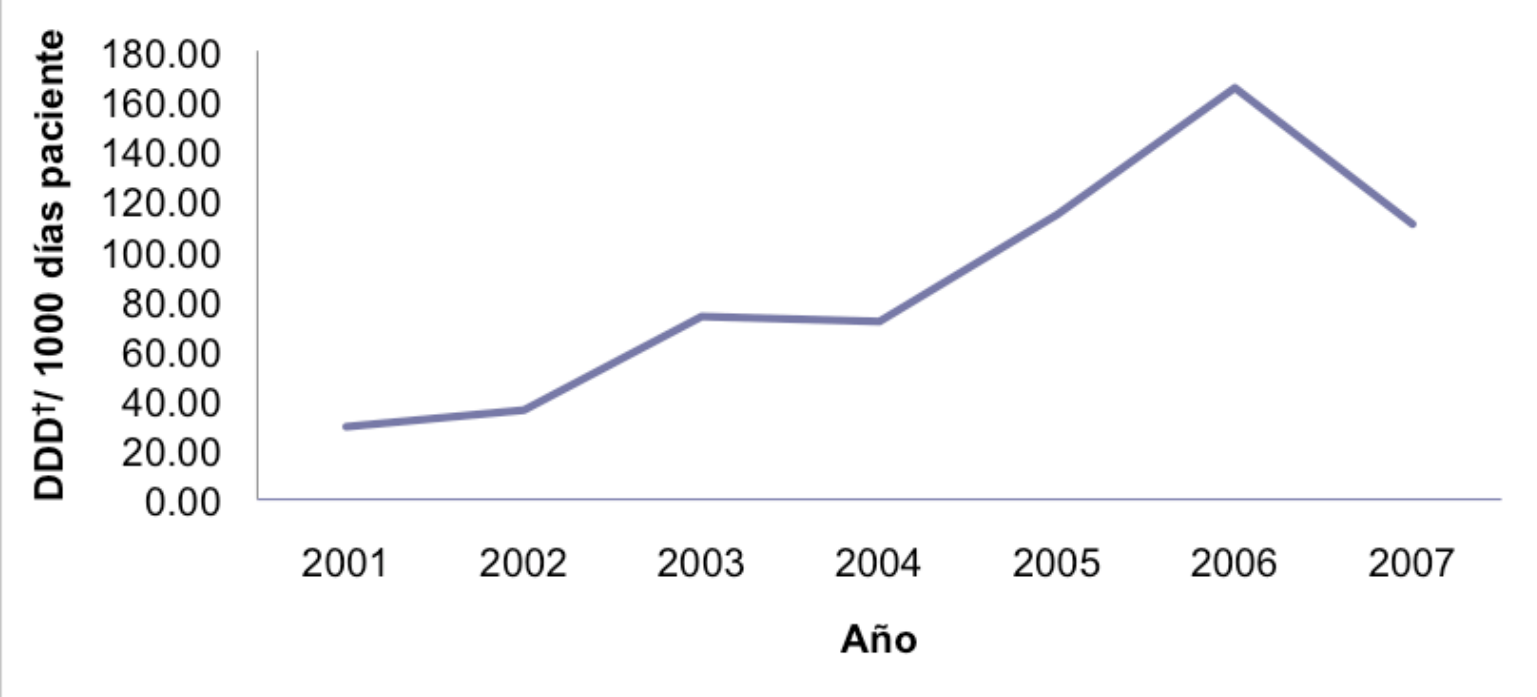

Figura 13. Variación del uso de aminopenicilinas en la unidad de cuidados intensivos durante los años 2001 a 2007 expresado en dosis diarias definidas/1000 días paciente. Sanatorio Adventista del Plata, Argentina.

* $\mathrm{UCl}$ : unidad de cuidados intensivos, $\uparrow$ : dosis diarias definidas.

De la observación de la figura 13 surge que, en 2006, existió un aumento significativo del uso de aminopenicilinas en $\mathrm{UCl}(p<0.05)$ respecto a los años 2001, 2002 y 2004.

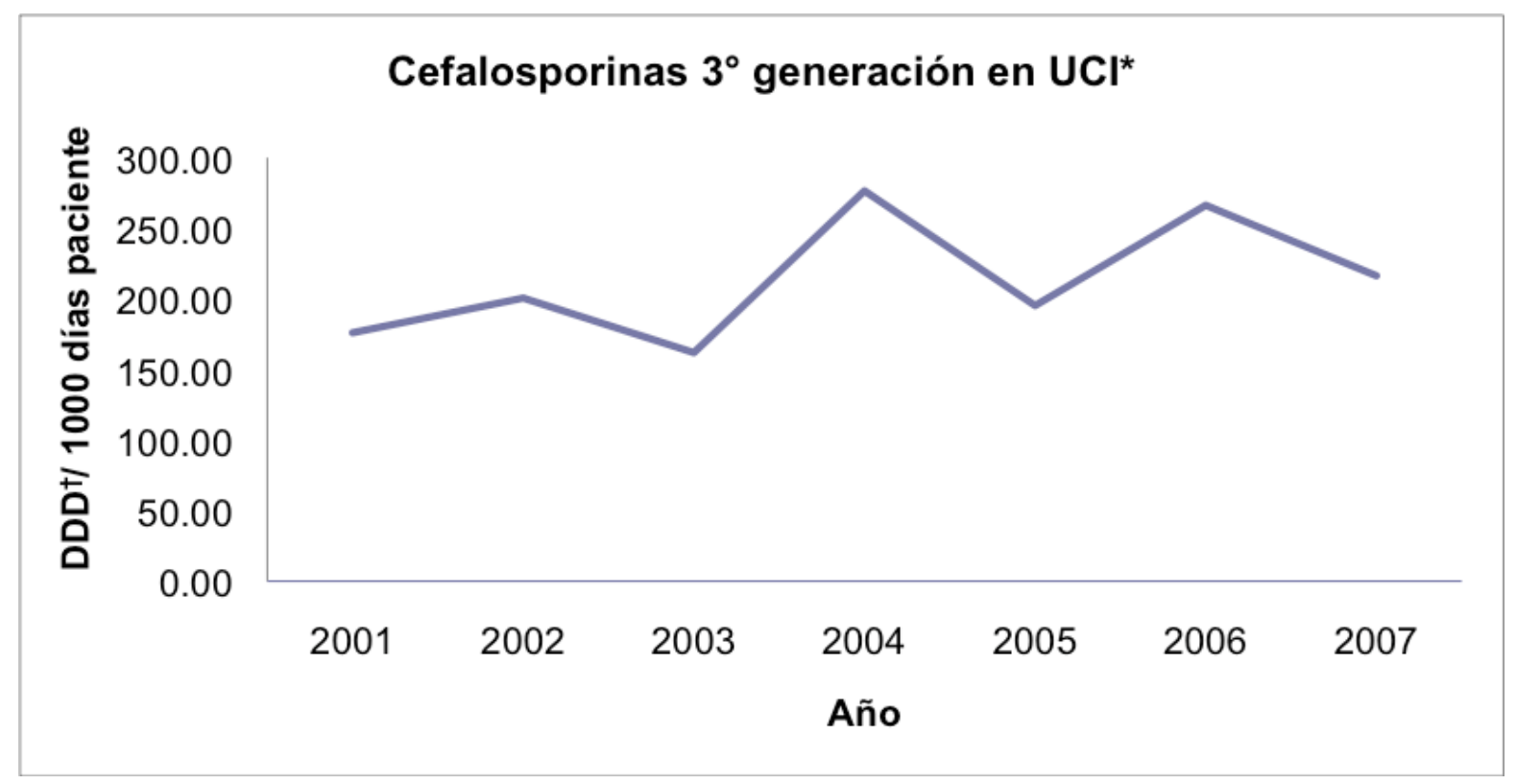

Figura 14. Variación del uso de cefalosporinas $3^{a}$ generación en la unidad de cuidados intensivos durante los años 2001 a 2007 expresado en dosis diarias definidas/1000 días paciente. Sanatorio Adventista del Plata, Argentina.

${ }^{*} \mathrm{UCl}$ : unidad de cuidados intensivos, $\uparrow$ : dosis diarias definidas. 
De la observación de la figura 14 surge que, en 2004, se produce un aumento significativo del uso de Cefalosporinas $3^{\mathrm{a}}$ generación en $\mathrm{UCl}(p<0.05)$ respecto a los años 2001,2003 y 2005.

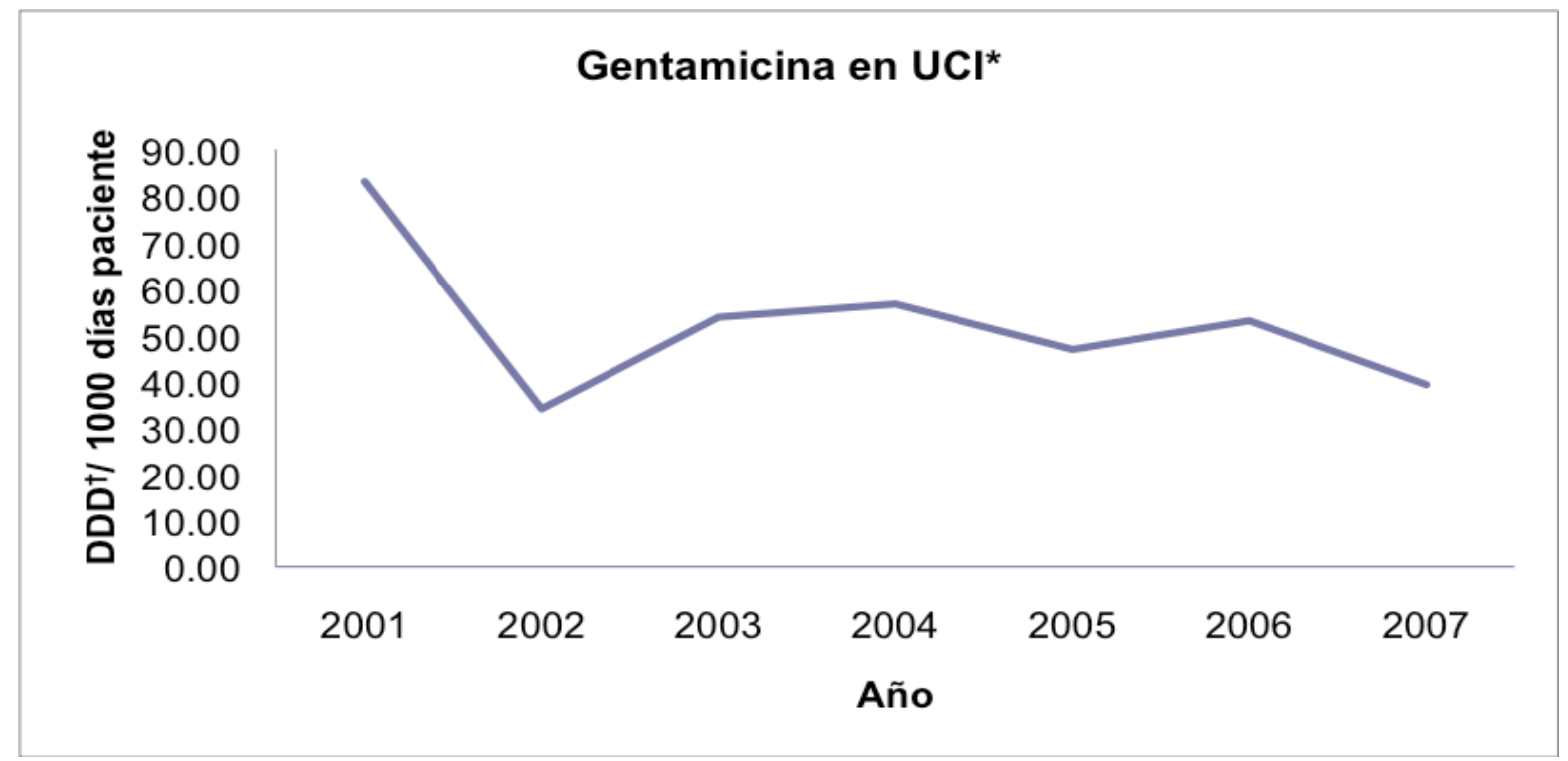

Figura 15. Variación del uso de gentamicina en unidad de cuidados intensivos durante los años 2001 a 2007 expresado en dosis diarias definidas/1000 días paciente. Sanatorio Adventista del Plata, Argentina.

*UCl: unidad de cuidados intensivos, $\uparrow$ : dosis diarias definidas.

De la observación de la figura 15 surge que, en 2002 y 2007, se presenta una disminución significativa del uso de gentamicina en $\mathrm{UCI}(p<0.05)$ respecto al año 2001.

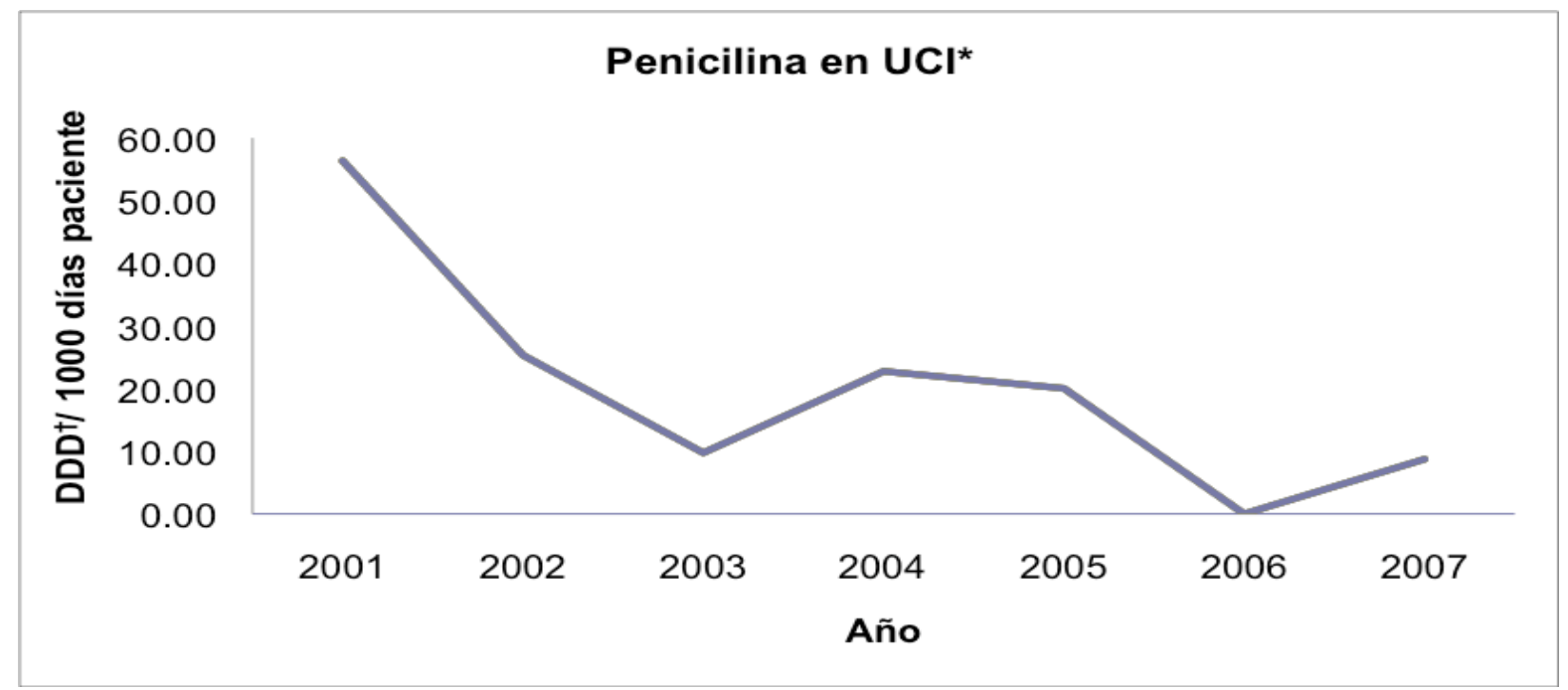

Figura 16. Variación del uso de penicilinas en unidad de cuidados intensivos durante los años 2001 a 2007 expresado en dosis diarias definidas/1000 días paciente. Sanatorio Adventista del Plata, Argentina.

*UCl: unidad de cuidados intensivos, $\dagger$ : dosis diarias definidas. 
De la observación de la figura 16 surge que, en 2006, existió una disminución significativa del uso de penicilina en $\mathrm{UCI}(p<0.05)$ respecto al año 2001.

Las DDD de los ATM en internación general disminuyeron un $64 \%$ en el período evaluado. Hubo una disminución significativa del uso de cefalosporinas de primera generación $(p<0,01)$, clindamicina $(p<0,01)$, fluoroquinolonas $(p=0,05)$ y gentamicina $(p<0,01)$, y un aumento significativo en el uso de aminopenicilinas $(p<0,01)$. Las cefalosporinas de segunda generación se dejaron de utilizar en el segundo período de evaluación. En la tabla 9 se presentan las DDD de ATM usados por cada 1000 días paciente, para los dos períodos estudiados.

Tabla 9. Comparación del uso de antimicrobianos en internación general expresado en dosis diarias definidas/1000 días paciente, durante los años 2001-2002 (preintervención) y 2003-2007 (posintervención). Sanatorio Adventista del Plata, Argentina.

\begin{tabular}{|c|c|c|c|c|c|}
\hline \multirow{2}{*}{ Antimicrobianos } & \multicolumn{2}{|c|}{$\mathrm{DDD}^{*} / 1000$ días paciente } & \multicolumn{2}{|c|}{ Variación } & \multirow{2}{*}{$p$} \\
\hline & $2001-2002$ & $2003-2007$ & $\mathrm{DDD}^{*}$ & (\%) & \\
\hline Amikacina & 7,21 & 5,51 & 1,70 & $(23,58)$ & 0,42 \\
\hline Aminopenicilinas & 40,99 & 68,06 & 27,07 & $(66,04)$ & $<0,01$ \\
\hline Carbapenems & 2,85 & 3,28 & 0,43 & $(15,09)$ & 0,70 \\
\hline $\begin{array}{l}\text { Cefalosporinas } 1^{a} \\
\text { generación }\end{array}$ & 236,30 & 163,74 & 72,56 & $(30,71)$ & $<0,01$ \\
\hline $\begin{array}{l}\text { Cefalosporinas } 2^{a} \\
\text { generación }\end{array}$ & 0,07 & 0,00 & 0,07 & $(100,00)$ & 0,33 \\
\hline $\begin{array}{l}\text { Cefalosporinas } 3^{a} \\
\text { generación }\end{array}$ & 39,86 & 37,61 & 2,25 & $(5,64)$ & 0,67 \\
\hline Clindamicina & 27,62 & 13,94 & 13,68 & $(49,53)$ & $<0,01$ \\
\hline Fluoroquinolonas & 37,54 & 32,36 & 5,18 & $(13,80)$ & 0,05 \\
\hline Gentamicina & 81,58 & 66,35 & 15,23 & $(18,69)$ & $<0,01$ \\
\hline Metronidazol & 44,03 & 44,16 & 0,13 & $(0,30)$ & 0,97 \\
\hline Penicilinas & 5,65 & 7,06 & 1,41 & $(24,96)$ & 0,51 \\
\hline $\begin{array}{l}\text { Penicilinas } \\
\text { antipseudomonas }\end{array}$ & 0,38 & 0,08 & 0,30 & $(73,17)$ & 0,24 \\
\hline TMS $^{\dagger}$ & 2,48 & 3,24 & 0,76 & $(30,65)$ & 0,50 \\
\hline Vancomicina & 5,46 & 4,80 & 0,66 & $(12,09)$ & 0,64 \\
\hline
\end{tabular}

${ }^{*}$ DDD: dosis diarias definidas, †TMS: trimetoprima-sulfametoxazol.

Las cefalosporinas de primera generación fueron los ATM más utilizados, siendo estos los que más frecuentemente se aplican en las profilaxis quirúrgicas. 
Tabla 10. Comparación del uso de antimicrobianos en internación general expresado en dosis diarias definidas/1000 días paciente, durante los años 2001 a 2007. Sanatorio Adventista del Plata, Argentina.

\begin{tabular}{lrrrrrrr}
\hline \multirow{2}{*}{ Antimicrobianos } & \multicolumn{7}{c}{ DDD $^{*} / 1000$ días paciente } \\
\cline { 2 - 8 } & 2001 & 2002 & 2003 & 2004 & 2005 & 2006 & 2007 \\
\hline Amikacina & 12,55 & 1,87 & 4,51 & 4,68 & 3,76 & 5,73 & 7,29 \\
Aminopenicilinas & 45,61 & 36,36 & 53,19 & 63,87 & 67,30 & 68,78 & 71,32 \\
Carbapenems & 3,00 & 2,70 & 4,30 & 3,29 & 1,36 & 3,94 & 2,90 \\
Cefalosporinas 1a & 247,62 & 224,99 & 172,58 & 178,31 & 157,08 & 155,32 & 127,64 \\
generación & & & & & & & \\
Cefalosporinas $2^{\text {a }}$ & 0,00 & 0,15 & 0,00 & 0,00 & 0,00 & 0,00 & 0,00 \\
generación & & & & & & & \\
Cefalosporinas $3^{\text {a }}$ & 35,02 & 44,70 & 40,97 & 39,98 & 35,65 & 29,13 & 34,79 \\
generación & 25,78 & 29,46 & 8,94 & 15,92 & 17,14 & 11,68 & 13,18 \\
Clindamicina & 35,72 & 39,36 & 36,54 & 30,26 & 35,27 & 25,09 & 28,38 \\
Fluoroquinolonas & 98,49 & 64,68 & 58,45 & 71,94 & 67,69 & 63,72 & 57,18 \\
Gentamicina & 41,54 & 46,52 & 39,90 & 45,94 & 42,25 & 46,46 & 37,81 \\
Metronidazol & 7,64 & 3,66 & 10,88 & 6,58 & 5,31 & 4,36 & 6,66 \\
Penicilinas & 2,76 & 2,19 & 1,45 & 1,14 & 1,37 & 7,96 & 3,50 \\
TMS & & 7,04 & 1,29 & 2,07 & 2,25 & 12,33 & 4,99 \\
\hline Vancomicina & 3,87 & 7,04 & & & & & \\
\hline
\end{tabular}

"DDD: dosis diarias definidas, †TMS: trimetoprima-sulfametoxazol.

En internación general, tal como se expone en la tabla 10, se presenta el uso de ATM expresado en DDD/1000 días paciente año a año. Al hacer el análisis se comprobaron diferencias significativas en el empleo de amikacina, aminopenicilinas, cefalosporinas primera generación, clindamicina, fluoroquinolonas, gentamicina, trimetoprima-sulfametoxazol y vancomicina. En los gráficos siguientes se presentan los resultados obtenidos. 


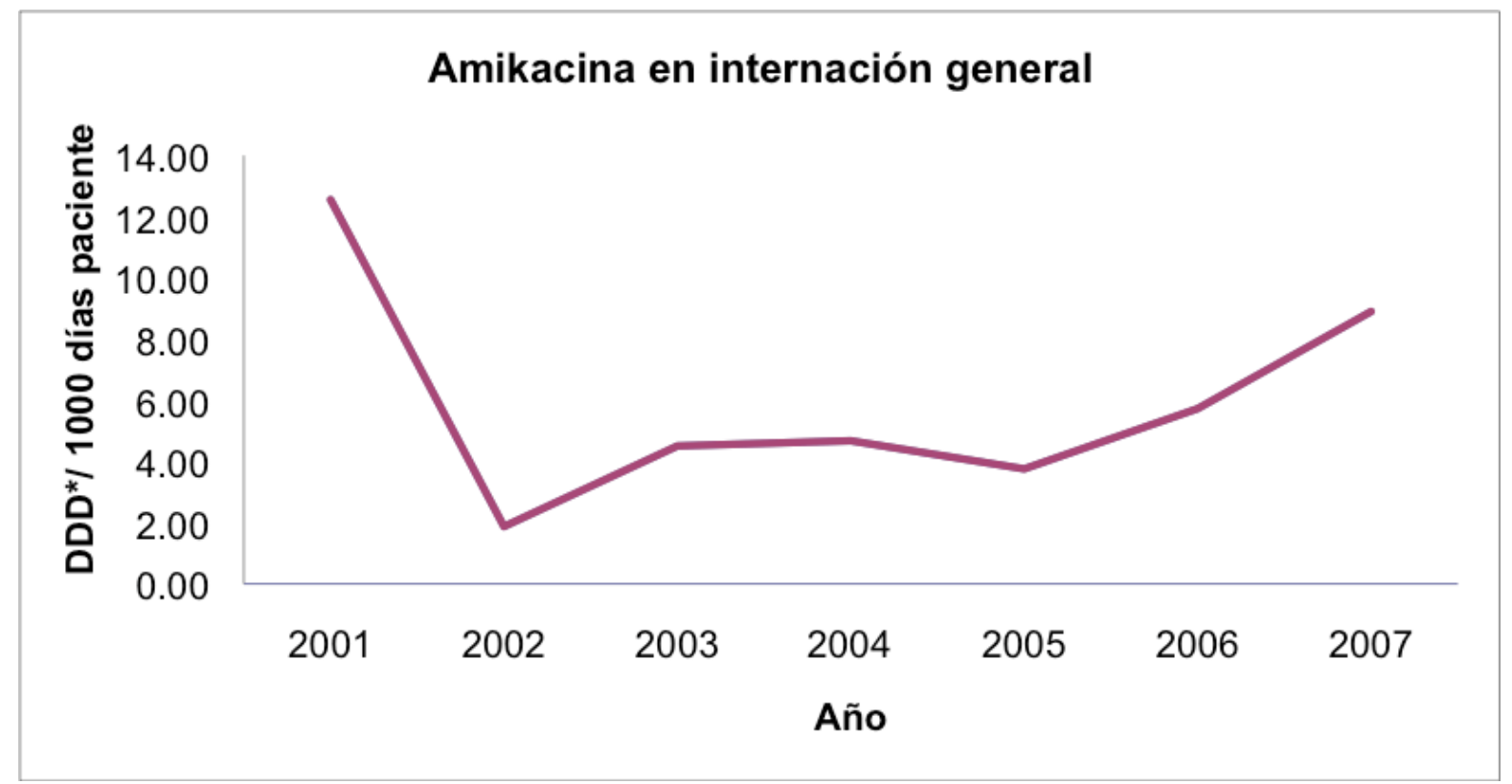

Figura 17. Variación del uso de amikacina en internación general durante los años 2001 a 2007 expresado en dosis diarias definidas/1000 días paciente. Sanatorio Adventista del Plata, Argentina.

* dosis diarias definidas.

De la observación de la figura 17 surge que, a partir del año 2002 existió una disminución significativa del uso de amikacina en internación general $(p<0.05)$ respecto al año 2001.

\section{Aminopenicilinas en internación general}

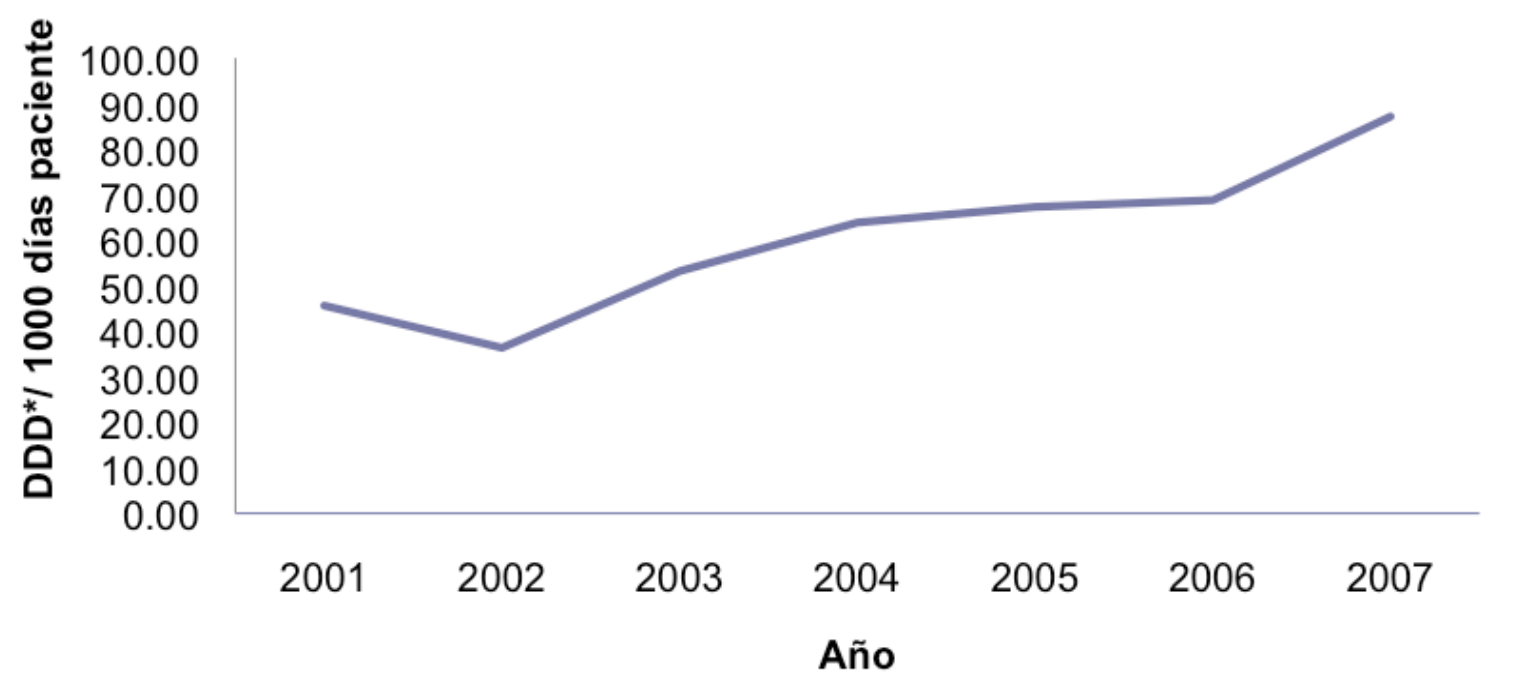

Figura 18. Variación del uso de aminopenicilinas en internación general durante los años 2001 a 2007 expresado en dosis diarias definidas/1000 días paciente. Sanatorio Adventista del Plata, Argentina.

* dosis diarias definidas. 
De la observación de la figura 18 surge que, en 2005, 2006 y 2007 existió un aumento significativo del uso de aminopenicilinas en internación general $(p<0.05)$ respecto al año 2001. Los valores medios para 2004, 2005, 2006 y 2007 son también significativamente mayores que el de $2002(p<0.05)$.

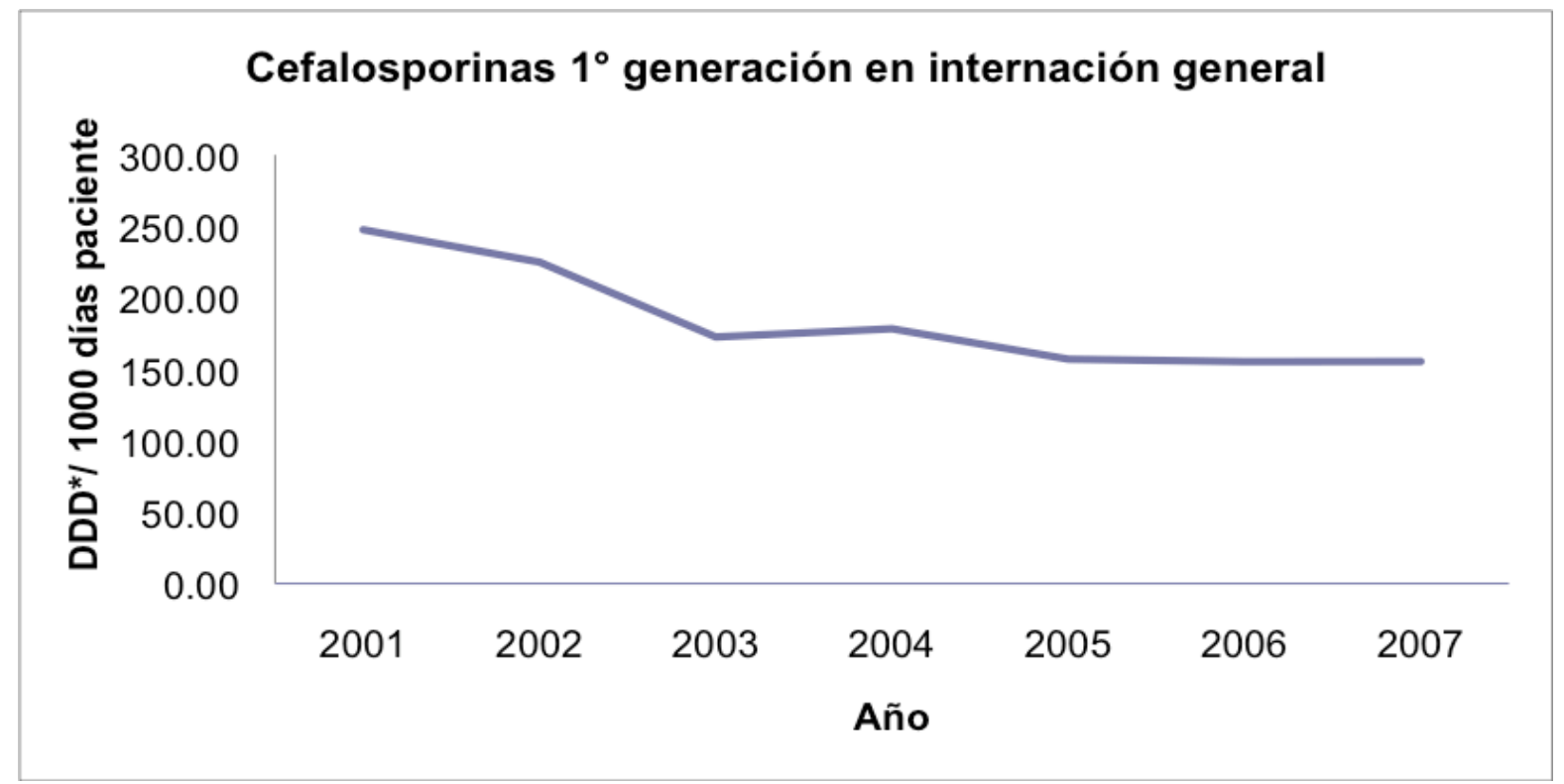

F9gura 19. Variación del uso de cefalosporinas $1^{\text {a }}$ generación en internación general durante los años 2001 a 2007 expresado en dosis diarias definidas/ 1000 días paciente. Sanatorio Adventista del Plata, Argentina.

${ }^{*}$ dosis diarias definidas.

De la observación de la figura 19 surge que, a partir del año 2003 existió una disminución significativa del uso de Cefalosporinas $1^{\text {a }}$ generación en internación general $(p<0.05)$. 


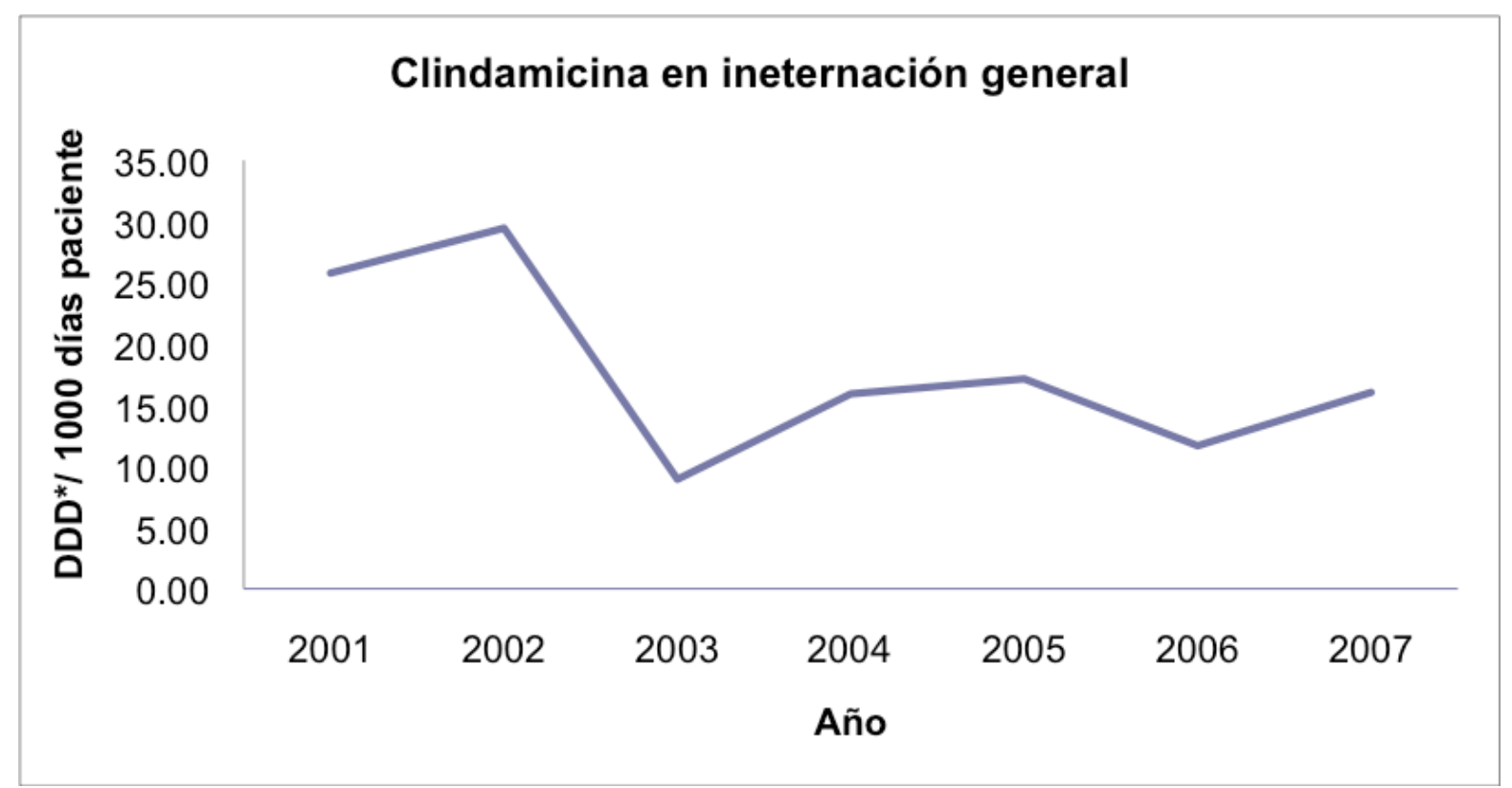

Figura 20. Variación del uso de clindamicina en internación general durante los años 2001 a 2007 expresado en dosis diarias definidas/1000 días paciente. Sanatorio Adventista del Plata, Argentina.

* dosis diarias definidas.

De la observación de la figura 20 surge que, en 2003 y 2006, se produce una disminución significativa del uso de clindamicina en internación general $(p<0.05)$ con respecto al año 2002.

\section{Fluoroquinolonas en internación general}

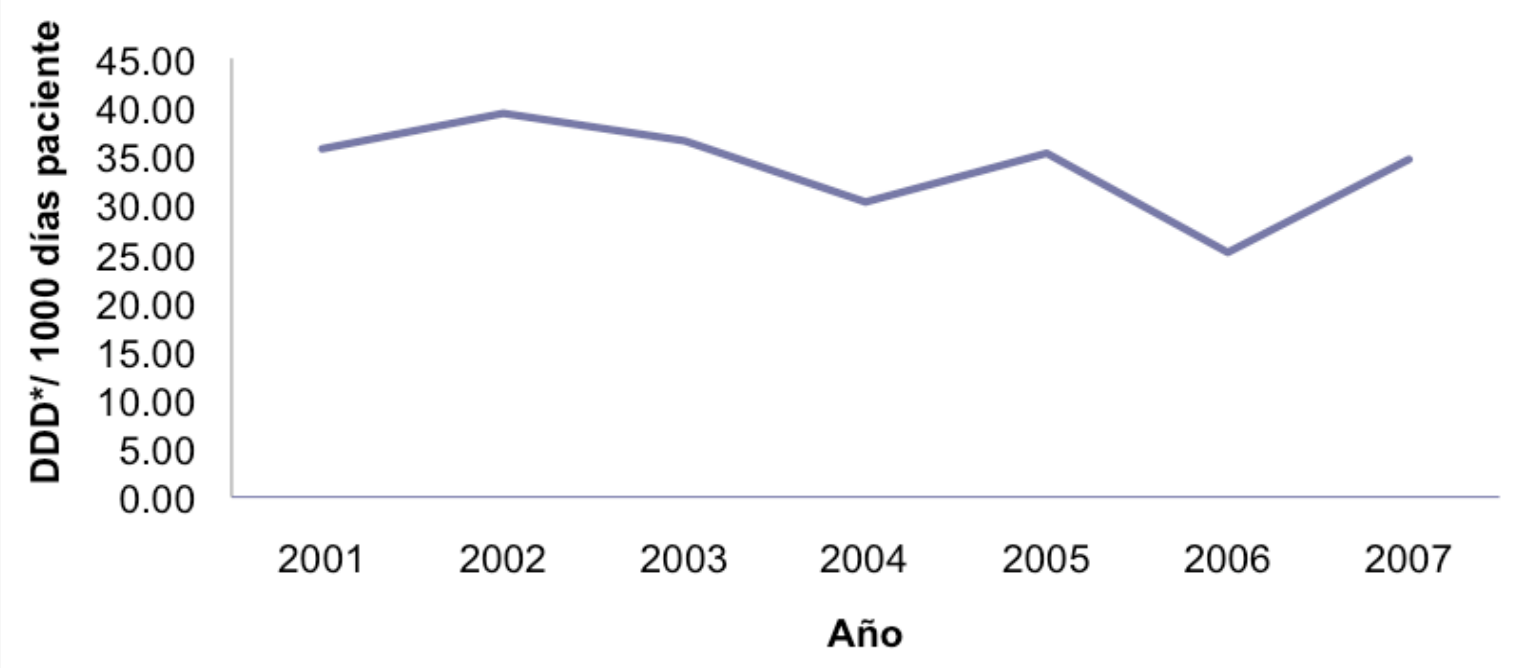

Figura 21. Variación del uso de fluoroquinolonas en internación general durante los años 2001 a 2007 expresado en dosis diarias definidas/1000 días paciente. Sanatorio Adventista del Plata, Argentina.

* dosis diarias definidas. 
De la observación de la figura 21 surge que, en 2006, existió una disminución significativa del uso de fluoroquinolonas en internación general $(p<0.05)$ con respecto al año 2002.

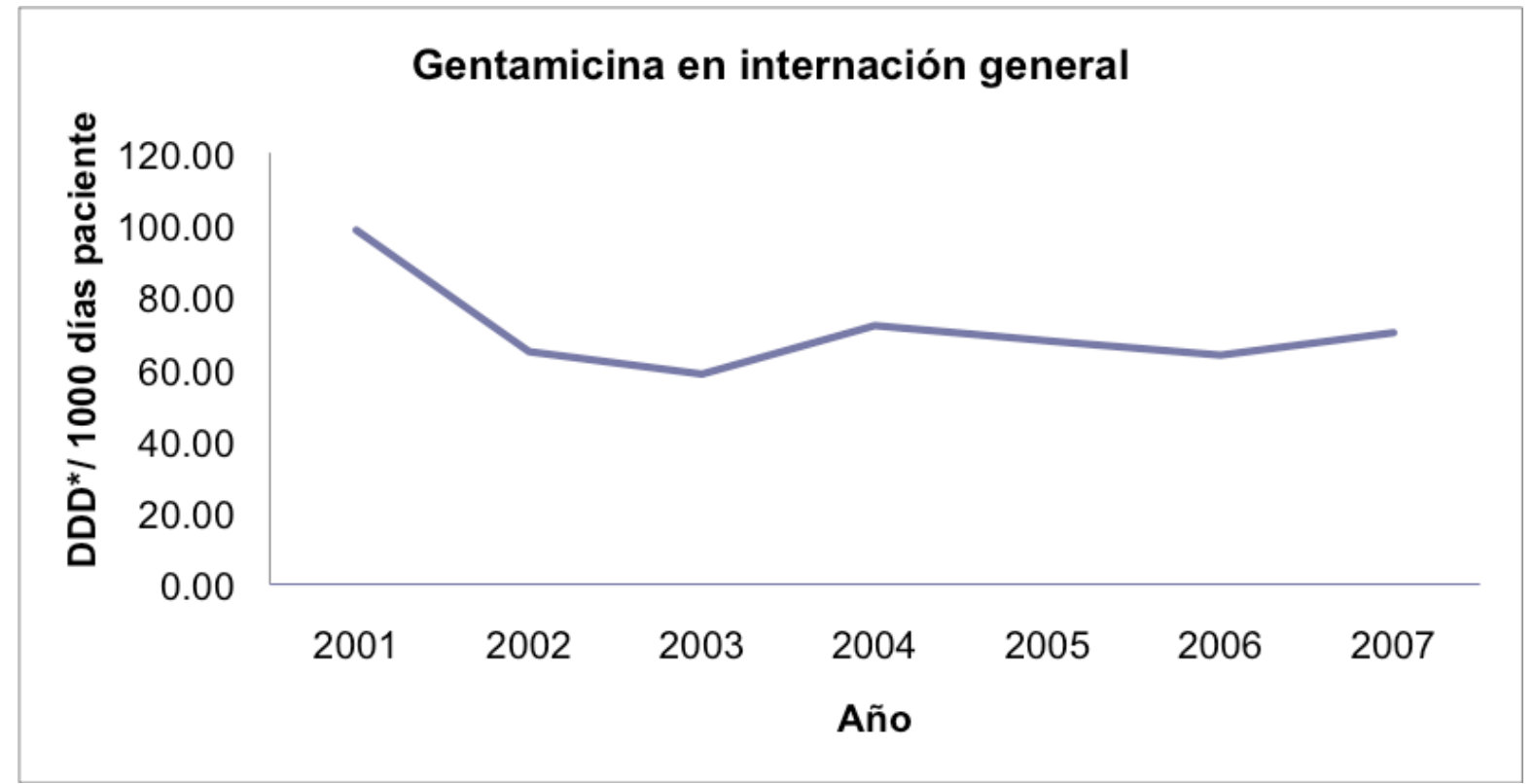

Figura 22. Variación del uso de gentamicina en internación general durante los años 2001 a 2007 expresado en dosis diarias definidas/1000 días paciente. Sanatorio Adventista del Plata, Argentina.

* dosis diarias definidas.

De la observación de la figura 22 surge que, a partir del año 2002, se presenta una disminución significativa del uso de gentamicina en internación general $(p<0.05)$ respecto del año 2001. 


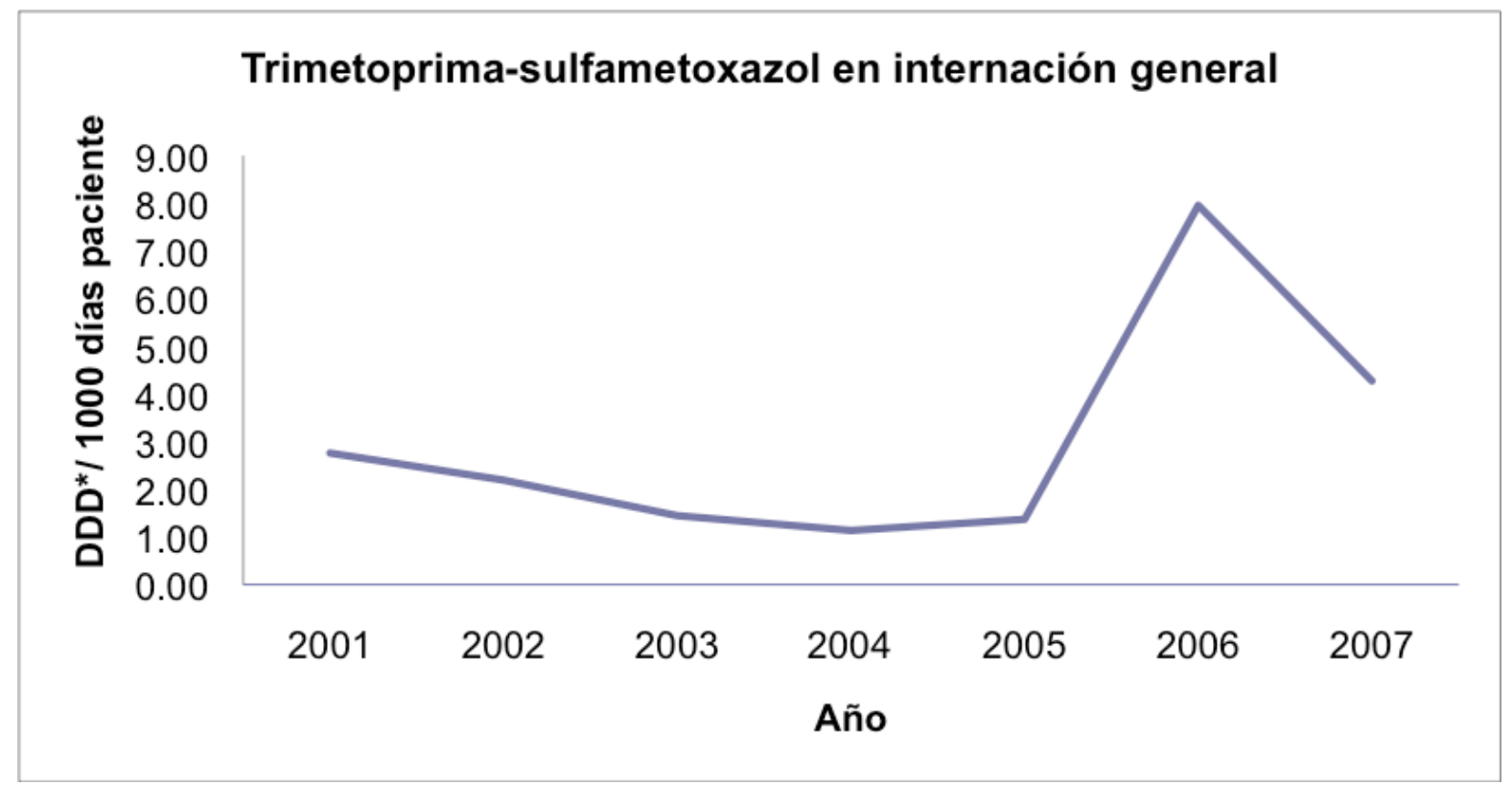

Figura 23. Variación del uso de trimetoprima-sulfametoxazol en internación general durante los años 2001 a 2007 expresado en dosis diarias definidas/1000 días paciente. Sanatorio Adventista del Plata, Argentina.

* dosis diarias definidas.

De la observación de la figura 23 surge que, en 2006, existió un aumento significativo del uso de trimetoprima-sulfametoxazol en internación general $(p<0.05)$ respecto a los años 2002, 2003, 2004 y 2005.

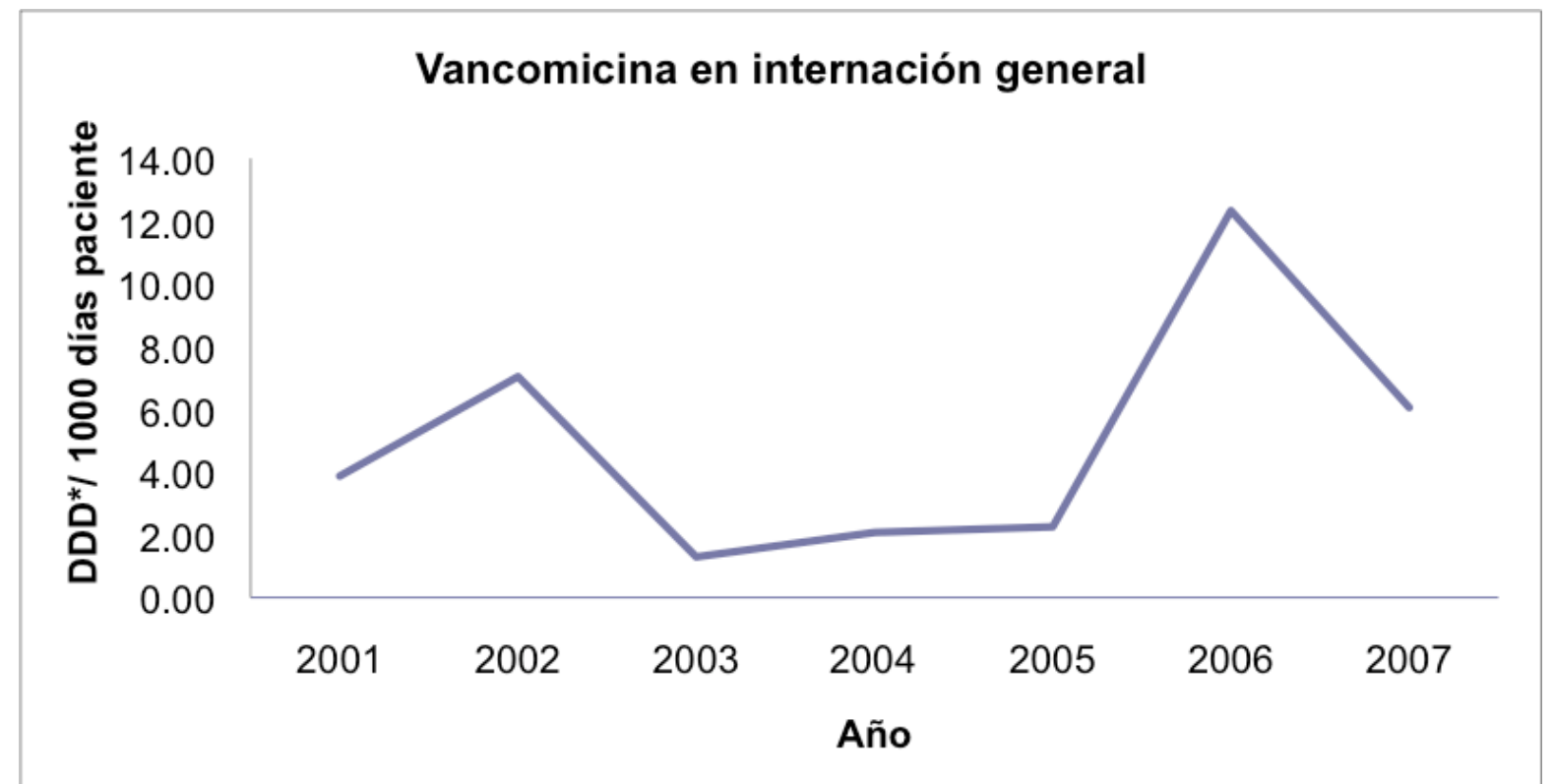

Figura 24. Variación del uso de vancomicina en internación general durante los años 2001 a 2007 expresado en dosis diarias definidas/1000 días paciente. Sanatorio Adventista del Plata, Argentina.

* dosis diarias definidas. 
De la observación de la figura 24 surge que, en 2006, existió un aumento significativo del uso de vancomicina en internación general $(p<0.05)$ respecto a los años 2001, 2003, 2004 y 2005.

El porcentaje de resistencia de los aislamientos estudiados varió según el sector de internación, aunque no hubo diferencias significativas en los resultados. No se efectuaron los cálculos para ERV y a S. pneumoniae resistente a cefalosporinas de tercera generación, porque fueron microorganismos de los cuales no se obtuvieron aislamientos (Tabla 11).

Tabla 11. Comparación del porcentaje de resistencia bacteriana de las cepas productoras de infecciones hospitalarias aisladas de pacientes en la unidad de cuidados intensivos y en internación general del Sanatorio Adventista del Plata, Argentina, durante los años 2001 2007.

\begin{tabular}{|c|c|c|c|c|c|}
\hline \multirow[b]{2}{*}{ Microorganismos resistentes } & \multicolumn{2}{|c|}{$\mathrm{UCl}$} & \multicolumn{2}{|c|}{ Internación general } & \multirow[b]{2}{*}{$p$} \\
\hline & $\begin{array}{l}\mathrm{N}^{\circ} \text { cepas } \\
\text { test. }\end{array}$ & $\% \mathrm{R}^{\dagger}$ & $\mathrm{N}^{\circ}$ cepas test. & $\% \mathrm{R}^{\dagger}$ & \\
\hline SARM $^{\ddagger}$ & 41 & 39 & 105 & 31 & 0,43 \\
\hline $\mathrm{SCNRM}^{\S}$ & 15 & 87 & 55 & 66 & 0,20 \\
\hline $\begin{array}{l}\text { S. pneumoniae resistente } \\
\text { penicilina }\end{array}$ & 11 & 0 & 27 & 15 & 0,44 \\
\hline E. coli resistente CEF $3^{a} \mathrm{G}^{\| \prime}$ & 43 & 2 & 230 & 7 & 0,47 \\
\hline E. coli resistente $\mathrm{FQ}^{\pi}$ & 46 & 15 & 243 & 25 & 0,21 \\
\hline $\begin{array}{l}\text { K. pneumoniae resistente } \\
\text { CEF } 3^{\text {a }} \mathrm{G}^{\|}\end{array}$ & 17 & 6 & 48 & 13 & 0,30 \\
\hline $\begin{array}{l}\text { Enterobacter spp. resistente } \\
\text { CEF } 3^{\text {a }} G^{l l}\end{array}$ & 15 & 47 & 46 & 35 & 0,60 \\
\hline $\begin{array}{l}\text { Enterobacter spp. resistente } \\
\text { imipenem }\end{array}$ & 13 & 8 & 39 & 0 & 0,56 \\
\hline $\begin{array}{l}P \text {. aeruginosa resistente } \\
\text { ceftazidima }\end{array}$ & 46 & 13 & 115 & 6 & 0,25 \\
\hline $\begin{array}{l}P . \text { aeruginosa resistente } \\
\text { imipenem }\end{array}$ & 45 & 9 & 110 & 4 & 0,35 \\
\hline$P$. aeruginosa resistente $\mathrm{FQ}^{\mathbb{}}$ & 45 & 18 & 114 & 24 & 0,48 \\
\hline
\end{tabular}

*UCl: unidad de cuidados intensivos; † \%R: porcentaje de resistencia bacteriana; ¥SARM: Staphylococcus aureus resistente a meticilina; § SCNRM: Staphylococcus spp. (coagulasa negativa) resistente a meticilina; $S$.

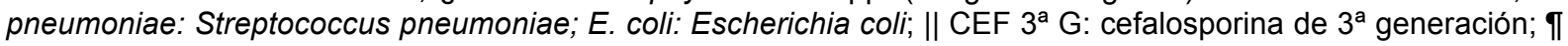
FQ: fluoroquinolonas; K. pneumoniae: Klebsiella pneumoniae; P. aeruginosa: Pseudomonas aeruginosa

En UCI, $P$. aeruginosa y $E$. coli fueron los microorganismos más frecuentemente aislados (23\%), seguidos por S. aureus (20\%), K. pneumoniae (8\%), Staphylococcus spp. coagulasa negativo y $S$. pneumoniae $(7 \%)$, especies de Enterobacter y especies de Enterococcus (5\%). 
En cambio, en internación general el microorganismo más frecuentemente aislado fue, E. coli (35\%), seguido por $P$. aeruginosa (16\%), S. aureus (15\%), especies de Enterococcus (9\%), Staphylococcus spp. coagulasa negativo $(7 \%)$, K. pneumoniae y especies de Enterobacter (7\%) y S. pneumoniae (4\%).

$S$. aureus, E. coli y $P$. aeruginosa fueron las bacterias más frecuentemente aisladas en $\mathrm{UCl}$, habiéndose realizado 10 o más aislamientos correspondientes a infecciones hospitalarias. Para el SARM se detectó una disminución significativa $(p<0,01)$ en la resistencia entre los dos períodos estudiados. En la Tabla 12 se presenta la evolución de la resistencia bacteriana en ambos períodos.

Tabla 12. Comparación del porcentaje de resistencia bacteriana de las cepas productoras de infecciones hospitalarias aisladas en la unidad de cuidados intensivos, durante los años 2001-2002 (preintervención) y 2003-2007 (posintervención). Sanatorio Adventista del Plata, Argentina.

\begin{tabular}{|c|c|c|c|c|c|}
\hline \multirow[b]{2}{*}{ Microorganismos resistentes } & \multicolumn{2}{|c|}{ 2001-2002 } & \multicolumn{2}{|c|}{$2003-2007$} & \multirow[b]{2}{*}{$p$} \\
\hline & $\begin{array}{l}\mathrm{N}^{\circ} \text { cepas } \\
\text { testeadas }\end{array}$ & $\% \mathrm{R}^{*}$ & $\begin{array}{l}\mathrm{N}^{\circ} \text { cepas } \\
\text { testeadas }\end{array}$ & $\% \mathrm{R}^{*}$ & \\
\hline $\mathrm{SARM}^{\dagger}$ & 25 & 56 & 16 & 13 & 0,01 \\
\hline E. coli resistente CEF $3^{\mathrm{a}} \mathrm{G}^{\ddagger}$ & 21 & 0 & 22 & 5 & 0,98 \\
\hline E. coli resistente $\mathrm{FQ}^{\S}$ & 23 & 9 & 23 & 22 & 0,41 \\
\hline $\begin{array}{l}\text { P. aeruginosa resistente } \\
\text { Ceftazidima }\end{array}$ & 16 & 0 & 30 & 20 & 0,15 \\
\hline $\begin{array}{l}P \text {. aeruginosa resistente } \\
\text { Imipenem }\end{array}$ & 15 & 7 & 30 & 10 & 0,85 \\
\hline P. aeruginosa resistente $F Q^{\S}$ & 16 & 19 & 29 & 17 & 0,78 \\
\hline
\end{tabular}

En internación general, las bacterias aisladas de pacientes con infecciones hospitalarias internados en dicho servicio, y de las que se obtuvieron 10 o más aislamientos fueron S. aureus, Staphylococcus spp. coagulasa negativo, Enterococcus spp., $K$. pneumoniae, E. coli, Enterobacter spp. y P. aeruginosa. Se observó una diferencia significativa $(p=0,02)$ en la resistencia de SARM. No se efectuaron los cálculos para ERV y Enterobacter spp. resistente a Imipenem, porque fueron microorganismos de los cuales no se obtuvieron aislamientos. En la tabla 13 se exponen los resultados obtenidos. 
Tabla 13. Comparación del porcentaje de resistencia bacteriana de las cepas productoras de infecciones hospitalarias aisladas de internación general, durante los años 2001-2002 (preintervención) y 2003-2007 (posintervención). Sanatorio Adventista del Plata, Argentina.

\begin{tabular}{|c|c|c|c|c|c|}
\hline \multirow{2}{*}{$\begin{array}{l}\text { Microorganismos } \\
\text { resistentes }\end{array}$} & \multicolumn{2}{|c|}{$2001-2002$} & \multicolumn{2}{|c|}{ 2003-2007 } & \multirow[b]{2}{*}{$p$} \\
\hline & $\mathrm{N}^{\circ}$ cepas test. & $\% \mathrm{R}$ & $\mathrm{N}^{\circ}$ cepas test. & $\% \mathrm{R}^{*}$ & \\
\hline $\mathrm{SARM}^{\dagger}$ & 37 & 46 & 68 & 22 & 0,02 \\
\hline $\mathrm{SCNRM}^{\ddagger}$ & 16 & 69 & 39 & 64 & 0,99 \\
\hline E. coli resistente CEF $3^{a} \mathrm{G}^{\S}$ & 93 & 7 & 137 & 7 & 0,81 \\
\hline E. coli resistente $\mathrm{FQ}^{\|}$ & 99 & 19 & 144 & 29 & 0,11 \\
\hline $\begin{array}{l}\text { K. pneumoniae resistente } \\
\text { CEF } 3^{\text {a }} \mathrm{G}^{\S}\end{array}$ & 20 & 5 & 28 & 18 & 0,38 \\
\hline $\begin{array}{l}\text { Enterobacter spp. resistente } \\
\text { CEF } 3^{a} G^{\S}\end{array}$ & 16 & 25 & 30 & 40 & 0,49 \\
\hline $\begin{array}{l}P \text {. aeruginosa resistente } \\
\text { ceftazidima }\end{array}$ & 51 & 4 & 64 & 8 & 0,64 \\
\hline $\begin{array}{l}P \text {. aeruginosa resistente } \\
\text { imipenem }\end{array}$ & 48 & 6 & 62 & 2 & 0,44 \\
\hline$P$. aeruginosa resistente $\mathrm{FQ}^{\|}$ & 51 & 24 & 63 & 25 & 0,99 \\
\hline
\end{tabular}

* \% R: porcentaje de resistencia bacteriana; †SARM: Staphylococcus aureus resistente a meticilina; $\ddagger$ SCNRM: Staphylococcus spp. (coagulasa negativa) resistente a meticilina; E. coli: Escherichia coli; $\S$ CEF $3^{a}$ G: cefalosporinas de $3^{\mathrm{a}}$ generación; || FQ: fluoroquinolonas; K. pneumoniae: Klebsiella pneumoniae; P. aeruginosa: Pseudomonas aeruginosa

\subsection{Resultados correspondientes al objetivo IV}

Objetivo IV: Analizar la variación económica surgida como consecuencia de la aplicación de un programa de control de uso de antimicrobianos en las profilaxis quirúrgicas evaluando el gasto de antimicrobianos y el costo del desarrollo de infección del sitio quirúrgico.

\subsubsection{Gasto de antimicrobianos}

El gasto de los ATM utilizados en la PAP durante la etapa inicial fue de $\$ 2549,55 / 1000$ días de paciente, mientras que en la etapa final fue de $\$ 1822,21 / 1000$ días de paciente. En la tabla 14 se presenta el gasto, expresado en pesos, de ATM utilizados en la PAP cada 1000 días de paciente para cada grupo de ATM, en las dos etapas del estudio. 
Tabla 14. Gasto de antimicrobianos utilizados en la profilaxis antibiótica prequirúrgica por cada 1000 días paciente en las etapa inicial y final del estudio. Sanatorio Adventista del Plata, Argentina, enero de 2002 a octubre de 2003.

\begin{tabular}{|c|c|c|c|c|}
\hline \multirow[b]{2}{*}{ Antimicrobianos } & \multirow{2}{*}{$\begin{array}{c}\text { Etapa inicial } \\
\$ / 1000 \text { días de } \\
\text { paciente }\end{array}$} & \multirow{2}{*}{$\begin{array}{c}\text { Etapa final } \\
\$ / 1000 \text { días de } \\
\text { paciente }\end{array}$} & \multicolumn{2}{|c|}{ Variación } \\
\hline & & & $\begin{array}{l}\$ / 1000 \text { días } \\
\text { paciente }\end{array}$ & $(\%)$ \\
\hline $\begin{array}{l}\text { Cefalosporinas } 1^{a} \\
\text { generación }\end{array}$ & 1327,71 & 1013,62 & 314,09 & $(23,66)$ \\
\hline Gentamicina & 385,44 & 267,32 & 118,12 & $(30,65)$ \\
\hline Metronidazol & 673,72 & 365,97 & 307,75 & $(45,68)$ \\
\hline Aminopenicilinas & 162,68 & 175,59 & $-12,91$ & $(-7,93)$ \\
\hline Total & 2549,55 & 1822,21 & 727,05 & $(28,52)$ \\
\hline
\end{tabular}

Teniendo en cuenta los días paciente que hubieron en los 8 meses (abril-noviembre 2003) durante los cuales se realizó el seguimiento de las cirugías, se logró un ahorro debido al uso de ATM en la PAP de $\$ 2478,50 /$ US $\$ 779,40$.

El ahorro por uso de todos los ATM en UCl comparando los años 2001-2002 y 2003-2007 fue de $\$ 1755,84$ cada 1000 días paciente $(9,42 \%)$. En la figura 25 se presenta las diferencias que se produjeron en los costos para cada grupo de ATM .

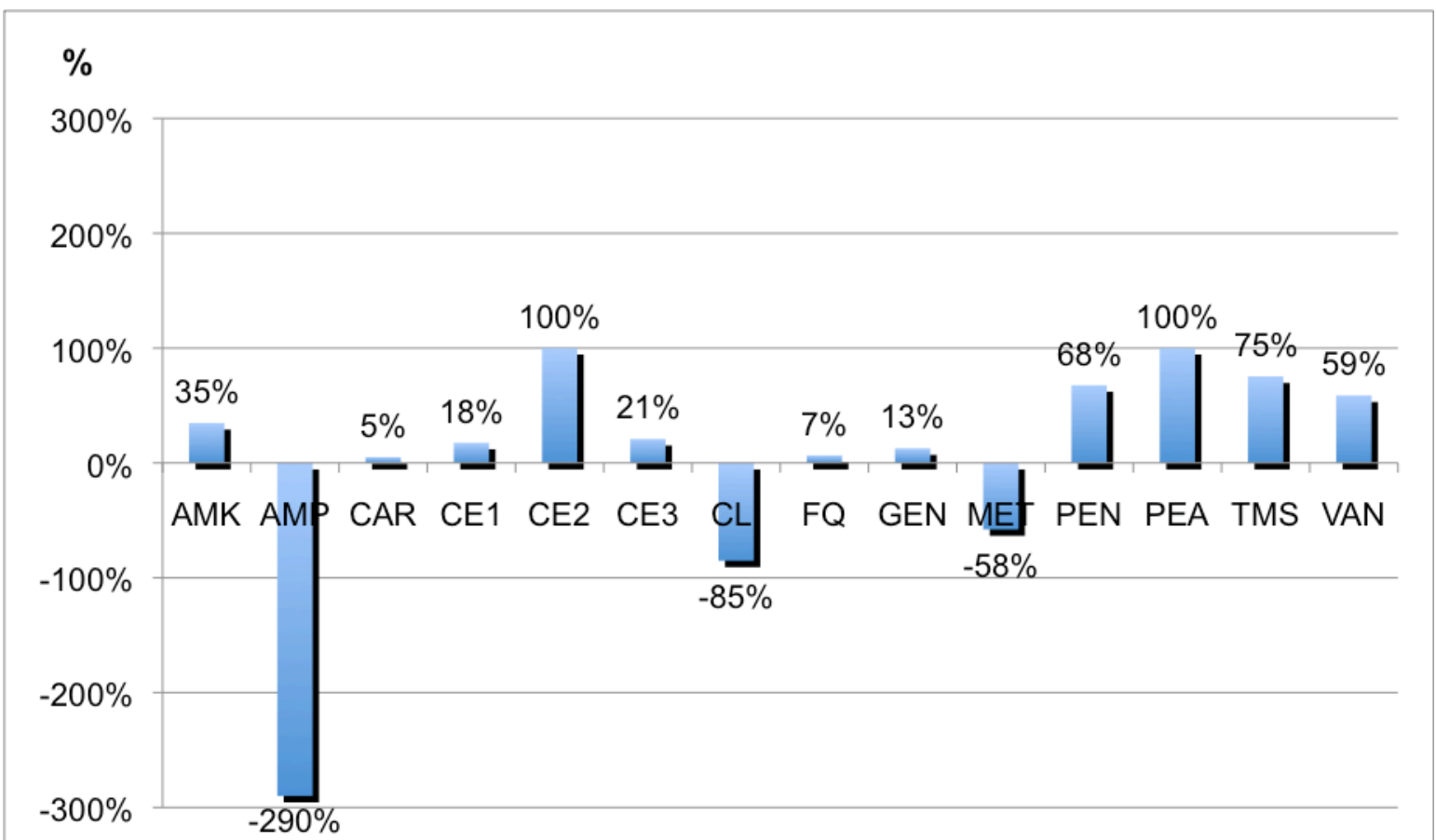

Figura 25. Porcentajes de ahorro o pérdidas debido al uso de antimicrobianos en la unidad de cuidados intensivos durante los años 2001-2002 (preintervención) y 2003-2007 (posintervención). Sanatorio Adventista del Plata, Argentina.

AMK: amikacina; AMP: aminopenicilinas; CAR: carbapenems; CE1: cefalosporinas de $1^{a}$ generación; CEF2: cefalosporinas de $2^{\mathrm{a}}$ generación; CE3: cefalosporinas de $3^{\mathrm{a}}$ generación; CLI: clindamicina; FQ: fluoroquinolonas; GEN: gentamicina; MET: metronidazol; PEN: penicilinas; PEA: penicilinas anatipseudomonas; TMS: trimetoprima-sulfametoxazol; VAN: vancomicina. 
El ahorro debido al uso de todos los ATM en internación general comparando los años $2001-2002$ y $2003-2007$ fue de $\$ 248,64$ cada 1000 días paciente $(5,49 \%)$. En la figura 26 se presenta el ahorro o el gasto extra para cada grupo de ATM.

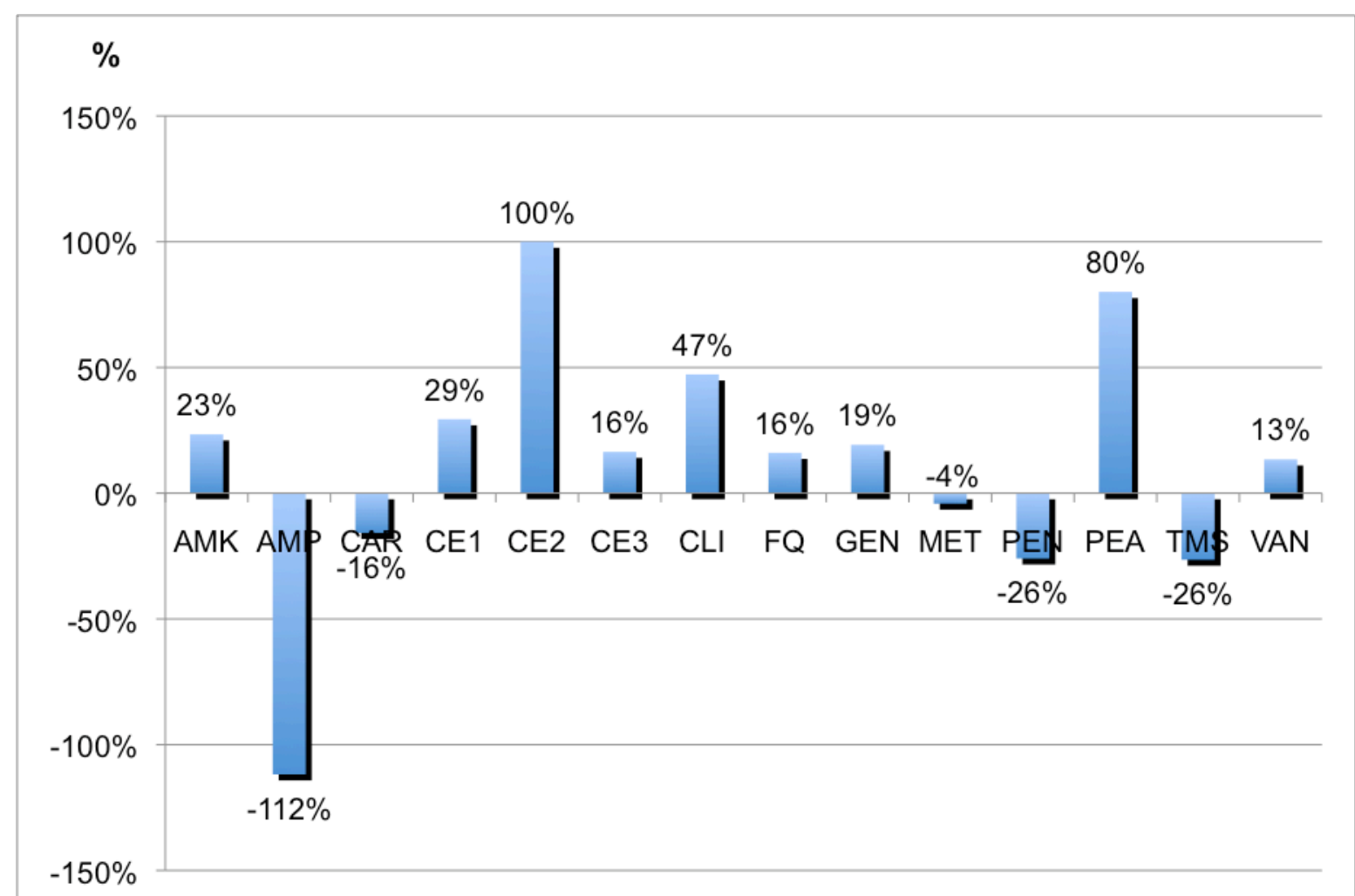

Figura 26. Porcentajes de ahorro o pérdidas debido al uso de antimicrobianos en internación general durante los años 2001-2002 (preintervención) y 2003-2007 (posintervención) expresado en $\$ / 1000$ días paciente. Sanatorio Adventista del Plata, Argentina.

AMK: amikacina; AMP: aminopenicilinas; CAR: carbapenems; CE1: cefalosporinas de $1^{\text {a }}$ generación; CEF2: cefalosporinas de $2^{\mathrm{a}}$ generación; CE3: cefalosporinas de $3^{\mathrm{a}}$ generación; CLI: clindamicina; FQ: fluoroquinolonas; GEN: gentamicina; MET: metronidazol; PEN: penicilinas; PEA: penicilinas anatipseudomonas; TMS: trimetoprima-sulfametoxazol; VAN: vancomicina.

\subsubsection{Comparación de costos directos generados por pacientes con infección del sitio quirúrgico}

En la tabla 15 se comparan los porcentajes de pareo obtenidos de los grupos de pacientes sometidos a cirugías BILI y VS con ISQ y del grupo control. Al comparar el grupo de casos con el de controles por la prueba de Mann-Whitney, no se encontraron diferencias significativas en cuanto a edad, género, diagnóstico de ingreso, ni número de diagnósticos adicionales. 
Tabla 15. Porcentaje de pareo de los pacientes sometidos a cirugía de hígado, páncreas y conductos biliares y cirugías vasculares con infección del sitio quirúrgico y del grupo control. Sanatorio Adventista del Plata, Argentina, 1998 a 2004.

\begin{tabular}{|c|c|c|c|c|c|c|}
\hline \multirow[b]{2}{*}{ Variable } & \multicolumn{3}{|c|}{ Cirugías BILI* } & \multicolumn{3}{|c|}{ Cirugías $\mathrm{VS}^{\dagger}$} \\
\hline & $\begin{array}{l}\text { Casos } \\
\mathrm{n}=10\end{array}$ & $\begin{array}{l}\text { Controles } \\
n=10\end{array}$ & $\begin{array}{c}\text { Porcentaje } \\
\text { de pareo }(\%)\end{array}$ & $\begin{array}{l}\text { Casos } \\
n=10\end{array}$ & $\begin{array}{c}\text { Controles } \\
n=10\end{array}$ & $\begin{array}{c}\text { Porcentaje de } \\
\text { pareo } \\
(\%)\end{array}$ \\
\hline Edad (+/- 10 años) & 8 & 8 & 80 & 7 & 7 & 70 \\
\hline Género & 9 & 9 & 90 & 8 & 8 & 80 \\
\hline Diagnóstico & 10 & 10 & 100 & 10 & 10 & 100 \\
\hline $\begin{array}{l}\text { Número de } \\
\text { diagnósticos }(+/-1)\end{array}$ & 10 & 10 & 100 & 10 & 10 & 100 \\
\hline
\end{tabular}

*BILI: hígado, páncreas y conductos biliares; †VS: vasculares.

\subsubsection{Cirugías de hígado, páncreas y conductos biliares}

El promedio de estancia hospitalaria de los pacientes con ISQ que habían sido sometidos a este tipo de cirugía fue de 21,3 días, mientras que en el grupo control fue de 5,1 días. Asimismo, los casos usaron 4,3 veces la cantidad de DDD de ATM con respecto los controles (29,8 y 6,9 DDD respectivamente). Se efectuaron cuatro veces más exámenes bacteriológicos a los pacientes que presentaron infección (Tabla 16).

El costo adicional por concepto de días-cama representó el $82 \%$ del costo total en exceso, y el uso de ATM el 15\%. Además, en los casos hubo tres reintervenciones mientras que en los controles ninguna.

Tabla 16. Costo en exceso de la infección del sitio quirúrgico asociadas a cirugías de hígado, páncreas y conductos biliares. Comparación de los promedios de días de hospitalización, gasto de antimicrobianos y número de cultivos en casos y controles. Sanatorio Adventista del Plata, Argentina, 1998 a 2004.

\begin{tabular}{|c|c|c|c|c|c|c|c|}
\hline \multirow[t]{2}{*}{ Variable } & \multicolumn{2}{|c|}{ Casos (a) } & \multicolumn{2}{|c|}{ Controles (b) } & \multirow{2}{*}{$\begin{array}{c}\text { Exces } \\
0 \\
(a-b)\end{array}$} & \multicolumn{2}{|c|}{$\begin{array}{l}\text { Costo del } \\
\text { exceso }\end{array}$} \\
\hline & Media & $\left(\mathrm{DS}^{\dagger}\right)$ & Media & $\left(\mathrm{DS}^{\dagger}\right)$ & & $\$$ & $(\%)$ \\
\hline $\begin{array}{l}\text { Días hospitalización en } \\
\text { internación general* }\end{array}$ & 17,3 & $( \pm 11,3)$ & 4,7 & $( \pm 1,6)$ & 12,6 & 1085,11 & $(90,00)$ \\
\hline $\begin{array}{l}\text { Días hospitalización en } \\
\mathrm{UCI}^{\ddagger *}\end{array}$ & 4,0 & $( \pm 4,4)$ & 0,4 & $( \pm 0,7)$ & 3,6 & 1655,32 & $(72,83)$ \\
\hline Cultivos microbiológicos* & 4,0 & $( \pm 3,3)$ & 0,0 & & 4,0 & 87,20 & $(100,00)$ \\
\hline Antimicrobianos $\left(\mathrm{DDD}^{\S}\right)^{*}$ & 29,8 & $( \pm 23,4)$ & 6,9 & $( \pm 4,8)$ & 22,9 & 509,10 & $(90,34)$ \\
\hline Total del costo en exceso & & & & & & 3336,73 & $(83,84)$ \\
\hline
\end{tabular}

* $p<0,05$; † DS: desvío estándar; † UCl: unidad de cuidados intensivos; §: DDD: dosis diarias definidas. 


\subsubsection{Cirugías vasculares}

Los casos de ISQ asociados a cirugías VS requirieron, en promedio, 10,7 días de internación, o sea, 3,2 veces la cantidad de días de hospitalización del grupo control (3,3 días). Además, en los casos se gastó 2,4 veces más DDD de ATM y se realizaron 1,6 veces más cultivos (Tabla 17).

El costo adicional por concepto de días-cama representó el $95 \%$ del costo total en exceso, y el uso de ATM el 3\%. También cabe mencionar que entre los casos hubo tres reintervenciones mientras que ninguna en el grupo control.

Tabla 17. Costo en exceso de las infecciones del sitio quirúrgico asociadas a cirugías vasculares. Comparación de los promedios de días de hospitalización, gasto de antimicrobianos y número de cultivos en casos y controles. Sanatorio Adventista del Plata, Argentina, 1998 a 2004.

\begin{tabular}{|c|c|c|c|c|c|c|c|}
\hline \multirow[t]{2}{*}{ Variable } & \multicolumn{2}{|c|}{ Casos (a) } & \multicolumn{2}{|c|}{ Controles (b) } & \multirow{2}{*}{$\begin{array}{c}\text { Exceso } \\
(a-b)\end{array}$} & \multicolumn{2}{|c|}{$\begin{array}{l}\text { Costo del } \\
\text { exceso }\end{array}$} \\
\hline & Media & (DS) & Media & (DS) & & $\$$ & $(\%)$ \\
\hline $\begin{array}{l}\text { Días hospitalización en } \\
\text { internación general* }\end{array}$ & 6,8 & $( \pm 6,4)$ & 2,5 & $( \pm 1,3)$ & 4,3 & 370,32 & $(79,49)$ \\
\hline $\begin{array}{l}\text { Días hospitalización en } \\
\mathrm{UCI}^{\dagger *}\end{array}$ & 3,9 & $( \pm 5,3)$ & 0,8 & $( \pm 0,6)$ & 3,1 & 1425,41 & $(63,24)$ \\
\hline Cultivos microbiológicos & 1,6 & $( \pm 2,5)$ & 0,0 & & 1,6 & 34,88 & $(100,00)$ \\
\hline Antimicrobianos $\left(D^{\prime} D^{\ddagger}\right)$ * & 9,2 & $( \pm 10,5)$ & 3,9 & $( \pm 2,6)$ & 5,3 & 58,68 & $(69,59)$ \\
\hline Total del costo en exceso & & & & & & 1889,29 & $(75,63)$ \\
\hline
\end{tabular}

${ }^{{ } p<0,05 ; ~ † ~ U C l: ~ u n i d a d ~ d e ~ c u i d a d o s ~ i n t e n s i v o s ; ~} \ddagger$ DDD: dosis diarias definidas.

Los gastos extra ocasionados por las tres variables estudiadas dieron como resultado que por cada ISQ de una cirugía BILI, se produjo un gasto extra de $\$ 3336,73$ $(83,84 \%)$, y que para cada ISQ de una cirugía VS se produjo un gasto extra de $\$ 1889,29$ $(75,63 \%)$.

La cantidad y variedad de ATM utilizados fue mayor en los pacientes con ISQ, excepto para la cefalexina, que se utilizó más en los pacientes controles. Este mayor costo de ATM en los pacientes con ISQ de cirugías BILI y VS ocasionó que se haya gastado en forma extra $\$ 5091,00(90,34 \%)$ y $\$ 586,83(69,59 \%)$ respectivamente (Tabla 18$)$. Se debe tener en cuenta, que la tabla 18, presenta los datos absolutos del gasto de ATM para las cirugías BILI y VS, mientras que en las tablas anteriores los datos se presentaron como promedios de las 10 cirugías estudiadas para cada tipo y sus respectivos controles. 
Tabla 18. Gasto de antimicrobianos en pacientes con infección del sitio quirúrgico (casos) y los controles para cirugías de hígado, páncreas y conductos biliares y cirugías vasculares. Sanatorio Adventista del Plata, Argentina, 1998 a 2004.

\begin{tabular}{|c|c|c|c|c|c|c|c|c|c|c|}
\hline \multirow{3}{*}{ ATM $^{\ddagger}$} & \multicolumn{5}{|c|}{$\mathrm{BILI}^{*}$} & \multicolumn{5}{|c|}{$V S^{\dagger}$} \\
\hline & \multirow{2}{*}{$\begin{array}{l}\mathrm{DDD}^{\S} \\
\text { (caso) }\end{array}$} & \multirow{2}{*}{$\begin{array}{c}\mathrm{DDD}^{\S} \\
\text { (control) }\end{array}$} & \multirow{2}{*}{$\begin{array}{l}\text { Exceso } \\
\text { DDD }^{\S}\end{array}$} & \multicolumn{2}{|c|}{$\begin{array}{c}\begin{array}{c}\text { Costo del } \\
\text { exceso }\end{array} \\
\end{array}$} & \multirow{2}{*}{$\begin{array}{l}\mathrm{DDD}^{\S} \\
\text { (caso) }\end{array}$} & \multirow{2}{*}{$\begin{array}{l}\mathrm{DDD}^{\S} \\
\text { (control) }\end{array}$} & \multirow{2}{*}{$\begin{array}{l}\text { Exceso } \\
\text { DDD }^{\S}\end{array}$} & \multicolumn{2}{|c|}{$\begin{array}{c}\text { Costo del } \\
\text { exceso }\end{array}$} \\
\hline & & & & $\$$ & $\%$ & & & & $\$$ & $\%$ \\
\hline Amikacina & 0,5 & 0,0 & 0,5 & 4,41 & 100,00 & 17,0 & 0,0 & 17 & 149,90 & 100,00 \\
\hline Amoxicilina IV & 6,3 & 0,0 & 6,3 & 75,96 & 100,00 & 0,0 & 0,0 & 0,0 & 0,00 & 0,00 \\
\hline $\begin{array}{l}\text { Amoxicilina / } \\
\text { clavulánico VO }\end{array}$ & 4,0 & 0,0 & 4,0 & 34,48 & 100,00 & 2,0 & 0,0 & 2,0 & 17,24 & 100,00 \\
\hline Cefalexina & 1,0 & 1,5 & $-0,5$ & $-0,93$ & $-50,00$ & 4,5 & 11 & $-6,5$ & $-12,07$ & $-144,44$ \\
\hline Cefazolina & 67,6 & 45,0 & 22,6 & 200,65 & 33,52 & 43,3 & 26 & 17,3 & 153,48 & 40,04 \\
\hline Ceftazidima & 19,0 & 0,0 & 19,0 & 258,24 & 100,00 & 13,0 & 0,0 & 13,0 & 176,69 & 100,00 \\
\hline Ceftriaxona & 12,0 & 0,0 & 12,0 & 27,45 & 100,00 & 0,0 & 0,0 & 0,0 & 0,00 & 0,00 \\
\hline Ciprofloxacina IV & 35,0 & 0,0 & 35,0 & 360,45 & 100,00 & 1,5 & 0,0 & 1,5 & 15,45 & 100,00 \\
\hline $\begin{array}{l}\text { Ciprofloxacina } \\
\text { VO }\end{array}$ & 7,5 & 0,0 & 7,5 & 5,47 & 100,00 & 3,0 & 0,0 & 3,0 & 2,19 & 100,00 \\
\hline Clindamicina IV & 26 & 0,0 & 26,0 & 275,81 & 100,00 & 0,0 & 0,0 & 0,0 & 0,00 & 0,00 \\
\hline Gentamicina & 31,7 & 10,0 & 21,7 & 97,64 & 68,42 & 5,0 & 2 & 3,0 & 9,25 & 60,00 \\
\hline Imipenem & 14,0 & 0,0 & 14,0 & 3124,94 & 100,00 & 0,0 & 0,0 & 0,0 & 0,00 & 0,00 \\
\hline Metronidazol IV & 69,2 & 12,0 & 57,3 & 650,32 & 82,69 & 0,0 & 0,0 & 0,0 & 0,00 & 0,00 \\
\hline Vancomicina & 4,0 & 0,0 & 4,0 & 119,52 & 100,00 & 2,5 & 0,0 & 2,5 & 74,70 & 100,00 \\
\hline Total & 271,1 & 65,5 & 205,6 & 5091,00 & 90,34 & 91,8 & 39 & 52,8 & 586,83 & 69,59 \\
\hline
\end{tabular}

*BILI: cirugías de hígado, páncreas y conductos biliares; †VS: cirugías vasculares: $\ddagger$ ATM: antimicrobianos; $\S$ DDD: dosis diaria definida.

Si se considera el total de los 10 casos de infección estudiados para cada tipo de cirugía, el hospital asumió un costo extra de $\$ 33.367,30(83,84 \%)$ en relación con las cirugías BILI, y $\$ 18.892,90(75,63 \%)$ por las infecciones de herida de cirugía VS.

\subsection{Resultados correspondientes al objetivo V}

Objetivo V: Conocer la relación clonal entre las cepas de Staphylococcus aureus resistente a la meticilina aisladas de pacientes con infecciones adquiridas en el Sanatorio Adventista del Plata.

En la tabla 19 se presentan los resultados fenotípicos y genotípicos de las cepas de SARM obtenidos de pacientes con infecciones adquiridas en el hospital. En total se 
analizaron 6 aislamientos, obteniéndose 4 clones. En la tabla 19, cada letra corresponde a un clon.

Tabla 19. Caracterización feno y genotípica de los aislamientos de Staphylococcus aureus resistente a la meticilina incluidos en este estudio. Sanatorio Adventista del Plata, Argentina.

\begin{tabular}{|c|c|c|c|c|}
\hline Cepas & Fecha & $\begin{array}{l}\text { OD- } \\
\text { PCR }^{*}\end{array}$ & Material & Antibiotipo \\
\hline $1236-04$ & $20 / 05 / 2004$ & A & $\begin{array}{l}\text { Herida quirúrgica } \\
\text { abdominal }\end{array}$ & $\begin{array}{l}\mathrm{S}^{\dagger}: \text { gen-cip-rfa-van-tms-tei-min } \\
\mathrm{R}^{\ddagger} \text { : oxa- cli-eri }\end{array}$ \\
\hline $94159-06$ & $22 / 06 / 2006$ & G & Orina & $\begin{array}{l}S^{\dagger}: \text { cip-van- tms-tei-min-eri-cli-rfa } \\
\mathrm{R}^{\ddagger} \text { : oxa-fox-gen }\end{array}$ \\
\hline 74016-06 & 03/07/2006 & $\mathrm{H}$ & Prótesis de cadera & $\begin{array}{l}S^{\dagger} \text { : eri-cli-rfa-van-tms -tei-min } R^{\ddagger} \text { : } \\
\text { oxa-gen-fox-cip }\end{array}$ \\
\hline 74161-06 & $17 / 07 / 2006$ & $\mathrm{H}$ & Hemocultivo & $\begin{array}{l}\mathrm{S}^{\dagger} \text { : rfa-van-tms-tei-min } \mathrm{R}^{\ddagger} \text { : oxa- } \\
\text { gen-eri-cip-cli-fox }\end{array}$ \\
\hline 114383-06 & $24 / 10 / 2006$ & $\mathrm{D}$ & Herida quirúrgica pierna & $\begin{array}{l}S^{\dagger} \text { : rfa-van-tei- min-tms } R^{\ddagger} \text { : oxa- } \\
\text { gen-eri-cip-cli-fox }\end{array}$ \\
\hline $34131-07$ & $12 / 03 / 2007$ & A & Secreción columna & $\begin{array}{l}S^{\dagger} \text { : gen-eri-tms-cip-cli-rfa-van-tei- } \\
\min R^{\ddagger} \text { : oxa-fox }\end{array}$ \\
\hline
\end{tabular}

*OD-PCR: reacción en cadena de la polimerasa con oligonucleótidos degenerados; † S: sensible; † R: resistente; ams: ampicilina-sulbactam; cef: cefalotina; oxa: oxacilina; gen: gentamicina, eri: eritromicina; tms: trimetoprimasulfametoxazol; cip: ciprofloxacina; cli: clindamcina; rfa: rifampicina, van: vancomicina; tei: teicoplanina; min: minociclina; fox: cefoxitina. Cada letra corresponde a un clon. 


\section{DISCUSIÓN}

Los ATM son las drogas más frecuentemente prescriptas en los hospitales, y aproximadamente la mitad corresponden a la PAP $(130,131)$. En este contexto, el uso apropiado de la profilaxis es un tema importante para el sistema de salud.

Existen múltiples estrategias que pueden aplicarse para controlar la aplicación de drogas en el hospital (132-135). En este estudio se combinó un trabajo educativo con la implementación de un formulario de uso de ATM en las profilaxis quirúrgicas y una orden de paro-automático.

La educación es una herramienta útil para favorecer el uso adecuado de ATM, ya que simplemente una restricción puede no ser bien aceptada y acatada por el médico prescriptor. Los médicos perciben que los programas para controlar el uso de ATM basados en la educación son más beneficiosos para el tratamiento del paciente y traerán más beneficios en la prescripción futura de esos fármacos (136).

Por otro lado, la educación, como única forma de intervención, puede no lograr los resultados esperados. En un estudio realizado por Ozgun y cols. en Turquía, donde se efectuó solo una intervención educativa en la PAP se vio que no se logró cambiar el uso prolongado de ATM, ni el grado de cumplimiento general de los protocolos establecidos y tampoco reducir los costos (137). Por lo tanto, el proceso de educación solo, puede ser insuficiente para alcanzar los cambios prácticos esperados.

En un estudio similar a este, realizado en el año 2006 en Nebraska, Hermsen y cols. vieron que el uso de un formulario normalizado para la profilaxis antimicrobiana en cirugía junto con la educación de médicos, farmacéuticos y enfermeros, tuvo un cumplimiento conveniente de las directrices para la prevención de las infecciones del sitio quirúrgico (138). Mejoras significativas se obtuvieron en la prescripción de un ATM adecuado para el procedimiento y la suspensión dentro de las 24 horas luego de la intervención quirúrgica. Al igual que en este estudio, aunque fue parte del proceso educativo, el momento de la administración del ATM no se trataba específicamente en el formulario y si no se había documentado, se consideró que el caso no reunía los criterios para ser considerado como aplicado dentro de la hora previa a la cirugía, lo que podría explicar el relativamente bajo número de pacientes que cumplen con este criterio (138).

En este estudio, todos los servicios obtuvieron mejores resultados en cuanto al tiempo de administración del ATM, pero el Servicio de Urología fue el único que tuvo una mejoría significativa $(p=0,05)$. El trabajo de educación en este Servicio, mejoró el tiempo de 
administración de los fármacos, aunque continúa siendo el que tiene menor adecuación a las normas establecidas. También cabe señalar, como ya fuera mencionado, que cuando no se indicaba la hora de administración del fármaco, se tomó como tiempo inadecuado, por lo que estos resultados podrían no reflejar con exactitud la realidad de la práctica.

Si consideramos todo el hospital, la elección del esquema ATM también tuvo una mejoría estadísticamente significativa $(p<0,01)$ luego de la aplicación del formulario. Los profesionales que se desempeñan en los servicios de Cirugía General, Otorrinolaringología, Traumatología y Urología fueron los que mejoraron significativamente en la elección del fármaco indicado específicamente para cada tipo de cirugía. Sin embargo, cabe mencionar que Cirugía Cardiovascular, Ginecología y Neurocirugía no presentaron cambio alguno ya que ellos venían trabajando con esquemas correctos de ATM antes de la implementación del formulario. En los primeros servicios enumerados fue de gran ayuda el trabajo educativo junto con la aplicación del formulario para lograr una mejor adherencia al esquema propuesto.

La administración prolongada de ATM en la PAP no disminuye el índice de ISQ (139). La profilaxis más breve posible, con una cefalosporina de primera o de segunda generación debe ser usada en cirugía para prevenir la ISQ sin promover el desarrollo de cepas resistentes (99). Con la aplicación del formulario y de la orden de paro-automático se obtuvo una mejoría significativa en la duración de la profilaxis. Lo mismo se observó en un trabajo realizado en Brasil, donde luego de la implementación del protocolo para la PAP, se obtuvo un aumento del número de indicaciones apropiadas de droga de $56,4 \%$ a $100 \%$, y la mejoría en la duración del ATM profiláctico aumentó de 21,9\% a 95,7\% (140).

A pesar de la evidencia, algunos servicios son aún reacios a seguir las guías de uso de ATM de espectro reducido y la profilaxis con dosis única, porque temen un aumento de la incidencia de ISQ. Muchas directrices, por lo tanto, no han encontrado una buena aplicación en la práctica diaria.

En este trabajo, la administración de los ATM en los servicios de Cirugía General y Ginecología mejoró en forma estadísticamente significativa la duración de la profilaxis. Si embargo, se observó que todavía, alrededor del 30\% de los pacientes intervenidos quirúrgicamente por el servicio de Cirugía General, tuvieron una duración inadecuada del tratamiento. Esto puede deberse a que las cirugías que involucran el intestino producen en el médico el temor de un mayor riesgo de infección, debido a que es un área colonizada con una flora bacteriana variada. Sobre esto, hay evidencia que muestra que una única dosis de ATM por vía intravenosa inmediatamente antes de la cirugía de colon es suficiente como profilaxis de la infección perioperatoria cuando se realiza la preparación adecuada (141).

La duración en la administración del ATM en la profilaxis quirúrgica por parte del 
Servicio de Otorrinolaringología a pesar de la intervención realizada, fue inadecuada (ver tabla 4). Esto se debió a que con el programa de educación sobre la PAP, los cirujanos de dicho servicio comenzaron a prescribirlos, siendo que anteriormente no consideraban el hecho de la profilaxis.

Neurocirugía y Cirugía Cardiovascular tuvieron un cumplimiento adecuado del esquema ATM utilizado; sin embargo, la duración de la profilaxis fue prolongada, debido a que la mayoría de las cirugías son de alto riesgo, por lo que el cirujano prefirió continuar con el ATM por más de 24 horas. En otro trabajo publicado sobre profilaxis antimicrobiana en cirugía cardiovascular, también se advirtió que en un intento de prevenir infecciones mientras los pacientes estuvieron hospitalizados, se usaba el ATM durante más tiempo del recomendado, generalmente hasta el día del alta (104).

El servicio de Traumatología también tuvo un buen cumplimiento del esquema ATM; sin embargo, hubo un uso prolongado de los mismos, debido a que el cirujano mantuvo el ATM mientras estaban colocados los drenajes. Aunque Urología presentó un progreso en cuanto al comienzo del tratamiento y al régimen de droga utilizada, utilizó la PAP durante mayor tiempo que el sugerido.

Cabe destacar que los servicios más involucrados en la educación, asistiendo a los ateneos y mostrando particular interés en la adhesión a las normas fueron Ginecología y Cirugía General; este hecho se vio reflejado en los resultados obtenidos. En un estudio donde se evaluaron los factores predictivos y el cumplimiento de las guías para prevenir la infección del sitio quirúrgico, se observó que las cirugías ginecológicas fueron un predictor independiente del cumplimiento de las directrices de la profilaxis antibiótica en los casos electivos (142). El servicio de Ginecología en el SAP está en consonancia con lo que se observa en otros lugares en relación a esta especialidad $(142,143)$.

Las cefalosporinas de primera generación fueron los ATM más utilizados en las profilaxis, lo que está en concordancia con las recomendaciones establecidas para el tipo de cirugías que se llevan a cabo en el nosocomio y además, comparable con los resultados obtenidos en otros lugares $(99,100,144)$. En la etapa final del estudio se utilizaron menos DDD cada 1000 días paciente de cefalosporinas de primera generación, gentamicina y metronidazol. Los ATM recomendados en las cirugías otorrinolaringológicas son las aminopenicilinas. Debido a que la duración de la profilaxis fue mayor en la etapa final, se utilizaron más DDD de este grupo de drogas.

La intervención realizada a través del programa para controlar la PAP no solamente disminuyó el consumo de ATM sino que además no se asoció a ningún dato que hiciera sospechar peor evolución de los pacientes, ya que se encontró un descenso estadísticamente significativo del número de ISQ. De esta manera se demostró que el uso 
excesivo de ATM no necesariamente es un uso correcto. Estos resultados están en consonancia con los obtenidos en algunos estudios donde se ha observado que mejoras en el tiempo inicial de administración, el uso del régimen apropiado de ATM y la duración de la administración adecuada llevan a una reducción del número de ISQ $(131,145,146)$.

Aunque no siempre la aplicación de una política de uso de ATM más prudente en hospitales disminuye el riesgo de ISQ, se ha demostrado que los ATM de espectro reducido son tan eficaces como los agentes de amplio espectro para la prevención de ISQ y que la profilaxis con dosis única es tan efectiva como profilaxis de dosis múltiples (147).

En los hospitales es crucial desarrollar proyectos integrales enfocados a mejorar la prescripción de ATM, reducir la incidencia y la propagación de las infecciones asociadas al cuidado de la salud, y vincular la terapéutica y las decisiones de suministro de drogas.

En este trabajo se encontró que UCl es el Servicio que más utiliza ATM si se lo compara con las áreas de internación general. Esta información surge del análisis de los datos sobre los ATM utilizados en el hospital desde 2001 hasta 2007. Estos resultados coinciden con la bibliografía consultada que presentan esta situación como característica típica del empleo de estos fármacos en el hospital (148). En un estudio realizado por la Escuela de Medicina de la Universidad de Washington (Washington University School of Medicine) en 2001 se mostró que en el $70 \%$ de los días de internación en la UCl el paciente recibe ATM, y los que permanecen en internación general los reciben en al menos el $40 \%$ de sus días de internación (149).

Las cefalosporinas de primera y de tercera generación fueron los ATM usados habitualmente en la $\mathrm{UCI}$, mientras que en internación general fueron las cefalosporinas de primera generación, aminopenicilinas, metronidazol y la gentamicina, que son los más frecuentemente utilizados en la profilaxis prequirúrgica. Las cefalosporinas de primera generación se usaron con mayor frecuencia en ambas áreas del hospital, siendo esta una característica de los hospitales médico-quirúrgicos (150).

Como es de esperar, no todos los hospitales tienen el mismo patrón de gastos de ATM, y en general, el mayor consumo se observa en las instituciones que carecen de programas activos de control de su uso (151). El proyecto ICARE, reveló la existencia de sorprendentes diferencias en los patrones de empleo de ATM y de resistencia bacteriana entre los hospitales (150). Esto mismo se observó en un trabajo realizado en 35 unidades de cuidados intensivos de Alemania, donde se encontró que los ATM prescriptos variaba según el tipo de UCI (152). Aunque los datos del proyecto ICARE fueron publicados en el año 1999, en este trabajo fueron utilizados para comparar el uso de ATM, ya que se aplicó la misma metodología para la recolección y el análisis de los resultados. Si comparamos los datos obtenidos en la UCI de esta investigación, con los publicados por el proyecto ICARE 
para una $\mathrm{UCI}$ médico-quirúrgica, hubo un menor uso de TMS y vancomicina; un empleo similar de aminopenicilinas, carbapenems, cefalosporinas de tercera generación y fluoroquinolonas; y mayor utilización de cefalosporinas de primera generación y penicilina (150).

En internación general, en comparación con los datos publicados del proyecto ICARE, hubo un empleo similar de DDD cada 1000 días paciente en el grupo de las penicilinas, y una menor utilización de aminopenicilinas, carbapenems, cefalosporinas de primera y de tercera generación, fluoroquinolonas, trimetoprima-sulfametoxazol y vancomicina (150). El menor uso de vancomicina en nuestro hospital se puede deber a que es un ATM de uso restringido, que se administra sólo con la autorización de auditoria médica, y en el proyecto ICARE, sólo en el $20 \%$ de los hospitales, su uso estaba restringido (151).

Algunos ATM como amikacina, gentamicina, clindamicina y metronidazol no se los pudo comparar porque no están dentro de los ATM vigilados por el proyecto ICARE, sin embargo, son muy utilizados en el SAP por lo que se los monitoreó para poder tener un control de su uso.

Es de esperar que haya una variación en la indicación de ATM a lo largo de los años debido a diferentes causas. Entre ellas se pueden mencionar variaciones en la resistencia bacteriana que llevan a modificar los protocolos terapéuticos, modificaciones en el formulario fármaco-terapéutico del hospital, medidas de control en la prescripción de ATM. Como mencionan Avorn y Solomon (153), muchos factores, además de las características del paciente o del tipo de infección, pueden influir en la prescripción de ATM. Esos factores, que pueden ser culturales o económicos son difíciles de determinar en un estudio de empleo de ATM .

Los datos de uso de ATM en UCI teniendo en cuenta la intervención realizada en el PAP, presentaron un aumento en el empleo de aminopenicilinas, clindamicina y de metronidazol y una disminución en la aplicación de penicilinas y vancomicina. No se pudo observar alguna relación entre el uso de los fármacos en $\mathrm{UCl}$ y la intervención realizada, ya que habitualmente los pacientes sometidos a una cirugía que se encuentran internados en dicha área, corresponden a cirugías complicadas, donde el médico generalmente no suspende la profilaxis.

Al considerar los resultados año a año en $\mathrm{UCl}$, se observó que hubo un aumento significativo en la utilización de aminopenicilinas. Debido a que esta droga no era controlada, se la dispensó sin autorización previa, por lo que no fue posible encontrar una explicación a este hecho. También se presentó un aumento en el empleo de cefalosporinas de tercera generación lo cual podría deberse a que como los pacientes de este sector presentaban 
estados críticos y generalmente estaban internados varios días, había una tendencia mayor a prescribir esta droga para el tratamiento empírico de la infección. La gentamicina y la penicilina presentaron una disminución en su uso. En el caso de la gentamicina, esta variación se observa en el año 2002, cuando se comenzó a trabajar sobre la educación en la administración de la PAP, y se presentó una tendencia a disminuir su prescripción. En el caso de la penicilina, este fenómeno podría deberse a que, en la actualidad, ha sido suplantada por las aminopenicilinas.

Como ya fuera mencionado, las cefalosporinas de primera generación son los ATM utilizados frecuentemente en las profilaxis prequirúrgicas, estando esto en concordancia con las recomendaciones establecidas para el tipo de cirugías que se llevaron a cabo en el nosocomio. El hecho que en el año 2003 se aplicó el programa de control de las PAP se vio reflejado en una disminución significativa del uso de cefalosporinas de $1^{\circ}$ generación en internación general, siendo este ATM el empleado normalmente en cirugía, y a una disminución de la administración de metronidazol. Así mismo, en cirugía general y en otorrinolaringología, la estandarización de los protocolos de profilaxis quirúrgica llevó a un aumento en el uso de aminopenicilinas.

Al comparar los resultados del empleo de ATM en internación general año a año, se observó que existió una disminución significativa en la administración de amikacina, cefalosporinas de $1^{\circ}$ generación, clindamicina, fluoroquinolonas y gentamicina. En el caso de la amikacina y las fluoroquinolonas, aunque son drogas controladas, no se pudo conocer la razón de esta variación en la prescripción. La disminución en la utilización de cefalosporinas de $1^{\circ}$ generación, clindamicina y gentamicina, y el aumento en la utilización de aminopenicilinas, generalmente están relacionados al año 2002 y 2003 cuando se realizó la intervención en la PAP. La trimetoprima-sulfametoxazol tuvo un aumento significativo en la demanda en el año 2006 como consecuencia de la incorporación del médico infectólogo a la institución. En el caso de la vancomicina, no se pudo determinar la razón del aumento en su prescripción.

La disminución significativa en la administración de fluoroquinolonas es un aspecto importante para destacar ya que se ha visto que el uso de este grupo de fármacos se ha asociado con la infección y colonización por SARM (154), mayor resistencia entre enterobacterias y $P$. aeruginosa (155) y también infecciones causadas por otras bacterias como C. difficile (156). De ahí la importancia de prescribir las fluoroquinolonas en forma más selectiva, indicando otros agentes ATM cuando es adecuado, como puede ser, en pacientes con infecciones del tracto urinario causadas por patógenos sensibles a trimetoprimasulfametoxazol, o para pacientes que tienen infecciones intraabdominales para quienes podría considerarse la aplicación de un betalactámico/inhibidor de la betalactamasa. 
La reducción en el empleo de aminoglucósidos observada en los años 2002 y 2007 en UCl, y a partir del año 2002 en internación general, aunque con escasa trascendencia en el gasto, es de significativa importancia, teniendo en cuenta que frecuentemente los pacientes manifiestan deterioro de la función renal o que se los utiliza en casos en los que los aminoglucósidos no suelen estar indicados (157). Además, presentan un riesgo potencial de nefrotoxicidad y ototoxicidad (158).

Se debe mencionar que en el año 2004 se ingresó al formulario fármacoterapéutico del hospital la ampicilina-sulbactama, para el tratamiento de la neumonía adquirida en la comunidad, lo que también pudo implicar un gradual aumento de la administración de aminopenicilinas y una disminución del uso de cefalosporinas de tercera generación en internación general.

Aunque es difícil establecer relaciones causales, debido a que múltiples factores contribuyen al desarrollo y la persistencia de la resistencia a los ATM, los programas de administración adecuada de ATM tienen el potencial de limitar la aparición y propagación de agentes patógenos resistentes. Estos programas tienen como objetivo reducir la presión de selección que ejercen los ATM, y que se ha demostrado que promueven el desarrollo de la resistencia (159).

Para muchos microorganismos frecuentemente aislados de infecciones asociadas al cuidado de la salud, la resistencia tiende a estar enfocada en la UCl (160). En este trabajo, el porcentaje de resistencia bacteriana no presenta diferencia según el área de internación. Un alto grado de uso de ATM en UCI no está en paralelo con valores más elevados de resistencia bacteriana en dicha área, como se había observado en el proyecto ICARE en Estados Unidos (46). Esto sugiere que otros factores, como pueden ser la transmisión cruzada y las medidas de control de infecciones, juegan un rol importante en la propagación de estos microorganismos.

Las bacterias resistentes de mayor frecuencia en la UCl fueron SARM, $P$. aeruginosa resistente a ceftazidima y a fluoroquinolonas, y $E$. coli resistente a fluoroquinolonas.

Los patrones de resistencia fueron un poco diferentes en internación general, donde las bacterias resistentes predominantes fueron Staphylococcus spp. (coagulasa negativo) resistente a meticilina, especies de Enterobacter resistentes a cefalosporinas de tercera generación, $P$. aeruginosa resistente a fluoroquinolonas, SARM y Escherichia coli resistente a fluoroquinolonas.

Al comparar los datos de resistencia bacteriana de $\mathrm{UCl}$ con los publicados por el proyecto ICARE, se observaron valores de resistencia similares para SARM y $P$. aeruginosa resistente a imipenem. La resistencia encontrada en este estudio es más baja para ERV y $S$. 
pneumoniae resistente a penicilina, pero más elevada para el resto de las bacterias estudiadas (151).

En internación general se presentó una situación similar. Los valores de resistencia fueron comparables a los expuestos por el proyecto ICARE para SARM y $P$. aeruginosa resistente a ceftazidima. Es más baja para ERV y $P$. aeruginosa resistente a imipenem, pero fue más alta para el resto de las bacterias estudiadas (150).

SARM es un patógeno nosocomial frecuente. Llama la atención la disminución temporal en el número de aislamientos de esta bacteria durante el transcurso del estudio debido a que esto difiere con lo que dice la literatura internacional y también de nuestro país, en la que habitualmente se insiste en el aumento del número de aislamientos de SARM (161-164).

En el Informe Anual de la Red de Monitoreo/Vigilancia de la Resistencia a los Antibióticos -2004- publicado por la OPS, se comunicó que en Argentina, la proporción de S. aureus resistente a la oxacilina fue de $42 \%$ (165). Tres años más tarde, el mismo programa informó que el $45 \%$ de los aislamientos de $S$. aureus fueron resistentes a oxacilina y presentaron una elevada multirresistencia acompañante (166).

Muchos estudios han notificado sobre la contribución del uso de ATM en la colonización o infección de pacientes por SARM (167-169). Cuando se toma en cuenta el uso de ATM por grupo farmacológico en forma separada, las cefalosporinas y las fluoroquinolonas son frecuentemente identificadas como factores de riesgo para el aumento de SARM (167-169). En esta investigación, se observó una disminución en el porcentaje de SARM y una disminución significativa del empleo de cefalosporinas de primera generación, fluoroquinolonas y clindamicina en internación general. De la misma manera, un descenso en la incidencia de pacientes con cultivos positivos de SARM (44\% al 41\%) se observó luego de la aplicación, durante 2 años, del programa nacional de restricción de antibióticos en Turquía (170).

Aunque la mayoría de los aislamientos de SARM son resistentes a la combinación de antibiótico más inhibidor de la beta-lactamasa, inhibiendo el efecto de las penicilinasas se restablece mucha de la actividad de la ampicilina. Por lo tanto, la colonización con SARM puede ocurrir con menos frecuencia en pacientes que reciben un betalactámico/inhibidor de la betalactamasa que uno recibiendo cefalosporinas (169). Las instituciones que desean disminuir la incidencia infecciones causadas por este patógeno deben controlar cuidadosamente los patrones de uso de ATM con el fin de prescribir menos cefalosporinas y enfatizar el uso de betalactámicos más inhibidores de la betalactamasa.

También cabe mencionar que la colonización por SARM en el momento de la admisión es el factor de riesgo independiente más fuerte para el desarrollo de infección por 
dicho microorganismo. Ser sometido a una intervención quirúrgica, haber recibido corticoides sistémicos y sufrir de úlcera péptica son otros factores de riesgo para el desarrollo de resistencia no relacionados con el uso de ATM (154).

Durante el transcurso de los años en que se realizó el estudio no se aislaron ERV. Esto puede estar influenciado por el hecho de que la vancomicina es de uso restringido. Sin embargo, se ha visto que la aparición de ERV se asocia no solo al uso de este antibiótico, sino también al de cefalosporinas de tercera generación, metronidazol e incluso quinolonas $(171,172)$. De ahí la importancia del empleo racional de todos los ATM.

En este trabajo no se observó variación significativa en los valores de resistencia de $P$. aeruginosa en los dos períodos estudiados, pero llama la atención la elevada resistencia a las fluoroquinolonas. $P$. aeruginosa es un patógeno oportunista que es responsable de una proporción significativa de infecciones adquiridas en el hospital, y que generalmente son difíciles de erradicar. En un estudio realizado para identificar factores de riesgo para adquirir $P$. aeruginosa resistente a múltiples medicamentos en pacientes internados en $\mathrm{UCl}$ durante un período de dos años, los datos demostraron que el uso de ATM con una elevada actividad antipseudomonas, particularmente ciprofloxacina, fue un factor de riesgo independiente para seleccionar $P$. aeruginosa resistente a múltiples medicamentos. Los autores sugieren que "si se necesita un tratamiento con un antibiótico activo contra (otra) bacteria gramnegativa, se deben preferir los agentes con poca actividad antipseudomonas sobre aquellos con actividad antipseudomonas específica para limitar el surgimiento de $P$. aeruginosa resistente a múltiples medicamentos" (173).

Se puede establecer un paralelismo entre el elevado uso de ATM en la UCl y el elevado porcentaje de resistencia observado en dicha área de internación para especies de Staphylococcus y cefalosporinas de primera generación, $P$. aeruginosa y cefalosporinas de tercera generación, y especies de Enterobacter y $P$. aeruginosa e imipenem. Una correlación significativa entre los porcentajes de Staphylococcus spp. (coagulasa negativo) resistente a la meticilina y el empleo de betalactámicos y gentamicina también fue observada en un trabajo realizado en cuatro hospitales de Holanda en el año 1990 (174).

En otros casos, aunque la utilización de ATM fue más elevada en la $\mathrm{UCl}$, los valores de resistencia fueron iguales que en internación general. Por ejemplo, la administración de fluoroquinolonas fue más elevada en $\mathrm{UCl}$, pero el porcentaje de $E$. coli o $P$. aeruginosa resistentes a fluoroquinolonas entre las distintas áreas de internación fue similar. No obstante, en un trabajo realizado por Cristino y cols. en el año 1999, en Portugal, se reportó que haber recibido previamente fluoroquinolonas fue el único factor de riesgo para el posterior surgimiento de $P$. aeruginosa resistente a fluoroquinolonas (175). El incremento en el uso de fluoroquinolonas y aminoglucósidos se ha asociado con un 
incremento en el número de aislamientos de $P$. aeruginosa y enterobacterias resistentes (155).

Un aspecto alarmante que se observa en el presente estudio es la actividad disminuida de la ciprofloxacina. La disminución de la actividad de la ciprofloxacina se ha correlacionado con un aumento mayor al $2,5 \%$ en el uso de fluoroquinolonas, ya que han sido comúnmente utilizadas para el tratamiento de neumonía adquirida en la comunidad, infecciones del tracto urinario e infecciones de piel y tejidos blandos en los últimos 10 años (176). Sin embargo, en este estudio, se observa una disminución en el empleo de fluoroquinolonas, que puede atribuirse a distintas causas. Por un lado, puede deberse a que la información del empleo de ATM en el hospital está sesgada debido a que en algunos casos los pacientes traen la medicación oral que estaban recibiendo al momento de la internación. Por otro lado, podría deberse a los mecanismos de resistencia de las bacterias. Se ha observado resistencia cruzada entre las distintas fluoroquinolonas; mientras que también se ha sugerido que está relacionada, fenotípicamente, la resistencia a fluoroquinolonas con la presencia de betalactamasas de espectro extendido mediada por plásmidos, de lo que se infiere que la resistencia a las fluoroquinolonas puede ser inducida por el uso de cefalosporinas, ya que la resistencia a fluoroquinolonas no se ha vinculado genéticamente con resistencia a otra clase de drogas (176). También se debe aludir al hecho de que el uso de ATM en la comunidad puede ser especialmente importante para las fluoroquinolonas ya que estas se prescriben en forma extensa en los pacientes ambulatorios, debido a que son comúnmente utilizados para muchas infecciones adquiridas en la comunidad, y esto podría tener algún efecto en los porcentajes de resistencia a nivel hospitalario (177).

La frecuencia de aislamientos de cepas de $K$. pneumoniae que tienen betalactamasas de espectro extendido ha ido aumentando a lo largo del tiempo (178). Muchos de los aislamientos en este trabajo fueron sensibles a cefalosporinas de tercera generación, sin embargo, los valores de resistencia son más altos que los presentados por el proyecto ICARE. Se ha visto que el uso previo de una cefalosporina de tercera generación es un factor de riesgo para el desarrollo de infecciones por cepas de K. pneumoniae y E. coli productoras betalactamasas de espectro extendido (179).

En este estudio, al igual que en el proyecto ICARE, se vio que el empleo de grandes cantidades de ATM no se correlacionaba necesariamente con una elevada prevalencia de resistencia (74). Esto sugiere que otros factores, como el empleo de otros medicamentos, o la transmisión cruzada, juegan un rol importante en la propagación de estos microorganismos. Se deberían realizar más estudios para correlacionar la utilización de ATM y la resistencia bacteriana en las distintas áreas de internación. 
La vigilancia de la resistencia a los ATM entre los microorganismos causantes de infecciones adquiridas en el hospital es difícil, debido a la escasez de datos apropiados acerca de varios parámetros que son relevantes para el estudio de la resistencia. Estos incluyen las diferencias entre los pacientes, validación de resultados microbiológicos, severidad de la enfermedad y exactitud de los datos de administración de ATM. Además, la aparición y la diseminación de microorganismos no ocurren solamente dentro del centro de salud. Por ejemplo, nuestro análisis no incluye o no se ajusta a posibles factores de confusión importantes como es el uso previo de ATM. Por lo tanto, el sistema de vigilancia de la resistencia antimicrobiana entre los microorganismos causantes de infecciones adquiridas en el hospital necesitaría tener en cuenta estos aspectos.

Estos datos sugieren que el seguimiento de la utilización de ATM a nivel hospitalario puede ayudar a distinguir problemas entre áreas donde su administración parece ser un factor principal en la contribución de la resistencia, de aquellas áreas donde factores como la transmisión cruzada puede necesitar mayor atención. Con información sobre el empleo de ATM y la resistencia, los grupos de trabajo en control de infecciones van a estar un paso más cerca de ganar la batalla contra la emergencia y diseminación de resistencia bacteriana en los centros de salud.

Los datos obtenidos en el presente estudio son importantes porque pueden ser usados en un proceso para mejorar la calidad de atención al paciente, al enfocar los esfuerzos en aquellas áreas donde se informa un uso excesivo de ATM. La vigilancia rutinaria de esta actividad, puede ayudar a los hospitales en la selección del objetivo para controlar las infecciones. Sin embargo, se necesitan más estudios para determinar de forma más precisa el impacto de las prácticas de control de ATM y los porcentajes de resistencia bacteriana en el área de salud.

Aunque los protocolos de control de infecciones pueden ayudar a controlar la diseminación de patógenos nosocomiales, una vez introducidos en el hospital son frecuentemente difíciles de erradicar. La aparición de algunas bacterias en particular puede estar aumentado por la presión de selección ejercida por los ATM usados en una institución. El control en el uso de ATM puede ser un método efectivo para limitar la propagación de gérmenes resistentes (170).

EI SARM fue la bacteria de la cual se obtuvieron más aislamientos en el SAP durante los años 2001 y 2002, razón por la cual se consideró importante conocer la relación clonal de los aislamientos de este microorganismo y así poder evaluar si las infecciones por esta bacteria se debían a falta de adhesión a las medidas de control de infecciones o a otra causa. 
Como presenta la literatura, dentro de las bacterias causantes de infecciones asociadas al cuidado de la salud, el SAMR es un patógeno nosocomial prevalente en muchos hospitales. Debido a que las opciones de tratamiento para las infecciones por este germen son limitadas, el conocimiento preciso de la epidemiología de estos agentes es necesario para optimizar el diagnóstico y proveer herramientas que permitan el desarrollo de esquemas terapéuticos sobre una base racional para cada institución de la salud $(180,181)$.

Esta información es muy útil, sobre todo cuando se producen brotes epidémicos, porque permite determinar el número de clones circulantes, identificar las fuente de contaminación o reservorio y los vehículos de transmisión, evaluar la eficacia de las medidas de control dirigidas a evitar la diseminación de clones y diferenciar entre infección y recidiva (182-184). La vigilancia permanente del SARM en el laboratorio y la notificación oportuna a las autoridades de salud, permitirá la aplicación de medidas adecuadas para prevenir su distribución en el medio hospitalario como también en la comunidad.

El principal reservorio de $S$. aureus es el ser humano. Las cepas SARM se introducen en el medio hospitalario a través de visitantes, trabajadores sanitarios y fundamentalmente por los pacientes ingresados que están infectados o colonizados (portan la bacteria en sus cuerpos pero aún no presentan síntomas), y se expanden a otros pacientes por infección cruzada. A medida que progresa un brote epidémico, aumenta el número de portadores nasales de SARM que constituyen, a menudo, la propia fuente de infección (185).

Las manos de los trabajadores de la salud pueden contaminarse con la bacteria SARM por el contacto con pacientes infectados o "colonizados". Si un trabajador de la salud no se lava las manos con agua y jabón o no usa un antiséptico para las manos a base de alcohol, después de estar en contacto con un enfermo, la bacteria se puede propagar cuando el trabajador toca a otros pacientes $(186,187)$.

La transmisión a través del entorno inanimado (reservorio ambiental) también puede ser digna de mención (185) así como otros factores asociados a la adquisición nosocomial de SARM como son la manipulación diagnóstico-terapéutica (catéter intravascular, sondaje vesical, intubación orotraqueal, etc.), la estancia en Unidad de Cuidados Intensivos, enfermedad grave de base, antibioticoterapia previa, estancia hospitalaria prolongada, cirugía previa o herida quirúrgica, úlceras isquémicas $(188,189)$.

En este trabajo no se observó una relación clonal entre los aislamientos de SARM que se pudieron analizar. Aunque fue un número no significativo de aislamientos, se puede inferir que los casos de infección no se deben a falta de medidas de control de infecciones relacionadas a los cuidados que debe tener el personal de la salud y que pueden favorecer 
la infección cruzada, o por la falta de limpieza ambiental, sino a otras causas como podrían ser el uso inadecuado de los ATM (189).

La implementación de un programa para controlar el uso de ATM puede o no ser efectiva desde el punto de vista de los costos (190). En este caso, en la etapa final del estudio se utilizaron menos DDD cada 1000 días paciente de cefalosporinas de primera generación, gentamicina y metronidazol; aunque hubo un aumento en el uso de aminopenicilinas, igualmente se obtuvo un importante ahorro económico.

En un trabajo similar realizado en Brasil, se consiguió una reducción del 40,5\% en los costos de la profilaxis antibiótica (140). En este trabajo, se logró una reducción de los costos del $28,52 \%$, lo que llevó en 8 meses a un ahorro en empleo de ATM de \$2478,50.

A lo largo de los 7 años de seguimiento en el uso de ATM, se logró una disminución de los costos ocasionados por el uso de dichos fármacos del 9,42\% en la $\mathrm{UCl}$ y del $5,49 \%$ en internación general. Cabe mencionar que además del costo correspondiente al medicamento, también se lograron ahorros en la cantidad de jeringas, agujas y soluciones parenterales necesarias para aplicarlo. También se puede señalar el tiempo de enfermería dedicado a la administración del ATM, las pérdidas causadas por roturas accidentales y los posibles efectos adversos de los medicamentos.

Además, cuando se aplicó el programa de control de la PAP se observó una disminución del $55 \%$ en el número de pacientes con ISQ. El cálculo de costo de cualquier complicación ocurrida durante el tratamiento del paciente proporciona una indicación del ahorro potencial que se podría conseguir invirtiendo en programas de control de infecciones.

Uno de los factores determinantes de la calidad asistencial es el control de las infecciones asociadas al cuidado de la salud. Este problema tiene un gran impacto clínico que repercute significativamente en el costo de la asistencia sanitaria.

Recordando los conceptos ya mencionados, la evaluación del costo de las infecciones nosocomiales es compleja. Los costos directos componen uno de los aspectos para considerar ya que pueden asignarse de manera objetiva a cada paciente. Son aquellos que se hallan directamente relacionados con el sistema de atención sanitaria, que corresponden al consumo de materiales y la mano de obra (especialidades farmacéuticas, estudios, estadía hospitalaria, etc.). Los costos indirectos son los que se asocian a la repercusión que sufre el paciente a consecuencia del tiempo que le quita la enfermedad.

Para el presente estudio se evaluaron únicamente los costos directos debido a tres variables que representan solo una parte mínima del costo real de las infecciones intrahospitalarias. Además, se evaluaron solo dos categorías de cirugías, las BILI y las VS, ya que se ha observado que el impacto negativo de la ISQ difiere grandemente para los 
distintos tipos de cirugía, por lo que es importante medir el impacto para categorías definidas más que para la ISQ en forma general (191).

En este trabajo puede haber un sesgo de selección como resultado de la extensión del período de estudio. Sin embargo, como ya se mencionara, en todos los casos el control se seleccionó para el mismo período de internación que el caso infectado, y cuando se encontró más de un control para un caso determinado, la selección se hizo al azar.

En otros estudios se ha visto que los pacientes con ISQ tienen una duración de internación en la $\mathrm{UCl}$ y en el piso general significativamente más prolongada, con mayor número de reintervenciones $\mathrm{y}$, por ende, con costos más elevados y mayor índice de mortalidad (192-194). En el presente trabajo se observó que la presencia de ISQ lleva a una prolongación de la estancia hospitalaria de aproximadamente dos semanas en las cirugías BILI y de una semana en cirugías VS. Es interesante notar que la duración de la internación es un componente importante del costo; en este caso corresponden al $77 \%$ del costo en las infecciones de cirugías BILI y del $94 \%$ en las VS.

Como era esperable, la cantidad y variedad de ATM administrados en los pacientes con ISQ fueron mayores que en los utilizadas por los controles, excepto para la cefalexina, debido a que es el ATM habitualmente utilizado en la profilaxis antibiótica luego de la cirugía. Esto, además de aumentar los costos de la internación para cirugías BILI y VS en un promedio de $\$ 509,10(90,34 \%)$ y $\$ 58,68$ (69,59\%) respectivamente, puede llevar a la aparición de reacciones adversas a los medicamentos y al desarrollo de cepas resistentes a esos fármacos. Los resultados económicos atribuibles a la ISQ demostraron que la infección con bacterias multirresistentes incrementan los costos hospitalarios y tienen un alto riesgo de mortalidad (194).

Debido a que se prolongan los días de internación, y a la presencia de las infecciones, aumentan la cantidad de cultivos bacteriológicos que hay que realizar, lo que genera un gasto adicional, en este caso de $\$ 87,20$ y $\$ 34,88$ por cada ISQ en cirugías BILI y VS respectivamente.

En este estudio en ningún caso hubo relación entre IACS y resistencia a los ATM, ya que la mayoría de los microorganismos aislados se trataba de gérmenes comensales de piel, sensibles a la mayoría de los ATM.

De esta forma se puede ver que la presencia de ISQ lleva a un aumento en los días de internación, el gasto de ATM y el número de cultivos bacteriológicos realizados, lo que produce un exceso de gasto.

Este tipo de IACS está específicamente relacionada con la técnica quirúrgica utilizada y las características endógenas del paciente (195), pero también se ha observado la reducción de la tasa de ISQ luego de la implementación de un programa de control de 
infecciones (196). Es por esto que para disminuir el impacto de las IACS es necesario contar con un Departamento de Control de Infecciones que asegure la vigilancia epidemiológica y la coordinación de actividades para el control de las infecciones, de un laboratorio de microbiología que identifique los agentes patógenos nosocomiales y de farmacia hospitalaria que controle la indicación y dispensación de ATM.

Los programas para controlar el uso de ATM dentro del hospital, generalmente tienen un impacto positivo en el costo (159). En este caso se obtuvo un ahorro no solo debido al uso de medicamentos $(28,52 \%)$, sino también a causa de la disminución del número de pacientes con ISQ. La implementación del programa para controlar la PAP, resultado de un esfuerzo multidisciplinario, fue efectivo en cuanto a los costos.

Este estudio tuvo algunas limitaciones. Al implementar el programa para controlar el uso de ATM en cirugía, tomó 6 meses el trabajo de educación al personal del sistema de salud, algunos médicos no se adhirieron a las guías, y fue una intervención que demandó mucho tiempo. Sin embargo, fue gratificante ver algunos progresos: la intervención en general logró una adecuación significativa a los protocolos de PAP, tanto en el tiempo de administración del ATM $(p=0,01)$, en el esquema ATM utilizado $(p \leq 0,01)$ como en la duración de la profilaxis $(p \leq 0,01)$. Además, hubo una disminución de los pacientes que desarrollaron ISQ (figura 12) lo que produjo un ahorro de $\$ 3336,73$ (83,84\%) por cada cirugía BILI y de $\$ 1889,29$ (75,63\%) por cada cirugía VS.

También se debe mencionar el período prolongado de tiempo durante el cual se recolectaron los datos de uso de ATM en todo el hospital y de resistencia bacteriana. Este período tan extenso fue necesario para poder obtener un número importante de bacterias de modo de realizar los cálculos de resistencia. Sin embargo, aunque en el año 2003 se implementó el programa de control de la PAP, es de esperar que se hayan suscitado otros cambios a lo largo de tantos años de seguimiento, y que no fueron controlados, como el ingreso de nuevos médicos al plantel del SAP. Estas variaciones también pueden haber contribuido a modificar los valores de empleo de ATM o los porcentajes de resistencia bacteriana.

Otras limitaciones inherentes del estudio en relación al cálculo de costos de la ISQ es que la comparación mediante apareamiento no garantiza el pleno control de posibles sesgos que podrían influir en la subestimación de los costos. Además, cabe mencionar otros factores como ciertas características de la práctica médica, del equipo quirúrgico actuante y del tipo de hospital.

No se cuantificó el tiempo de trabajo que supuso la realización del proyecto, pero, aunque requirió de tiempo y esfuerzo, no fue necesaria la incorporación de más personal ni de equipamiento específico, ya que se utilizaron los insumos presentes en el hospital. 
Sin duda existen otros beneficios del programa que no han sido cuantificados, como la simplificación y la mayor comodidad del tratamiento para los pacientes y la enfermería, la reducción en el número de días de canalización endovenosa (con su correspondiente menor riesgo de complicaciones) y los aspectos educativos sobre los prescriptores.

Este programa aplicado para la administración adecuada de la PAP tienen el potencial de reducir el uso de ATM, resistencia bacteriana, los costos de salud y los efectos adversos relacionados con la droga al tiempo que mejoran los resultados clínicos. Los esfuerzos y los gastos necesarios para implementarlos y mantenerlos son más que justificados habida cuenta de sus beneficios potenciales tanto para el hospital y como para el paciente.

En el contexto actual de necesidad en la contención del gasto farmacéutico y de honda preocupación por la progresión de la resistencia bacteriana es preciso desarrollar programas para controlar el uso de ATM en forma eficiente que aúnen la reducción del gasto y de la presión selectiva sobre los microorganismos con una mayor calidad asistencial. Los programas multidisciplinarios donde se realiza una restricción con orientación educativa constituyen, en la opinión de esta tesista, la mejor y más interesante opción.

Por último, cabe destacar que los resultados obtenidos reflejan el esfuerzo de un equipo multidisciplinario de salud para mejorar el cuidado del paciente promoviendo el uso racional de ATM en los procedimientos quirúrgicos. 


\section{CONCLUSIONES}

Se demostró que a través de la implementación del programa para controlar la PAP se logró una mejoría en el tiempo de administración del ATM y una reducción significativa del uso de dichos fármacos mediante la disminución del número de dosis administradas y del empleo del ATM indicado específicamente para el procedimiento.

Se consiguió una disminución del número de pacientes con ISQ luego de la aplicación del programa para controlar la PAP.

Las cefalosporinas fueron los ATM más frecuentemente utilizados. Se obtuvo una disminución significativa del uso de cefalosporinas de primera generación en internación general a lo largo de los años en que se realizó el estudio,

Los microorganismos identificados con más frecuencia fueron SARM, E. coli resistente a cefalosporinas de tercera generación y a fluoroquinolonas y $P$. aeruginosa resistente a ceftazidima, imipenem y fluoroquinolonas.

El programa de control de uso de ATM en las profilaxis quirúrgicas refleja un impacto económico positivo debido al menor consumo de ATM y a la disminución del desarrollo de ISQ. La presencia de ISQ conlleva a un aumento en los costos debido al aumento en los días de internación, el gasto de ATM y el número de cultivos bacteriológicos realizados.

No se encontró una relación clonal entre los aislamientos de SARM que se pudieron analizar, por lo que los casos de infección se pueden deber a otras causas que no dependen de las medidas preventivas de control de infecciones.

Este programa puede ser implementado en cualquier hospital ya que no requiere el uso de computadoras ni tecnología específica, por lo que es muy útil para favorecer el uso racional de ATM en países en vías de desarrollo.

Se manifiesta que los programas destinados al control y uso adecuado de ATM deben basar su acción en la confección de guías, el desarrollo de planes de vigilancia, la capacitación continua y el trabajo multidisciplinario entre el equipo encargado del control de uso de ATM, los servicios médicos involucrados, la farmacia del hospital y el laboratorio de microbiología. 


\section{REFERENCIAS BIBLIOGRÁFICAS}

1. Ministerio de Salud Pública, Secretaría de Políticas Regulación y Relaciones Sanitarias, Administración Nacional de Medicamentos Alimentos y Tecnología Médica, Instituto Nacional de Medicamentos. Farmacopea Argentina. Séptima ed. Buenos Aires: 2003.

2. Laborda Rodríguez F. Conceptos microbiológicos. Principios básicos de la farmacoterapia antibacteriana. En: Argentina CF, editor. Farmacología de las enfermedades infecciosas y parasitarias. Capital Federal: Alfa Beta; 2002. p. 9.

3. Madigan MT, Martinko JM, Parker J. Brock. Biología de los medicamentos. 10a ed. Madrid: Pearson Educación, S.A.; 2004.

4. Cid Ledesma E, Cid Ledesma MT, Cortés Gabaudan F, Ledesma Martín MC, Marchena M, Pedrero $\mathrm{P}$, et al. Dicciomed.es. Diccionario médico-biológico, histórico y etimológico: Ediciones Universidad de Salamanca; 2007.

5. Mosby Diccionario Medicina, Enfermería y Ciencias de la Salud. $6^{a}$ ed. Madrid: Elsevier Science; 2003. Microorganismo; p. 1031.

6. Chambers H. Quimioterapéuticos. In: Katzung B, editor. Farmacología básica y clínica. Décima ed. México: Manual Moderno; 2007. p. 751-806.

7. Nobelprize.org. Gerhard Domagk - Biography. [acceso 31 de mayo de 2011]; Disponible en: http://nobelprize.org/nobel prizes/medicine/laureates/1939/domagk-bio.html.

8. Ehrlich P. Encyclopædia Britannica.; [acceso 31 de mayo de 2011]; Disponible en: http://www.britannica.com/EBchecked/media/97130/Paul-Ehrlich.

9. Chambers H. Principios generales de la antibioticoterapia. In: Goodman, Gilman, editors. Las bases farmacológicas de la terapéutica. Undécima ed. México: Mc Graw Hill; 2006. p. 1095-109.

10. Nobelprize.org. Sir Alexander Fleming - Biography. [acceso 31 de mayo de 2011]; Disponible en: http://nobelprize.org/nobel prizes/medicine/laureates/1945/fleming.html.

11. Inventos del siglo XX: La Penicilina. [acceso 1 de junio de 2011]; Disponible en: http://inventosigloxx.blogspot.com/2008 0301 archive.html.

12. Calvo J, Martinez-Martinez L. Mecanismos de accion de los antimicrobianos. Enferm Infecc Microbiol Clin. 2009 Jan;27(1):44-52.

13. Sánchez de Rivas C. ¿Antibióticos, ayer, hoy y mañana...? Revista QuímicaViva [revista en Internet]. 2006 [acceso 15 de junio de 2011]; 2(5): Disponible en: http://www.quimicaviva.qb.fcen.uba.ar/v5n2/sanchez.html.

14. Gold HS, Moellering RC, Jr. Antimicrobial-drug resistance. N Engl J Med. 1996;335(19):1445-53.

15. Errecalde J. Uso de antimicrobianos en animales de consumo. Incidencia del desarrollo de resistencias en la salud pública. 2004 [acceso 1 de marzo de 2010]: Disponible en: http://www.fao.org/docrep/007/y5468s/y5468s00.htm\#Contents.

16. Becerra G, Plascencia A, Luévanos A, Domínguez M, Hernández I. Mecanismo de resistencia a antimicrobianos en bacterias. Enf Inf Microbiol [revista en Internet]. 2009 [acceso 18 de abril de 2011]; 29(2): Disponible en: http://www.amimc.org.mx/revista/2009/29-2/mecanismo.pdf. 
17. MacDougall C, Polk RE. Antimicrobial stewardship programs in health care systems. Clin Microbiol Rev. 2005;18(4):638-56.

18. Lederberg J, Shope RE, Oaks Jr SC. Emerging infections: microbial threats to health in the United Satates. Washington, DC: National Academy Press; 1992.

19. de Kraker ME, Davey PG, Grundmann H, BURDEN study group. Mortality and hospital stay associated with resistant Staphylococcus aureus and Escherichia coli bacteremia: estimating the burden of antibiotic resistance in Europe. PLoS Med [revista en Internet]. 2011 [acceso 15 de abril de 2012]; 8(10): Disponible en: http://www.ncbi.nlm.nih.gov/pmc/articles/PMC3191157/?tool=pubmed.

20. de Kraker ME, Wolkewitz M, Davey PG, Koller W, Berger J, Nagler J, et al. Burden of antimicrobial resistance in European hospitals: excess mortality and length of hospital stay associated with bloodstream infections due to Escherichia coli resistant to third-generation cephalosporins. J Antimicrob Chemother. 2011;66(2):398-407.

21. Smith RD, Coast J. Antimicrobial resistance: a global response. Bull World Health Organ. 2002;80(2):126-33.

22. Fishman N. Antimicrobial stewardship. Am J Med. 2006 Jun;119(6 Suppl 1):S5361;S2-70.

23. Inesta García A. Relation between medication expenses and health budget. II PanAmerHosplnfect Congr; Mar del Plata, Argentina1998.

24. McCaig LF, Hughes JM. Trends in antimicrobial drug prescribing among office-based physicians in the United States. JAMA. 1995;273(3):214-9.

25. Binyon D, Cooke RPD. Restrictive antibiotic policies - how effective are they? Hospital Pharmacist [revista en Internet]. 2000 [acceso 25 de marzo de 2010]; 7(7): Disponible

en: http://www.pharmi.com/hospital/editorial/200007/features/antibiotics policies.html.

26. Shalit I, Low M, Levy E, Chowers M, Zimhony O, Riesenberg K, et al. Antibiotic use in 26 departments of internal medicine in 6 general hospitals in Israel: variability and contributing factors. J Antimicrob Chemother. 2008;62(1):196-204.

27. Yokoe DS, Mermel LA, Anderson DJ, Arias KM, Burstin H, Calfee DP, et al. A compendium of strategies to prevent healthcare-associated infections in acute care hospitals. Infect Control Hosp Epidemiol. 2008;29 Suppl 1:S12-21.

28. Raveh D, Levy Y, Schlesinger Y, Greenberg A, Rudensky B, Yinnon AM. Longitudinal surveillance of antibiotic use in the hospital. QJM. 2001;94(3):141-52.

29. Gonzales R, Malone DC, Maselli JH, Sande MA. Excessive antibiotic use for acute respiratory infections in the United States. Clin Infect Dis. 2001;33(6):757-62.

30. Hecker MT, Aron DC, Patel NP, Lehmann MK, Donskey CJ. Unnecessary use of antimicrobials in hospitalized patients: current patterns of misuse with an emphasis on the antianaerobic spectrum of activity. Arch Intern Med. 2003;163(8):972-8.

31. Apisarnthanarak A, Danchaivijitr S, Khawcharoenporn T, Limsrivilai J, Warachan B, Bailey TC, et al. Effectiveness of education and an antibiotic-control program in a tertiary care hospital in Thailand. Clin Infect Dis. 2006;42(6):768-75.

32. Lallemand S, Thouverez M, Bailly $P$, Bertrand X, Talon D. Non-observance of guidelines for surgical antimicrobial prophylaxis and surgical-site infections. Pharm World Sci. 2002;24(3):95-9.

33. Metzger R, Swenson BR, Bonatti H, Hedrick TL, Hranjec T, Popovsky KA, et al. Identification of risk factors for the development of clostridium difficile-associated diarrhea following treatment of polymicrobial surgical infections. Ann Surg. 2010;251(4):722-7. 
34. Sohn AH, Parvez FM, Vu T, Hai HH, Bich NN, Le Thu TA, et al. Prevalence of surgical-site infections and patterns of antimicrobial use in a large tertiary-care hospital in Ho Chi Minh City, Vietnam. Infect Control Hosp Epidemiol. 2002;23(7):382-7.

35. Alliance for the Prudent Use of Antibiotic. Antibiotic resistance: Careful antibiotic use can help control the growing problem. 1999 [acceso 13 de abril de 2010]: Disponible en: http://www.tufts.edu/med/apua/Practitioners/ABRcontrol.html.

36. Ali SQ, Zehra A, Naqvi BS, Shah S, Bushra R. Resistance pattern of ciprofloxacin against different pathogens. Oman Med J. 2010;25(4):294-8.

37. Gustafsson I, Sjolund M, Torell E, Johannesson M, Engstrand L, Cars $O$, et al. Bacteria with increased mutation frequency and antibiotic resistance are enriched in the commensal flora of patients with high antibiotic usage. J Antimicrob Chemother. 2003;52(4):645-50.

38. Monnet DL, MacKenzie FM, Lopez-Lozano JM, Beyaert A, Camacho M, Wilson R, et al. Antimicrobial drug use and methicillin-resistant Staphylococcus aureus, Aberdeen, 19962000. Emerg Infect Dis. 2004;10(8):1432-41.

39. Hsueh PR, Shyr JM, Wu JJ. Decreased erythromycin use after antimicrobial reimbursement restriction for undocumented bacterial upper respiratory tract infections significantly reduced erythromycin resistance in Streptococcus pyogenes in Taiwan. Clin Infect Dis. 2005;40(6):903-5.

40. Lodise TP, Jr., McKinnon PS, Rybak M. Prediction model to identify patients with Staphylococcus aureus bacteremia at risk for methicillin resistance. Infect Control Hosp Epidemiol. 2003;24(9):655-61.

41. Echeverri Toro LM, Atehortúa Muñoz SL, Robledo Restrepo J. K. pneumoniae y betalactamasas: un problema creciente. Med UPB [revista en Internet]. 2009 [acceso 5 de julio de 2011]; 28(2): Disponible ttp://revistas.upb.edu.co/index.php/Medicina/article/viewFile/453/400.

42. Yates RR. New intervention strategies for reducing antibiotic resistance. Chest. 1999;115(3 Suppl):24S-7S.

43. Recommendations for Preventing the Spread of Vancomycin Resistance Recommendations of the Hospital Infection Control Practices Advisory Committee (HICPAC). MMWR [revista en Internet]. 1995 [acceso 30 de junio de 2008]; 44: Disponible en: http://wonder.cdc.gov/wonder/prevguid/m0039349/m0039349.asp.

44. Nolan SM, Gerber JS, Zaoutis T, Prasad P, Rettig S, Gross K, et al. Outbreak of vancomycin-resistant enterococcus colonization among pediatric oncology patients. Infect Control Hosp Epidemiol. 2009;30(4):338-45.

45. Sakka V, Tsiodras S, Galani L, Antoniadou A, Souli M, Galani I, et al. Risk-factors and predictors of mortality in patients colonised with vancomycin-resistant enterococci. Clin Microbiol Infect. 2008;14(1):14-21.

46. Fridkin SK, Lawton R, Edwards JR, Tenover FC, McGowan JE, Jr., Gaynes RP. Monitoring antimicrobial use and resistance: comparison with a national benchmark on reducing vancomycin use and vancomycin-resistant enterococci. Emerg Infect Dis. 2002;8(7):702-7.

47. Harbarth S, Cosgrove S, Carmeli Y. Effects of antibiotics on nosocomial epidemiology of vancomycin-resistant enterococci. Antimicrob Agents Chemother. 2002;46(6):1619-28.

48. Graffunder EM, Venezia RA. Risk factors associated with nosocomial methicillinresistant Staphylococcus aureus (MRSA) infection including previous use of antimicrobials. J Antimicrob Chemother. 2002;49(6):999-1005. 
49. Alliance for the Prudent Use of Antibiotic. Urinary tract infection in developing world increasingly drug-resistant. APUA Newsletter [revista en Internet]. 2010 [acceso 29 de marzo de 2011]; 28(1): Disponible en: http://www.tufts.edu/med/apua/news/Vol28No1.pdf.

50. World Health Organization. Resistencia a los antimicrobianos (RAM). 2011 [acceso 2 de abril de 2012]; Disponible http://www.who.int/mediacentre/factsheets/fs194/es/index.html.

51. Amoroso A, Di Conza J, Massa R, Power P, Radice M, Gutkind G. Mecanismos de acción y resistencia a drogas antibacterianas. En: Basualdo $\mathrm{J}$, Coto $\mathrm{C}$, de Torres $\mathrm{R}$, editors. Microbiología biomédica. Segunda ed. Buenos Aires: Atlante; 2006. p. 163-82.

52. Passerini de Rossi B. Transferencia de genes. En: Basualdo J, Coto C, de Torres R, editors. Microbiología biomédica. $2^{\mathrm{a}}$ ed. Buenos Aires: Atlante; 2006. p. 163-82.

53. Moreno MC, González ER, Beltrán C. Mecanismos de resistencia antimicrobiana en patógenos respiratorios. Rev Otorrinolaringol Cir Cabeza Cuello [revista en Internet]. 2009 [acceso 5 de julio de 2011]; 69(2): Disponible en: http://www.scielo.cl/scielo.php?pid=S0718$48162009000200014 \&$ script $=$ sci arttext.

54. Diretório Acadêmico Antônio Pinho. Resistência Microbiana - Mecanismos e impacto clínico. Pelotas: Diretório Acadêmico Antônio Pinho; 2007 [actualizado 05 de julio de 2011; acceso 5 de agosto de 2011]; Disponible en: http://www.damedpel.com/CDD/4oAno/CGA/Antimicrobianos\%20MS\%20-

\%202008/opas web/modulo3/mec animacao.htm.

55. Gould IM. A review of the role of antibiotic policies in the control of antibiotic resistance. J Antimicrob Chemother. 1999;43(4):459-65.

56. Paterson DL. The role of antimicrobial management programs in optimizing antibiotic prescribing within hospitals. Clin Infect Dis. 2006;42 Suppl 2:S90-5.

57. Christiansen K, Mccullough C, Coombs G. Multi Resistant Organisms (MROs) Isolated from Victims of the Bali Terrorist Bombing. En: Interscience Conference on Antimicrobial Agents and Chemotherapy. Chicago: 2003.

58. Quale J, Bratu S, Landman D, Heddurshetti R. Molecular epidemiology and mechanisms of carbapenem resistance in Acinetobacter baumannii endemic in New York City. Clin Infect Dis. 2003;37(2):214-20.

59. Deplano A, Denis O, Poirel L, Hocquet D, Nonhoff C, Byl B, et al. Molecular characterization of an epidemic clone of panantibiotic-resistant Pseudomonas aeruginosa. J Clin Microbiol. 2005;43(3):1198-204.

60. Zanetti G, Blanc DS, Federli I, Raffoul W, Petignat C, Maravic P, et al. Importation of Acinetobacter baumannii into a burn unit: a recurrent outbreak of infection associated with widespread environmental contamination. Infect Control Hosp Epidemiol. 2007;28(6):723-5.

61. Mangram AJ, Horan TC, Pearson ML, Silver LC, Jarvis WR. Guideline for prevention of surgical site infection, 1999. Hospital Infection Control Practices Advisory Committee. Infect Control Hosp Epidemiol. 1999;20(4):250-78; quiz 79-80.

62. D'Agata EM, Dupont-Rouzeyrol M, Magal P, Olivier D, Ruan S. The impact of different antibiotic regimens on the emergence of antimicrobial-resistant bacteria. PLoS One. 2008;3(12):e4036.

63. Levy SB, O'Brien TF. Global antimicrobial resistance alerts and implications. Clin Infect Dis. 2005;41 Suppl 4:S219-20.

64. Jarvis WR. Benchmarking for prevention: the Centers for Disease Control and Prevention's National Nosocomial Infections Surveillance (NNIS) system experience. Infection. 2003;31 Suppl 2:44-8. 
65. Zelenitsky SA, Ariano RE, Harding GK, Silverman RE. Antibiotic pharmacodynamics in surgical prophylaxis: an association between intraoperative antibiotic concentrations and efficacy. Antimicrob Agents Chemother. 2002;46(9):3026-30.

66. Sader HS, Moet GJ, Jones RN. Antimicrobial resistance among Gram-positive bacteria isolated in Latin American hospitals. J Chemother. 2009;21(6):611-20.

67. Sader HS, Jones RN. Antimicrobial susceptibility of Gram-positive bacteria isolated from US medical centers: results of the Daptomycin Surveillance Program (2007-2008). Diagn Microbiol Infect Dis. 2009;65(2):158-62.

68. Stelling JM, O'Brien TF. Surveillance of antimicrobial resistance: the WHONET program. Clin Infect Dis. 1997;24 Suppl 1:S157-68.

69. Sharma A, Grover PS. Application of WHONET for the surveillance of antimicrobial resistance. Indian J Med Microbiol. 2004;22(2):115-8.

70. Murray BE. Can antibiotic resistance be controlled? $\mathrm{N}$ Engl $\mathrm{J}$ Med. 1994;330(17):1229-30.

71. Bronzwaer SL, Cars O, Buchholz U, Molstad S, Goettsch W, Veldhuijzen IK, et al. A European study on the relationship between antimicrobial use and antimicrobial resistance. Emerg Infect Dis. 2002;8(3):278-82.

72. Picazo JJ, Betriu C, Rodriguez-Avial I, Culebras E, Gomez M. Vigilancia de resistencias a los antimicrobianos: estudio VIRA 2004. Enferm Infecc Microbiol Clin. 2004;22(9):517-25.

73. Emory University. Project ICARE 2007 [acceso 20 de octubre de 2008]; Disponible en: http://www.sph.emory.edu/ICARE/index.php.

74. Fridkin SK, Steward CD, Edwards JR, Pryor ER, McGowan JE, Jr., Archibald LK, et al. Surveillance of antimicrobial use and antimicrobial resistance in United States hospitals: project ICARE phase 2. Project Intensive Care Antimicrobial Resistance Epidemiology (ICARE) hospitals. Clin Infect Dis. 1999;29(2):245-52.

75. La resistencia a antimicrobianos en las Américas. Rev Panam Salud Publica [revista en Internet]. 1999 [acceso 8 de abril de 2010]; 6(6): Disponible en: http://www.scielosp.org/scielo.php?script=sci arttext\&pid=S102049891999001100016\&lng=en. doi: 10.1590/S1020-49891999001100016.

76. WHONET. WHONET Supporting Global Surveillance of Infectious Diseases. 2009 [acceso 20 de julio de 2010]; Disponible en: http://www.whonet.org/dnn/WHONETCommunity/Argentina/tabid/62/language/en-

US/Default.aspx.

77. Rossi MA, Tokumoto M, Couto E, Di Bella A, Alstchuler M, Gomez N, et al. Survey of the levels of antimicrobial resistance in Argentina: WHONET program--1991 to 1994. Int J Antimicrob Agents. 1995;6(2):103-10.

78. Ministerio de Salud de la Nación. Programa Nacional de Vigilancia de las Infecciones Hospitalarias. Mar del Plata: Instituto Nacional de Epidemiología "Dr. Juan H Jara"; 2004 [acceso 10 de julio de 2007]; Disponible en: http://www.vihda.gov.ar/.

79. Executive summary: global antimicrobial resistance alerts and implications. Clin Infect Dis. 2005;41 Suppl 4:S221-3.

80. Dellit TH, Owens RC, McGowan JE, Jr., Gerding DN, Weinstein RA, Burke JP, et al. Infectious Diseases Society of America and the Society for Healthcare Epidemiology of America guidelines for developing an institutional program to enhance antimicrobial stewardship. Clin Infect Dis. 2007;44(2):159-77. 
81. Smith DW. Decreased antimicrobial resistance after changes in antibiotic use. Pharmacotherapy. 1999;19(8 Pt 2):129S-32S;33S-37S.

82. Girón Aguilar N, Rodriguez de Bittner M. Selección y Formulario de Medicamentos. OPS/OMS; 1997 [acceso 14 abril 2010]; Disponible en: http://www.paho.org/Spanish/HSP/HSE/doc185.pdf.

83. Secretaría de Salud del Ministerio de Salud y Acción Social. Normativa acreditación de farmacia hospitalaria Buenos Aires. 2000 [acceso 13 enero 2008]; Disponible en: http://www.msal.gov.ar/htm/site/pngcam/normas/2000 641\%20Farmacia.htm.

84. Woodford EM, Wilson KA, Marriott JF. Documentation of antibiotic prescribing controls in UK NHS hospitals. J Antimicrob Chemother. 2004;53(4):650-2.

85. Sbarbaro JA. Can we influence prescribing patterns? Clin Infect Dis. 2001;33 Suppl 3:S240-4.

86. Cobo Reinoso J, Oliva Dominguez J, Soler Vigil M, Martinez-Beltran J, Pedraza Cezon L, Moreno Guillen S. Evaluación de un programa de asesoría en terapia antibiótica. Rev Clin Esp. 2002;202(2):78-83.

87. Coignard B, Siegel JD, Weinstein RA, Sohn AH, Sinkowitz-Cochran RL, Jarvis WR. Reality check: how should we control antimicrobial use? Current practices and controversies. Infect Control Hosp Epidemiol. 2000;21(12):792-5.

88. Gerding DN. Antimicrobial cycling: lessons learned from the aminoglycoside experience. Infect Control Hosp Epidemiol. 2000;21(1 Suppl):S12-7.

89. Bergstrom CT, Lo M, Lipsitch M. Ecological theory suggests that antimicrobial cycling will not reduce antimicrobial resistance in hospitals. Proc Natl Acad Sci U S A. 2004;101(36):13285-90.

90. Gould IM, Jappy B. Trends in hospital antibiotic prescribing after introduction of an antibiotic policy. J Antimicrob Chemother. 1996;38(5):895-904.

91. Morgan AS, Brennan PJ, Fishman NO. Impact of a vancomycin restriction policy on use and cost of vancomycin and incidence of vancomycin-resistant Enterococcus. Ann Pharmacother. 1997;31(9):970-3.

92. Buising KL, Thursky KA, Black JF, MacGregor L, Street AC, Kennedy MP, et al. Improving antibiotic prescribing for adults with community acquired pneumonia: Does a computerised decision support system achieve more than academic detailing alone?--A time series analysis. BMC Med Inform Decis Mak. 2008;8:35.

93. Camins BC, King MD, Wells JB, Googe HL, Patel M, Kourbatova EV, et al. Impact of an antimicrobial utilization program on antimicrobial use at a large teaching hospital: a randomized controlled trial. Infect Control Hosp Epidemiol. 2009;30(10):931-8.

94. Burke JP. Maximizing appropriate antibiotic prophylaxis for surgical patients: an update from LDS Hospital, Salt Lake City. Clin Infect Dis. 2001;33 Suppl 2:S78-83.

95. Patzer JA, Dzierzanowska D, Turner PJ. Trends in antimicrobial susceptibility of Gram-negative isolates from a paediatric intensive care unit in Warsaw: results from the MYSTIC programme (1997-2007). J Antimicrob Chemother. 2008;62(2):369-75.

96. Yalcin AN, Erbay RH, Serin S, Atalay H, Oner O, Yalcin AD. Perioperative antibiotic prophylaxis and cost in a Turkish University Hospital. Infez Med. 2007;15(2):99-104.

97. Cusini A, Rampini SK, Bansal V, Ledergerber B, Kuster SP, Ruef C, et al. Different patterns of inappropriate antimicrobial use in surgical and medical units at a tertiary care hospital in Switzerland: a prevalence survey. PLoS One. 2010;5(11):e14011. 
98. Bratzler DW, Houck PM. Antimicrobial prophylaxis for surgery: an advisory statement from the National Surgical Infection Prevention Project. Clin Infect Dis. 2004;38(12):1706-15.

99. Enzler MJ, Berbari E, Osmon DR. Antimicrobial prophylaxis in adults. Mayo Clin Proc. 2011;86(7):686-701.

100. Sociedad Argentina de Infectología, Instituto Nacional de Epidemiología. Prevención de infección del sitio quirúrgico y seguirdad del paciente en el pre, intra y postquirúrgico. 2009 [acceso 9 de abril 2012]; Disponible en: http://www.sadi.org.ar/files/CONSENSOISQFINAL.PDF.

101. Steinberg JP, Braun BI, Hellinger WC, Kusek L, Bozikis MR, Bush AJ, et al. Timing of antimicrobial prophylaxis and the risk of surgical site infections: results from the Trial to Reduce Antimicrobial Prophylaxis Errors. Ann Surg. 2009;250(1):10-6.

102. Tourmousoglou CE, Yiannakopoulou E, Kalapothaki V, Bramis J, St Papadopoulos J. Adherence to guidelines for antibiotic prophylaxis in general surgery: a critical appraisal. J Antimicrob Chemother. 2008;61(1):214-8.

103. Bratzler DW, Houck PM, Richards C, Steele L, Dellinger EP, Fry DE, et al. Use of antimicrobial prophylaxis for major surgery: baseline results from the National Surgical Infection Prevention Project. Arch Surg. 2005;140(2):174-82.

104. Al-Momany NH, Al-Bakri AG, Makahleh ZM, Wazaify MM. Adherence to international antimicrobial prophylaxis guidelines in cardiac surgery: a Jordanian study demonstrates need for quality improvement. J Manag Care Pharm. 2009;15(3):262-71.

105. Seppala H, Klaukka T, Vuopio-Varkila J, Muotiala A, Helenius $H$, Lager K, et al. The effect of changes in the consumption of macrolide antibiotics on erythromycin resistance in group A streptococci in Finland. Finnish Study Group for Antimicrobial Resistance. N Engl J Med. 1997;337(7):441-6.

106. Alemán Mondeja L, Guanche Garcell H. Etiología de la infección del sitio quirúrgico en pacientes egresados del Hospital Clinicoquirúrgico Docente "Joaquín Albarrán" Enero a marzo del 2000. Rev Cubana Cir [revista en Internet]. 2001 [acceso 13 de abril de 2010]; 40(3): Disponible en: $\quad$ http://scielo.sld.cu/scielo.php?script=sci arttext\&pid=S0034$74932001000400009 \&$ Ing $=$ es.

107. Hollenbeak CS, Murphy D, Dunagan WC, Fraser VJ. Nonrandom selection and the attributable cost of surgical-site infections. Infect Control Hosp Epidemiol. 2002;23(4):177-82.

108. Engemann JJ, Carmeli Y, Cosgrove SE, Fowler VG, Bronstein MZ, Trivette SL, et al. Adverse clinical and economic outcomes attributable to methicillin resistance among patients with Staphylococcus aureus surgical site infection. Clin Infect Dis. 2003;36(5):592-8.

109. Kim SP, Shah ND, Karnes RJ, Weight CJ, Frank I, Moriarty JP, et al. The Implications of Hospital Acquired Adverse Events on Mortality, Length of Stay and Costs for Patients Undergoing Radical Cystectomy for Bladder Cancer. J Urol. 2012 Apr 11.

110. Whitehouse JD, Friedman ND, Kirkland KB, Richardson WJ, Sexton DJ. The impact of surgical-site infections following orthopedic surgery at a community hospital and a university hospital: adverse quality of life, excess length of stay, and extra cost. Infect Control Hosp Epidemiol. 2002;23(4):183-9.

111. Jenney AW, Harrington GA, Russo PL, Spelman DW. Cost of surgical site infections following coronary artery bypass surgery. ANZ J Surg. 2001;71(11):662-4.

112. Hollenbeak CS, Alfrey EJ, Sheridan K, Burger TL, Dillon PW. Surgical site infections following pediatric liver transplantation: risks and costs. Transpl Infect Dis. 2003;5(2):72-8. 
113. Perencevich EN, Sands KE, Cosgrove SE, Guadagnoli E, Meara E, Platt R. Health and economic impact of surgical site infections diagnosed after hospital discharge. Emerg Infect Dis. 2003;9(2):196-203.

114. Ríos J, Murillo C, Carrasco G, Humet C. Incremento de costes atribuible a la infección quirúrgica de la apendicectomía y colectomía. Gac Sanit [revista en Internet]. 2003 [acceso 13 de abril de 2010]; 17(3): Disponible en: http://scielo.isciii.es/scielo.php?script=sci arttext\&pid=S0213-91112003000300008\&lng=es.

115. Sanz Granada A. Costes relevantes de la salud. Offarm. 2000;19(7):94-9.

116. Salvatierra González R. Costo de la infección nosocomial en nueve países de América Latina. Washington DC: OPS; 2003.

117. Sack S. Sanatorio Adventista del Plata. 2009 [acceso 22 de marzo de 2011]; Disponible en: http://www.panoramio.com/photo/21369162.

118. Enciclopedia Libre Universal. Entre Ríos (Argentina). 2010 [acceso 15 de julio de 2011]; Disponible en: http://enciclopedia.us.es/index.php/Entre R\%C3\%ADos (Argentina).

119. Universidad Adventista del Plata. Cómo llegar a Libertador San Martín. Libertador San Martín2011 [acceso 15 de julio de 2011]; Disponible en: http://www.inis.uap.edu.ar/index.php/projectos/jornadas-de-matermatica/como-llegar-a-lib-smartin.

120. Sociedad Argentina de Terapia Intensiva, Sociedad Argentina de Infectología, Asociación Argentina de Enfermeros en Control de Infecciones. Infección del Sitio Quirúrgico. Guías para la prevención. 2008 [acceso 12 de abril de 2012]; Disponible en: http://www.sati.org.ar/files/infectologia/2008-Recomendaciones-Infeccion-del-Sitio-

Quirurgico.pdf.

121. ANZ Journal of Surgery. American Society of Anesthesiologists (ASA) Score. Royal Australasian College of Surgeons; [acceso 17 de abril de 2011]; Disponible en: http://www.anzjsurg.com/view/0/ASAscore.html.

122. Centers for Disease Control and Prevention. Surgical Site Infection (SSI) Event. 2012 [acceso 9 de abril de 2012]; Disponible en: http://www.cdc.gov/nhsn/PDFs/pscManual/9pscSSIcurrent.pdf.

123. WHO Collaborating Centre for Drug Statistics Methodolgy. About the ATC/DDD system. Oslo2008 [acceso 10 de julio de 2008]; Disponible en: http://www.whocc.no/atcddd/.

124. Mensa J, Gatell J, García J, Letang E, López-Suñé E, Marco F. Guía de Terapéutica Antimicrobiana 2012. 22 ed. Barcelona: Antares; 2012.

125. Dawson B, Trapp R. Bioestadística médica. 4a ed. México: Manual Moderno; 2005.

126. Emory University. Project ICARE. 2007 [acceso 20 de octubre de 2008]; Disponible en: http://www.sph.emory.edu/lCARE/Phase2.php.

127. Biscione FM, Couto RC, Pedrosa TM. Accounting for incomplete postdischarge follow-up during surveillance of surgical site infection by use of the National Nosocomial Infections Surveillance system's risk index. Infect Control Hosp Epidemiol. 2009;30(5):433-9.

128. CLSI, editor. Performance standards for antimicrobial susceptibility testing; Eighteenth Informational Supplement. M100-S18. Wayne, PA.: Clinical and Laboratory Standards Institute; 2008.

129. Petti CA, Carroll KC, Reimer LG. Storage or Microorganisms. In: Murray PR, Baron EJ, Jorgensen JH, Louise-Landry M, Pfalles MA, editors. Manual of Clinical Microbiology. 9 ed. Washington, DC: ASM Press; 2007. p. 55-61. 
130. Caldeira L, Teixeira I, Vieira I, Batel Marques F, Santiago LM, Rodrigues V, et al. [Monitoring antibiotic consumption in the surgery and orthopaedics]. Acta Med Port. 2006;19(1):55-66.

131. Nichols RL. Preventing surgical site infections: a surgeon's perspective. Emerg Infect Dis. 2001;7(2):220-4.

132. Ding $\mathrm{H}$, Yang $\mathrm{Y}$, Wei J, Fan S, Yu S, Yao K, et al. Influencing the use of antibiotics in a Chinese pediatric intensive care unit. Pharm World Sci. 2008;30(6):787-93.

133. Willemsen I, Cooper B, van Buitenen C, Winters M, Andriesse G, Kluytmans J. Improving quinolone use in hospitals by using a bundle of interventions in an interrupted time series analysis. Antimicrob Agents Chemother. 2010;54(9):3763-9.

134. Bantar C, Sartori B, Vesco E, Heft C, Saul M, Salamone F, et al. A hospital wide intervention program to optimize the quality of antibiotic use: impact on prescribing practice, antibiotic consumption, cost savings, and bacterial resistance. Clin Infect Dis. 2003;37(2):180-6.

135. Ozkurt Z, Erol S, Kadanali A, Ertek M, Ozden K, Tasyaran MA. Changes in antibiotic use, cost and consumption after an antibiotic restriction policy applied by infectious disease specialists. Jpn J Infect Dis. 2005;58(6):338-43.

136. Juzych NS, Banerjee M, Essenmacher L, Lerner SA. Improvements in antimicrobial prescribing for treatment of upper respiratory tract infections through provider education. $\mathrm{J}$ Gen Intern Med. 2005;20(10):901-5.

137. Ozgun H, Ertugrul BM, Soyder A, Ozturk B, Aydemir M. Peri-operative antibiotic prophylaxis: adherence to guidelines and effects of educational intervention. Int $\mathrm{J}$ Surg. 2010;8(2):159-63.

138. Hermsen ED, Smith Shull S, Puumala SE, Rupp ME. Improvement in prescribing habits and economic outcomes associated with the introduction of a standardized approach for surgical antimicrobial prophylaxis. Infect Control Hosp Epidemiol. 2008;29(5):457-61.

139. De Chiara S, Chiumello D, Nicolini R, Vigorelli M, Cesana B, Bottino N, et al. Prolongation of antibiotic prophylaxis after clean and clean-contaminated surgery and surgical site infection. Minerva Anestesiol. 2010;76(6):413-9.

140. Prado MA, Lima MP, Gomes Ida R, Bergsten-Mendes G. The implementation of a surgical antibiotic prophylaxis program: the pivotal contribution of the hospital pharmacy. Am J Infect Control. 2002;30(1):49-56.

141. Suzuki T, Sadahiro S, Maeda Y, Tanaka A, Okada K, Kamijo A. Optimal duration of prophylactic antibiotic administration for elective colon cancer surgery: A randomized, clinical trial. Surgery. 2011;149(2):171-8.

142. Meeks DW, Lally KP, Carrick MM, Lew DF, Thomas EJ, Doyle PD, et al. Compliance with guidelines to prevent surgical site infections: As simple as 1-2-3? Am J Surg. 2010;201(1):76-83.

143. van Kasteren ME, Mannien J, Kullberg BJ, de Boer AS, Nagelkerke NJ, Ridderhof M, et al. Quality improvement of surgical prophylaxis in Dutch hospitals: evaluation of a multisite intervention by time series analysis. J Antimicrob Chemother. 2005;56(6):1094-102.

144. Fonseca SN, Kunzle SR, Junqueira MJ, Nascimento RT, de Andrade JI, Levin AS. Implementing 1-dose antibiotic prophylaxis for prevention of surgical site infection. Arch Surg. 2006;141(11):1109-13.

145. Young B, Ng TM, Teng C, Ang B, Tai HY, Lye DC. Nonconcordance with surgical site infection prevention guidelines and rates of surgical site infections for general surgical, 
neurological, and orthopedic procedures. Antimicrob Agents Chemother. 2011;55(10):465963.

146. Bowater RJ, Stirling SA, Lilford RJ. Is antibiotic prophylaxis in surgery a generally effective intervention? Testing a generic hypothesis over a set of meta-analyses. Ann Surg. 2009;249(4):551-6.

147. Mannien J, van Kasteren ME, Nagelkerke NJ, Gyssens IC, Kullberg BJ, Wille JC, et al. Effect of optimized antibiotic prophylaxis on the incidence of surgical site infection. Infect Control Hosp Epidemiol. 2006;27(12):1340-6.

148. MacDougall C, Polk RE. Variability in rates of use of antibacterials among 130 US hospitals and risk-adjustment models for interhospital comparison. Infect Control Hosp Epidemiol. 2008;29(3):203-11.

149. Kollef MH, Fraser VJ. Antibiotic resistance in the intensive care unit. Ann Intern Med. 2001;134(4):298-314.

150. Intensive Care Antimicrobial Resistance Epidemiology (ICARE) Surveillance Report, data summary from January 1996 through December 1997: A report from the National Nosocomial Infections Surveillance (NNIS) System. Am J Infect Control. 1999;27(3):279-84.

151. Salerno RA, Funes C, Sosa M, Ybarra V, Sarkis C, Vergara J, et al. Estudio Multicéntrico de validación de indicadores de vigilancia epidemiológica en unidades de cuidados intensivos del sistema NNIS. Revista del Hospital JM Ramos Mejía [revista en Internet]. 2005 [acceso 25 de julio de 2007]; 10(4): Disponible en: http://www.ramosmejia.org.ar/r/200504/7.doc.

152. Meyer E, Schwab F, Jonas D, Rueden H, Gastmeier P, Daschner FD. Surveillance of antimicrobial use and antimicrobial resistance in intensive care units (SARI): 1. Antimicrobial use in German intensive care units. Intensive Care Med. 2004;30(6):1089-96.

153. Avorn J, Solomon DH. Cultural and economic factors that (mis)shape antibiotic use: the nonpharmacologic basis of therapeutics. Ann Intern Med. 2000;133(2):128-35.

154. LeBlanc L, Pepin J, Toulouse K, Ouellette MF, Coulombe MA, Corriveau MP, et al. Fluoroquinolones and risk for methicillin-resistant Staphylococcus aureus, Canada. Emerg Infect Dis. 2006;12(9):1398-405.

155. Mutnick AH, Rhomberg PR, Sader HS, Jones RN. Antimicrobial usage and resistance trend relationships from the MYSTIC Programme in North America (1999-2001). J Antimicrob Chemother. 2004;53(2):290-6.

156. Pepin J, Saheb N, Coulombe MA, Alary ME, Corriveau MP, Authier S, et al. Emergence of fluoroquinolones as the predominant risk factor for Clostridium difficileassociated diarrhea: a cohort study during an epidemic in Quebec. Clin Infect Dis. 2005;41(9):1254-60.

157. Zahar JR, Rioux C, Girou E, Hulin A, Sauve C, Bernier-Combes A, et al. Inappropriate prescribing of aminoglycosides: risk factors and impact of an antibiotic control team. J Antimicrob Chemother. 2006;58(3):651-6.

158. Radigan EA, Gilchrist NA, Miller MA. Management of aminoglycosides in the intensive care unit. J Intensive Care Med. 2010;25(6):327-42.

159. Drew RH. Antimicrobial stewardship programs: how to start and steer a successful program. J Manag Care Pharm. 2009;15(2 Suppl):S18-23.

160. Edwards JR, Peterson KD, Mu Y, Banerjee S, Allen-Bridson K, Morrell G, et al. National Healthcare Safety Network (NHSN) report: data summary for 2006 through 2008, issued December 2009. Am J Infect Control. 2009;37(10):783-805. 
161. Diekema DJ, Pfaller MA, Schmitz FJ, Smayevsky J, Bell J, Jones RN, et al. Survey of infections due to Staphylococcus species: frequency of occurrence and antimicrobial susceptibility of isolates collected in the United States, Canada, Latin America, Europe, and the Western Pacific region for the SENTRY Antimicrobial Surveillance Program, 1997-1999. Clin Infect Dis. 200;32 Suppl 2:S114-32.

162. Paganini H, Della Latta MP, Muller Opet B, Ezcurra G, Uranga M, Aguirre C, et al. Estudio multicéntrico sobre las infecciones pediátricas por Staphylococcus aureus meticilinoresistente provenientes de la comunidad en la Argentina. Arch Argent Pediatr. 2008;106(5):397-403.

163. Brites C, Silva N, Sampaio-Sa M. Temporal evolution of the prevalence of methicillinresistant Staphylococcus aureus in a tertiary hospital in Bahia, Brazil: a nine-year evaluation study. Braz J Infect Dis. 2006;10(4):235-8.

164. Asensio A, Canton R, Vaque J, Rossello J, Calbo F, Garcia-Caballero J, et al. Nosocomial and community-acquired meticillin-resistant Staphylococcus aureus infections in hospitalized patients (Spain, 1993-2003). J Hosp Infect. 2006;63(4):465-71.

165. Organización Panamericana de la Salud. Informe Anual de la Red de Monitoreo/Vigilancia de la Resistencia a los Antibióticos -2004-. Brasilia: OPS 2005.

166. Organización Panamericana de la Salud. Informe Anual de la Red de Monitoreo/Vigilancia de la Resistencia a los Antibióticos.2008. Washington, D.C.: OPS 2008.

167. Soriano A, Martinez JA, Mensa J, Marco F, Almela M, Moreno-Martinez A, et al. Pathogenic significance of methicillin resistance for patients with Staphylococcus aureus bacteremia. Clin Infect Dis. 2000;30(2):368-73.

168. Rogues AM, Dumartin C, Amadeo B, Venier AG, Marty N, Parneix P, et al. Relationship between rates of antimicrobial consumption and the incidence of antimicrobial resistance in Staphylococcus aureus and Pseudomonas aeruginosa isolates from 47 French hospitals. Infect Control Hosp Epidemiol. 2007;28(12):1389-95.

169. Muller AA, Mauny F, Bertin M, Cornette C, Lopez-Lozano JM, Viel JF, et al. Relationship between spread of methicillin-resistant Staphylococcus aureus and antimicrobial use in a French university hospital. Clin Infect Dis. 2003;36(8):971-8.

170. Altunsoy A, Aypak C, Azap A, Ergonul O, Balik I. The impact of a nationwide antibiotic restriction program on antibiotic usage and resistance against nosocomial pathogens in Turkey. Int J Med Sci. 2011;8(4):339-44.

171. Carmeli Y, Eliopoulos GM, Samore MH. Antecedent treatment with different antibiotic agents as a risk factor for vancomycin-resistant Enterococcus. Emerg Infect Dis. 2002;8(8):802-7.

172. Fridkin SK, Edwards JR, Courval JM, Hill H, Tenover FC, Lawton R, et al. The effect of vancomycin and third-generation cephalosporins on prevalence of vancomycin-resistant enterococci in 126 U.S. adult intensive care units. Ann Intern Med. 2001;135(3):175-83.

173. Paramythiotou E, Lucet JC, Timsit JF, Vanjak D, Paugam-Burtz C, Trouillet JL, et al. Acquisition of multidrug-resistant Pseudomonas aeruginosa in patients in intensive care units: role of antibiotics with antipseudomonal activity. Clin Infect Dis. 2004;38(5):670-7.

174. Mouton RP, Hermans J, Simoons-Smit AM, Hoogkamp-Korstanje JA, Degener JE, van Klingeren $\mathrm{B}$. Correlations between consumption of antibiotics and methicillin resistance in coagulase negative staphylococci. J Antimicrob Chemother. 1990;26(4):573-83.

175. Cristino JM. Correlation between consumption of antimicrobials in humans and development of resistance in bacteria. Int J Antimicrob Agents. 1999;12(3):199-202. 
176. Neuhauser MM, Weinstein RA, Rydman R, Danziger LH, Karam G, Quinn JP. Antibiotic resistance among gram-negative bacilli in US intensive care units: implications for fluoroquinolone use. JAMA. 2003;289(7):885-8.

177. Kotwani A, Holloway K. Trends in antibiotic use among outpatients in New Delhi, India. BMC Infect Dis. 2011;11:99.

178. Daoud Z, Hakime N. Prevalence and susceptibility patterns of extended-spectrum betalactamase-producing Escherichia coli and Klebsiella pneumoniae in a general university hospital in Beirut, Lebanon. Rev Esp Quimioter. 2003;16(2):233-8.

179. Hyle EP, Bilker WB, Gasink LB, Lautenbach E. Impact of different methods for describing the extent of prior antibiotic exposure on the association between antibiotic use and antibiotic-resistant infection. Infect Control Hosp Epidemiol. 2007;28(6):647-54.

180. Boyce JM. MRSA patients: proven methods to treat colonization and infection. J Hosp Infect. 2001;48 Suppl A:S9-14.

181. Afif W, Huor P, Brassard P, Loo VG. Compliance with methicillin-resistant Staphylococcus aureus precautions in a teaching hospital. Am $\mathrm{J}$ Infect Control. 2002;30(7):430-3.

182. Kotilainen P, Routamaa M, Peltonen R, Oksi J, Rintala E, Meurman O, et al. Elimination of epidemic methicillin-resistant Staphylococcus aureus from a university hospital and district institutions, Finland. Emerg Infect Dis. 2003;9(2):169-75.

183. Pittet D. Compliance with hand disinfection and its impact on hospital-acquired infections. J Hosp Infect. 2001;48 Suppl A:S40-6.

184. Capriotti T. Preventing nosocomial spread of MRSA is in your hands. Medsurg Nurs. 2003;12(3):193-6.

185. Camarena J, Sánchez R. Infección por Staphylococcus aureus resistente a la meticilina. Valencia: Departamento de Microbiología. Hospital Universitario Doctor Peset. ; [acceso 29 de septiembre de 2010]; Disponible en: https://www.seimc.org/control/revi Bacte/pdf/sarm.pdf.

186. Tschudin-Sutter S, Pargger H, Widmer AF. Hand hygiene in the intensive care unit. Crit Care Med. 2010;38(8 Suppl):S299-305.

187. Gould I, Reilly J, Bunyan D, Walker A. Costs of healthcare associated methicillinresistant Staphylococcus aureus (MRSA) and its control. Clin Microbiol Infect. 2010; 16(12):1721-8.

188. McCarthy NL, Sullivan PS, Gaynes R, Rimland D. Risk factors associated with methicillin resistance among Staphylococcus aureus infections in veterans. Infect Control Hosp Epidemiol. 2010;31(1):36-41.

189. Wang JT, Wang JL, Fang CT, Chie WC, Lai MS, Lauderdale TL, et al. Risk factors for mortality of nosocomial methicillin-resistant Staphylococcus aureus (MRSA) bloodstream infection: With investigation of the potential role of community-associated MRSA strains. J Infect. 2010; 61(6):449-57.

190. von Gunten V, Troillet N, Beney J, Boubaker K, Luthi JC, Taffe P, et al. Impact of an interdisciplinary strategy on antibiotic use: a prospective controlled study in three hospitals. J Antimicrob Chemother. 2005;55(3):362-6.

191. Coello R, Charlett A, Wilson J, Ward V, Pearson A, Borriello P. Adverse impact of surgical site infections in English hospitals. J Hosp Infect. 2005;60(2):93-103.

192. Vogel TR, Dombrovskiy VY, Carson JL, Haser PB, Lowry SF, Graham AM. Infectious complications after elective vascular surgical procedures. J Vasc Surg. 2010;51(1):122-9; discussion 9-30. 
193. Nosrati M, Boroumand M, Tahmasebi S, Sotoudeh M, Sheikhfathollahi M, Goodarzynejad $\mathrm{H}$. Excess costs associated with common healthcare-associated infections in an Iranian cardiac surgical unit. J Hosp Infect. 2010; 76(4):304-7.

194. Weigelt JA, Lipsky BA, Tabak YP, Derby KG, Kim M, Gupta V. Surgical site infections: Causative pathogens and associated outcomes. Am J Infect Control. 2010;38(2):112-20.

195. Pessaux P, Msika S, Atalla D, Hay JM, Flamant Y. Risk factors for postoperative infectious complications in noncolorectal abdominal surgery: a multivariate analysis based on a prospective multicenter study of 4718 patients. Arch Surg. 2003;138(3):314-24.

196. McConkey SJ, L'Ecuyer PB, Murphy DM, Leet TL, Sundt TM, Fraser VJ. Results of a comprehensive infection control program for reducing surgical-site infections in coronary artery bypass surgery. Infect Control Hosp Epidemiol. 1999;20(8):533-8. 


\section{ANEXO I \\ SANATORIO ADVENTISTA DEL PLATA \\ Farmacia Interna \\ ORDEN PARA LA ADMINISTRACIÓN DE ANTIBIÓTICOS PROFILÁCTICOS}

Nombre del paciente:

Fecha: ................ Cirujano:

H.C.:

Cirugía:

Alergias:

\begin{tabular}{|c|c|c|c|}
\hline Sitio & Tipo & Antibiótico & $\begin{array}{l}\text { Dosis } \\
\text { totales }\end{array}$ \\
\hline $\begin{array}{l}\text { Cardiovascular } \\
\text { central }\end{array}$ & $\begin{array}{l}\square \text { Revascularización miocárdica } \\
\square \text { Prótesis intracardíaca }\end{array}$ & $\begin{array}{l}\text { Cefazolina } 2 \mathrm{~g} \text { ia }+5 \text { dosis } \mathrm{c} / 8 \mathrm{~h} \\
\text { Cefazolina } 2 \mathrm{~g} \text { ia }+5 \text { dosis } \mathrm{c} / 8 \mathrm{~h}\end{array}$ & $\begin{array}{l}6 \\
6\end{array}$ \\
\hline Cirugía Plástica & $\begin{array}{l}\square \text { Dermolipectomía abdominal } \\
\square \text { Reducción de mama }\end{array}$ & $\begin{array}{l}\text { Cefazolina } 2 \mathrm{~g} \text { ia }+2 \text { dosis } 1 \mathrm{~g} \\
\text { Cefazolina } 2 \mathrm{~g} \text { ia monodosis }\end{array}$ & $\begin{array}{l}3 \\
1\end{array}$ \\
\hline Cirugía Torácica & $\square$ Resección pulmonar & Cefazolina $1 \mathrm{~g}$ ia +2 dosis $\mathrm{c} / 8 \mathrm{~h}$ & 3 \\
\hline \multirow[t]{3}{*}{ Cirugía Vascular } & $\square$ Prótesis vascular & Cefazolina $1 \mathrm{~g}$ ia +2 dosis $\mathrm{c} / 8 \mathrm{~h}$ & 3 \\
\hline & $\square$ Colocación marcapaso definitivo & Cefazolina $1 \mathrm{~g}$ ia monodosis & 1 \\
\hline & $\square$ Cirugía vascular sin prótesis & Cefazolina $1 \mathrm{~g}$ monodosis & 1 \\
\hline \multirow[t]{5}{*}{ Gastrointestinal } & $\square$ Hígado, páncreas, vías biliares $\mathrm{C}$ y L* & Cefazolina $1 \mathrm{~g}$ monodosis & 1 \\
\hline & $\square$ Esófago, estómago, duodeno, hernias & Cefazolina $1 \mathrm{~g}$ monodosis & 1 \\
\hline & $\begin{array}{l}\square \text { Intestino delgado, colon y recto } \\
\text { (preparación mecánica) }\end{array}$ & $\begin{array}{l}\text { Metronidazol } 500 \mathrm{mg} \text { IV ia + Gentamicina } \\
1.5 \mathrm{mg} / \mathrm{kg} \text { ia }\end{array}$ & 1 \\
\hline & $\square$ Apendicectomía no complicada & $\begin{array}{l}\text { Metronidazol } 500 \mathrm{mg} \text { IV ia + Gentamicina } \\
1.5 \mathrm{mg} / \mathrm{kg} \text { ia }\end{array}$ & 1 \\
\hline & $\square$ Laparotomía exploradora & $\begin{array}{l}\text { Metronidazol } 500 \mathrm{mg} \text { IV ia + Gentamicina } \\
1.5 \mathrm{mg} / \mathrm{kg} \text { ia }\end{array}$ & 1 \\
\hline \multirow[t]{3}{*}{ Ginecología } & $\square$ Histerectomía y cirugía vaginal & Cefazolina $1 \mathrm{~g}$ ia monodosis & 1 \\
\hline & $\square$ Cesárea & $\begin{array}{l}\text { Cefazolina } 1 \mathrm{~g} \text { luego del clampeo del } \\
\text { cordón }\end{array}$ & 1 \\
\hline & $\square$ Cirugía mama & Cefazolina $1 \mathrm{~g}$ monodosis & 1 \\
\hline \multirow[t]{4}{*}{ Neurocirugía } & $\square$ Colocación de shunt & TMS 2 ampollas +2 amp. & 3 \\
\hline & $\square$ Transfenoidal o pasaje por mucosa & Clindamicina $600 \mathrm{mg}$ ia +2 dosis $\mathrm{c} / 8 \mathrm{~h}$. & 3 \\
\hline & $\square$ Craneotomía y Laminectomía & Cefazolina $1 \mathrm{~g}$ ia +2 dosis $\mathrm{c} / 8 \mathrm{~h}$ & 3 \\
\hline & $\square$ Artrodesis de columna & Cefazolina $1 \mathrm{~g}$ ia +2 dosis $\mathrm{c} / 8 \mathrm{~h}$ & 3 \\
\hline \multirow[t]{2}{*}{ ORL } & $\square$ Amigdalectomía / Adenoidectomía & $\begin{array}{l}\text { Clindamicina } 600 \mathrm{mg} \text { ia } \\
\text { ó Cefazolina } 2 \mathrm{~g} \text { ia } \\
\text { ó Ampicilina } 1 \mathrm{~g} \text { ia }+3 \text { dosis } 1 \mathrm{~g} \\
\end{array}$ & $\begin{array}{l}1 \\
1 \\
4 \\
\end{array}$ \\
\hline & $\square$ Septumplastia & Cefazolina $2 \mathrm{~g}$ ia & 1 \\
\hline \multirow[t]{5}{*}{ Traumatología } & $\square$ Fractura expuesta & Cefazolina $1 \mathrm{~g}+2$ dosis $\mathrm{c} / 8 \mathrm{~h}$ & 3 \\
\hline & $\square$ Amputación & $\begin{array}{l}\text { Clindamicina } 600 \mathrm{mg} \text { ia }+2 \text { dosis } \mathrm{c} / 8 \mathrm{~h} \text { y } \\
\text { Gentamicina } 1.5 \mathrm{mg} / \mathrm{kg} \text { ia monodosis }\end{array}$ & $\begin{array}{l}3 \\
1 \\
\end{array}$ \\
\hline & $\square$ Reemplazo total & Cefazolina $2 \mathrm{~g}$ ia +2 dosis $1 \mathrm{~g}$ & 3 \\
\hline & $\square$ Cirugía de columna & Cefazolina $1 \mathrm{~g}$ ia +2 dosis $\mathrm{c} / 8 \mathrm{~h}$ & 3 \\
\hline & $\square$ Otros procedimientos & Cefazolina $1 \mathrm{~g}$ ia monodosis & 1 \\
\hline \multirow[t]{2}{*}{ Urología } & $\begin{array}{l}\square \text { Endoprostática, endovesical, abdominal o } \\
\text { nefrectomía con urocultivo negativo }\end{array}$ & Cefazolina $1 \mathrm{~g}$ ia monodosis & 1 \\
\hline & $\begin{array}{l}\square \text { Cirugía urológica con manipuleo de } \\
\text { vísceras del tubo digestivo }\end{array}$ & $\begin{array}{l}\text { Metronidazol } 500 \mathrm{mg} \mathrm{IV} \mathrm{ia}+ \\
\text { Gentamicina } 1.5 \mathrm{mg} / \mathrm{kg} \text { ia }\end{array}$ & 1 \\
\hline
\end{tabular}

i.a.: La primera dosis de antibiótico debe ser administrada en la inducción anestésica.

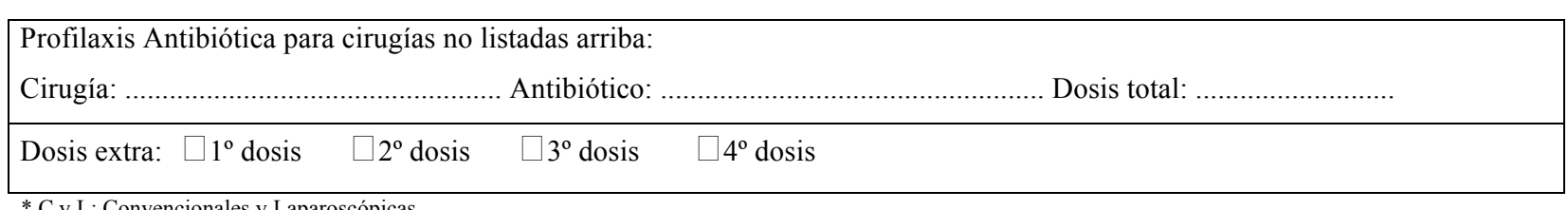

* C y L: Convencionales y Laparoscópicas 
Orden de paro-automático.

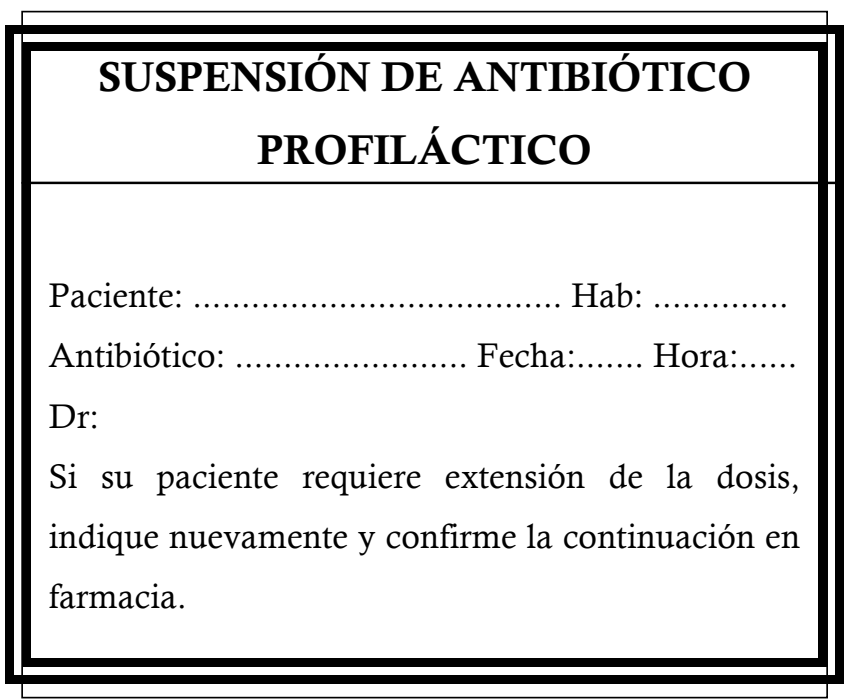


ANEXO III

Lisis rápida mediante ebullición (Welsh y McClelland, y Ghozzi et al., con modificaciones). Resuspender cuatro o cinco colonias crecidas en LB agar en $250 \mu \mathrm{l}$ de agua destilada estéril. Someterlas a una temperatura de $95^{\circ} \mathrm{C}$ durante $15 \mathrm{~min}$.

Centrifugar a $6.000 \mathrm{rpm}$ durante $5 \mathrm{~min}$. Emplear $10 \mu \mathrm{l}$ del sobrenadante como templado de la reacción.

\section{Protocolo de PCR empleando oligonucleótidos degenerados}

Mezcla de reacción para volumen final: 50 ul

\section{Ccs. finales de los reactivos Ccs. iniciales}

Buffer: $\quad 1 \mathrm{x}$

$\mathrm{MgCl}_{2}$ : $\quad 3 \mathrm{mM}$

Mezcla de dNTP: $200 \mu \mathrm{M} \quad 2 \mathrm{mM}$

Agua destilada estéril:

Cebador 19: $2,5 \mu \mathrm{M} \quad 62 \mu \mathrm{M}$

Cantidad de ADN: 20 a 200 ng

Aceite mineral

Taq polimerasa: $0,05 \mathrm{U} / \mu \mathrm{l} \quad 5 \mathrm{U} / \mu \mathrm{l}$

Recomendaciones para este procedimiento:

$\equiv$ Usar guantes.

$\equiv$ Colocar los reactivos en el orden arriba descripto.

$\equiv$ Someter a una primera etapa de desnaturalización a las muestras (en el termociclador a $95^{\circ}$ durante $5 \mathrm{~min}$, File 1). Terminado este paso, colocar en hielo para impedir la renaturalización.

$\equiv$ Agregar la Taq polimerasa (hot start). Colocar todos los tubos en el mismo tiempo en el termociclador (se pone pausa) cuando la temperatura alcanzada sea la de desnaturalización.

Condiciones de amplificación. El ensayo de reacción en cadena de la polimerasa (PCR) se llevó a cabo en un termociclador (modelo 480; Perkin-Elmer Cetus). La mezcla de reacción (50 mL) contenía $50 \mathrm{ng}$ de ADN, 2,5 U de Taq DNA polimerasa (Promega, Madi- son,WI), 2 $\mathrm{mM}$ primer de oligonucléotidos, $200 \mathrm{mM}$ de cada uno dATP, dCTP,dGTP, y dTTP, 1,5 mM $\mathrm{MgCl} 2,10 \mathrm{mM}$ Tris- $\mathrm{HCl}(\mathrm{pH} 8,4)$, y $50 \mathrm{mM} \mathrm{KCl}$. Para una amplificación de alto rigor, luego de 5 min de desnaturalizacón a $95^{\circ} \mathrm{C}$, la mezcla de reacción fue corrida a través de tres ciclos de $95^{\circ} \mathrm{C}$ por $1 \mathrm{~min}, 37^{\circ} \mathrm{C}$ por $1 \mathrm{~min}$, y $72^{\circ} \mathrm{C}$ por $30 \mathrm{~s}$, seguido de 32 ciclos a $95^{\circ} \mathrm{C}$ por $1 \mathrm{~min}, 55^{\circ} \mathrm{C}$ por $1 \mathrm{~min}$, y $72^{\circ} \mathrm{C}$ por $30 \mathrm{~s}$, y finalmente a $72^{\circ} \mathrm{C}$ por $10 \mathrm{~min}$. Para una 
amplificación de bajo rigor, 5 min de desnaturalización a $95^{\circ} \mathrm{C}$ fue seguido por 40 ciclos de 1 $\min$ a $93^{\circ} \mathrm{C}, 1,5 \min$ a $36^{\circ} \mathrm{C}$, y $2 \min$ a $72^{\circ} \mathrm{C}$, seguido de $10 \min$ a $72^{\circ} \mathrm{C}$.

En todos los casos, $20 \mathrm{~mL}$ del producto de amplificación fue analizado por electroforesis en gel de agarosa $1,2 \%$, siguiendo procedimientos convencionales. 


\section{LISTADO DE CUADROS}

Pág.

1. Año de descubrimiento de los agentes antimicrobianos más importantes y año de comunicación de la existencia de cepas resistentes a los mismos 5

2. Grupos farmacológicos y gramos de cada antimicrobiano utilizado correspondientes a una dosis diaria definida 


\section{LISTADO DE TABLAS}

1. Número de pacientes sometidos a intervenciones quirúrgicas por cada Servicio durante la etapa inicial y final del estudio. Sanatorio Adventista del Plata, Argentina, enero de 2002 a octubre de 2003.

2. Número de pacientes a quienes se les administró el antimicrobiano en el tiempo considerado adecuado o inadecuado, por Servicio, antes y después de la aplicación del formulario para el uso de antimicrobianos en cirugía. Sanatorio Adventista del Plata, Argentina, enero de 2002 a octubre de 2003.

3. Número de pacientes sometidos a intervenciones quirúrgicas por cada Servicio, con el esquema antimicrobiano adecuado o inadecuado, antes y después de la aplicación del formulario para el uso de antimicrobianos en cirugía. Sanatorio Adventista del Plata, Argentina, enero de 2002 a octubre de 2003.

4. Número de pacientes sometidos a intervenciones quirúrgicas por cada Servicio, con duración de la profilaxis antimicrobiana adecuada o inadecuada, antes y después de la aplicación del formulario para el uso de antimicrobianos en cirugía. Sanatorio Adventista del Plata, Argentina, enero de 2002 a octubre de 2003.

5. Antimicrobianos utilizados en la profilaxis antibiótica prequirúrgica, expresado en dosis diarias definidas/1000 días paciente antes y después de la aplicación del formulario para el uso de antimicrobianos en cirugía. Sanatorio Adventista del Plata, Argentina, enero de 2002 a octubre de 2003.

6. Comparación del uso de antimicrobianos en los pacientes internados en la unidad de cuidados intensivos y en internación general del Sanatorio Adventista del Plata, Argentina, durante los años 2001-2007.

7. Comparación del uso de antimicrobianos en la unidad de cuidados intensivos expresado en dosis diarias definidas/1000 días paciente, durante los años 2001-2002 (preintervención) y 2003-2007 (posintervención). Sanatorio Adventista del Plata, Argentina.

8. Comparación del uso de antimicrobianos en la unidad de cuidados intensivos expresado en dosis diarias definidas/1000 días paciente, durante los años 2001 a 2007. Sanatorio Adventista del Plata, Argentina.

9. Comparación del uso de antimicrobianos en internación general expresado en dosis diarias definidas/1000 días paciente, durante los años 2001-2002 (preintervención) y 2003-2007 (posintervención). Sanatorio Adventista del Plata, Argentina.

10. Comparación del uso de antimicrobianos en internación general expresado en dosis diarias definidas/1000 días paciente, durante los años 2001 a 2007. Sanatorio Adventista del Plata, Argentina. 
11. Comparación del porcentaje de resistencia bacteriana de las cepas productoras de infecciones hospitalarias aisladas de pacientes en la unidad de cuidados intensivos y en internación general del Sanatorio Adventista del Plata, Argentina, durante los años 2001-2007

12. Comparación del porcentaje de resistencia bacteriana de las cepas productoras de infecciones hospitalarias aisladas en la unidad de cuidados intensivos, durante los años 2001-2002 (preintervención) y 2003-2007 (posintervención). Sanatorio Adventista del Plata, Argentina.

13. Comparación del porcentaje de resistencia bacteriana de las cepas productoras de infecciones hospitalarias aisladas de internación general, durante los años 20012002 (preintervención) y 2003-2007 (posintervención). Sanatorio Adventista del Plata, Argentina.

14. Gasto de antimicrobianos utilizados en la profilaxis antibiótica prequirúrgica expresado en $\$ / 1000$ días paciente en las etapa inicial y final del estudio. Sanatorio Adventista del Plata, Argentina, enero de 2002 a octubre de 2003.

15. Porcentaje de pareo de los pacientes sometidos a cirugías de hígado, páncreas y conductos biliares y cirugías vasculares con infección del sitio quirúrgico y del grupo control. Sanatorio Adventista del Plata, Argentina, 1998 a 2004.

16. Costo en exceso de la infección del sitio quirúrgico asociadas a cirugías de hígado, páncreas y conductos biliares. Comparación de los promedios de días de hospitalización, gasto de antimicrobianos y número de cultivos en casos y controles. Sanatorio Adventista del Plata, Argentina, 1998 a 2004

17. Costo en exceso de las infecciones del sitio quirúrgico asociadas a cirugías vasculares. Comparación de los promedios de días de hospitalización, gasto de antimicrobianos y número de cultivos en casos y controles. Sanatorio Adventista del Plata, Argentina, 1998 a 2004

18. Gasto de antimicrobianos en pacientes con infección del sitio quirúrgico (casos) y los controles para cirugías hígado, páncreas y conductos biliares y cirugías vasculares. Sanatorio Adventista del Plata, Argentina, 1998 a 2004.

19. Caracterización feno y genotípica de los aislamientos de Staphylococcus aureus resistente a la meticilina incluidos en este estudio. Sanatorio Adventista del Plata, Argentina. 


\section{LISTADO DE FIGURAS}

Pág.

1. Paul Ehrlick

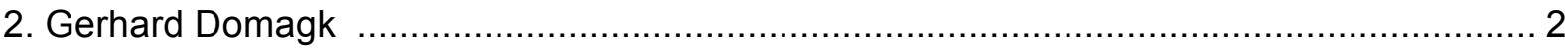

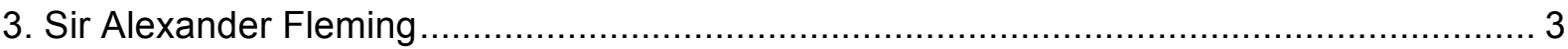

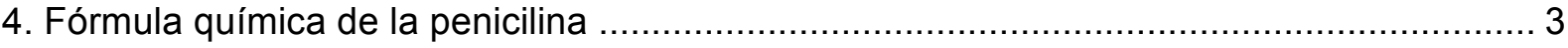

5. Mecanismos de acción de los antimicrobianos ............................................................... 3

6. Mecanismos de transferencia horizontal de genes de resistencia ............................... 10

7. Mecanismos de resistencia bacteriana a los antimicrobianos ...................................... 11

8. Porcentaje de cepas de Staphylococcus aureus resistentes a la meticilina aislados de hospitales, 2007, America Latina y el Caribe

9. Vista de la entrada del Sanatorio Adventista del Plata, Libertador San Martín, Entre Ríos, Argentina

10. Ubicación geográfica de Libertador San Martín, Entre Ríos, Argentina.

11. Esquema de la aplicación del programa para controlar el uso de antimicrobianos en la profilaxis quirúrgica.

12. Número de pacientes con infección del sitio quirúrgico antes y después de la aplicación del formulario para el uso de antimicrobianos en cirugía.

13. Variación del uso de aminopenicilinas en la unidad de cuidados intensivos durante los años 2001 a 2007 expresado en dosis diarias definidas/1000 días paciente. Sanatorio Adventista del Plata, Argentina.

14. Variación del uso de cefalosporinas $3^{a}$ generación en la unidad de cuidados intensivos durante los años 2001 a 2007 expresado en dosis diarias definidas/1000 días paciente. Sanatorio Adventista del Plata, Argentina.

15. Variación del uso de gentamicina en unidad de cuidados intensivos durante los años 2001 a 2007 expresado en dosis diarias definidas/1000 días paciente. Sanatorio Adventista del Plata, Argentina.

16. Variación del uso de penicilinas en unidad de cuidados intensivos durante los años 2001 a 2007 expresado en dosis diarias definidas/1000 días paciente. Sanatorio Adventista del Plata, Argentina 
17.Variación del uso de amikacina en internación general durante los años 2001 a 2007 expresado en dosis diarias definidas/1000 días paciente. Sanatorio Adventista del Plata, Argentina

18. Variación del uso de aminopenicilinas en internación general durante los años 2001 a 2007 expresado en dosis diarias definidas/1000 días paciente. Sanatorio Adventista del Plata, Argentina.

19. Variación del uso de cefalosporinas $1^{\text {a }}$ generación en internación general durante los años 2001 a 2007 expresado en dosis diarias definidas/1000 días paciente. Sanatorio Adventista del Plata, Argentina.

20. Variación del uso de clindamicina en internación general durante los años 2001 a 2007 expresado en dosis diarias definidas/1000 días paciente. Sanatorio Adventista del Plata, Argentina.

21. Variación del uso de fluoroquinolonas en internación general durante los años 2001 a 2007 expresado en dosis diarias definidas/1000 días paciente. Sanatorio Adventista del Plata, Argentina.

22. Variación del uso de gentamicina en internación general durante los años 2001 a 2007 expresado en dosis diarias definidas/1000 días paciente. Sanatorio Adventista del Plata, Argentina.

23. Variación del uso de trimetoprima-sulfametoxazol en internación general durante los años 2001 a 2007 expresado en dosis diarias definidas/1000 días paciente. Sanatorio Adventista del Plata, Argentina.

24. Variación del uso de vancomicina en internación general durante los años 2001 a 2007 expresado en dosis diarias definidas/1000 días paciente. Sanatorio Adventista del Plata, Argentina.

25. Porcentajes de ahorro o pérdidas debido al uso de antimicrobianos en la unidad de cuidados intensivos durante los años 2001-2002 (preintervención) y 2003-2007 (posintervención) expresado en $\$ / 1000$ días paciente. Sanatorio Adventista del Plata, Argentina.

26. Porcentajes de ahorro o pérdidas debido al uso de antimicrobianos en internación general durante los años 2001-2002 (preintervención) y 2003-2007 (posintervención) expresado en \$/1000 días paciente. Sanatorio Adventista del Plata, Argentina ..... 


\section{GLOSARIO}

ADN: Ácido Desoxiribonucleico

ANLIS: Administración Nacional de Enfermedades Infecciosas

APUA: Alianza para el Uso Prudente de Antibióticos

ASA: Sociedad Americana de Anestesiólogos

ATM: Antimicrobianos.

BILI: Hígado, Páncreas y Conductos Biliares

CDC: Centros para la Prevención y Control de Enfermedades

CLSI: Instituto de Estándares de Laboratorios Clínicos

DDD: Dosis Diaria Definida

EARSS: Sistema Europeo de Vigilancia de Resistencias Antimicrobianas

ERV: Enterococcus spp. resistentes a la vancomicina

GAARD: Consejo Mundial de Resistencia a Antibióticos

IACS: Infecciones Asociadas al Cuidado de la Salud

ICARE: Intensive Care Antimicrobial Resistance Epidemiology

INEI: Instituto Nacional de Enfermedades Infecciosas

ISQ: Infección del Sitio Quirúrgico

L: Limpias

LC: Limpio-Contaminadas

NNIS: Sistema Nacional de Vigilancia de Infecciones Nosocomiales

OD-PCR: PCR con oligonucleótidos degenerados

OMS: Organización Mundial de la Salud

OPS: Organización Panamericana de la Salud

PAP: Profilaxis Antibiótica Prequirúrgica

PCR: Reacción en Cadena de la Polimerasa

PFGE: Electroforesis en gel de campo pulsante

SAP: Sanatorio Adventista del Plata

SARM: Staphylococcus aureus resistente a la meticilina

SIP: Prevención de Infecciones Quirúrgicas

UCI: Unidad de Cuidados Intensivos

US\$: United States dollar 
VIHDA: Vigilancia de las Infecciones Hospitalarias de la Argentina

VIRA: Vigilancia de la Resistencia a los Antimicrobianos

VS: Vasculares 


\section{PUBLICACIONES, COMUNICACIONES Y PREMIOS}

\section{Publicaciones}

Acosta-Gnass S, Gómez-Tchilinguirian M, Schaab-Canteros M, Marsollier-Romano E, Basualdo-Farjat J. "Costos en exceso de las infecciones de sitio quirúrgico, Sanatorio Adventista del Plata, Argentina" Rev Panam infectol 2008; 10 (4 Supl 1): S83-88.

Gómez, Marisa, Basualdo, Juan A., Acosta de Gnass, Silvia. "Reduction in surgical antibiotic prophylaxis expenditure and the rate of surgical site infection by means of a protocol that controls the use of prophylaxis" Infect Control Hosp Epidemiol 2006; 27(12): 1358-1365.

\section{Comunicaciones}

Disertante: "Abordaje interdisciplinario de las infecciones nosocomiales"

VIII Congreso Argentino de Farmacia Hospitalaria

Santa Fe, noviembre 2008

Presentación del trabajo científico ganador del VII Congreso "Uso de antimicrobianos y resistencia bacteriana de las infecciones hospitalarias"

VIII Congreso Argentino de Farmacia Hospitalaria

Santa Fe, noviembre 2008

Gómez M, Basualdo J, Acosta Gnass S. "Uso de antimicrobianos y resistencia bacteriana de las infecciones hospitalarias".

VII Congreso Argentino de Farmacia Hospitalaria

Jujuy. 15 al 17 de noviembre de 2007

Gómez M, Basualdo J, Acosta Gnass S. "Incremento del costo hospitalario atribuible a la infección del sitio quirúrgico".

I Jornada de Investigación de la Facultad de Ciencias de la Salud

Universidad Adventista del Plata.

8 y 9 de noviembre de 2006 . 
Gómez M, Basualdo J, Acosta Gnass S. "Profilaxis antimicrobiana en pacientes intervenidos quirúrgicamente en un hospital universitario".

V Congreso Argentino de Farmacia Hospitalaria.

Córdoba. 10 al 12 de Noviembre de 2005

Gómez M.; Basualdo J.; Acosta Gnass S. "Uso de antimicrobianos y resistencia antimicrobiana en un hospital universitario".

V Congreso Argentino de la Sociedad Argentina de Infectología.

Mar del Plata. 6 al 8 de Mayo de 2005.

Gómez M. I., Basualdo J. A., Acosta Gnass S. I. "Optimización del uso de antimicrobianos en un hospital universitario".

XVII Congreso Latinoamericano de Microbiología y X Congreso Argentino de Microbiología.

Buenos Aires. 17 al 21 de octubre de 2004.

Gómez M. I., Basualdo J. A., Mosqueda Barboza L, Acosta Gnass S. I. "Impacto de un programa de control para disminuir el consumo de antimicrobianos en la profilaxis prequirúrgica".

XVII Congreso Latinoamericano de Microbiología y $X$ Congreso Argentino de Microbiología,

Buenos Aires. 17 al 21 de octubre de 2004.

Premios

Primer premio. Gómez M, Basualdo J, Acosta Gnass S. "Uso de antimicrobianos y resistencia bacteriana de las infecciones hospitalarias"

VII Congreso Argentino de Farmacia Hospitalaria

Jujuy. 15 al 17 de noviembre de 2007 